DIVISION OF THE HUMANITIES AND SOCIAL SCIENCES CALIFORNIA INSTITUTE OF TECHNOLOGY

PASADENA, CALIFORNIA 91125

Public Goods: A Survey of Experimental Research

John O. Ledyard

Forthcoming in The Handbook of Experimental Economics edited by Roth and Kagel

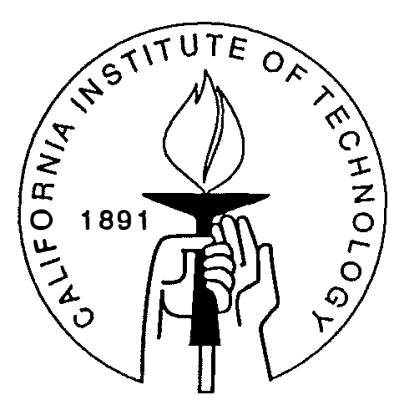

SOCIAL SCIENCE WORKING PAPER 861

August 1993

Revised February 1994 


\section{Contents}

1 Introduction $\quad 1$

1.1 A Simple Public Good Experiment . . . . . . . . . . . . . . 2

1.2 The Art of Experiment: Sensitivity and Control . . . . . . . . . . . . 4

1.3 The Language of Experiment: Mechanisms and Environments . . . . . 6

1.4 The Range of Public Goods Environments . . . . . . . . . . . . 9

1.5 What Is And Is Not To Be Surveyed . . . . . . . . . . . . . 11

2 Are People Selfish or Cooperative? $\quad 13$

2.1 Bohm: Estimating Demand .................. 14

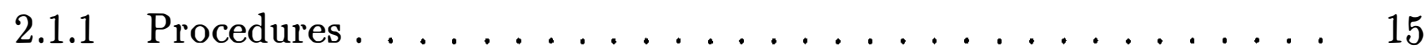

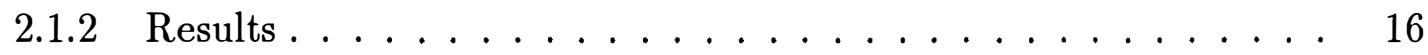

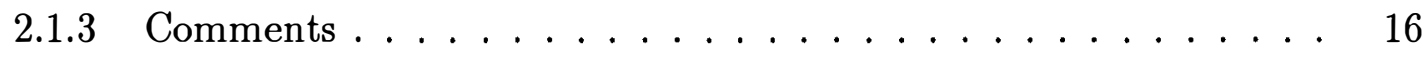

2.2 Dawes et al.: Social Dilemmas . . . . . . . . . . . . . . 19

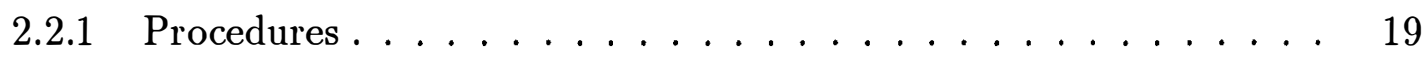

2.2 .2 Results ........................ 21

2.2 .3 Comments .......................... 21

2.3 Marwell et al.: The Free Rider Problem . . . . . . . . . . . . . . . . 24

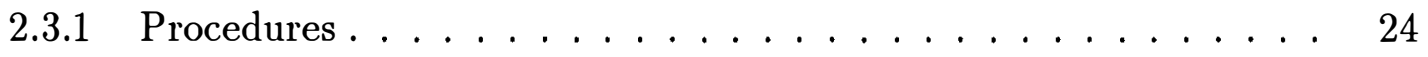

2.3.2 Results....................... 27

2.3 .3 Comments .......................... 27

2.4 Economists Begin to React . . . . . . . . . . . . . . . . . 29

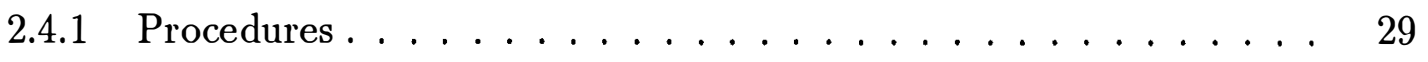

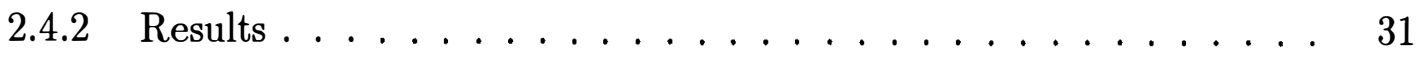


2.4 .3 Comments . . . . . . . . . . . . . . . . . . 31

2.5 Isaac et al.: Systematic Study by Economists . . . . . . . . . . . . . . . 32

2.5 .1 Procedures . . . . . . . . . . . . . . . . . 33

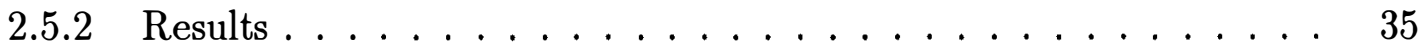

2.5 .3 Comments . . . . . . . . . . . . . . . . 36

2.5 .4 A Summary to this Point . . . . . . . . . . . . 36

$\begin{array}{lll}3 & \text { What Improves Cooperation? } & 38\end{array}$

3.1 Thresholds and Provision Points . . . . . . . . . . . . . . . . . . . 40

3.2 Experience, Repetition, and Learning . . . . . . . . . . . . . 43

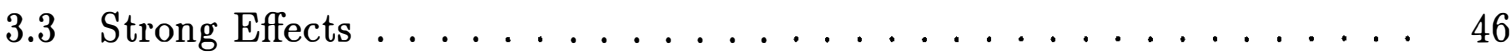

3.3.1 Marginal Payoffs and Rebates . . . . . . . . . . . . 46

$3.3 .2 \quad$ Numbers . . . . . . . . . . . . . . . . . . . . . . . . . . . . 48

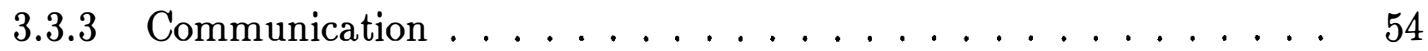

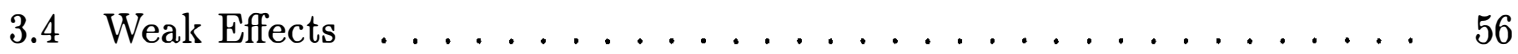

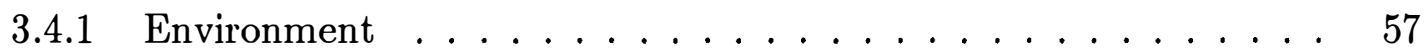

$3.4 .2 \quad$ Systemic . . . . . . . . . . . . . . . . . 59

3.4 .3 Institutional $\ldots \ldots \ldots \ldots \ldots \ldots \ldots \ldots \ldots$

3.5 Unknown Effects . . . . . . . . . . . . . . . . . . 66

4 Final Thoughts $\quad 69$

$\begin{array}{lr}\text { References } & 75\end{array}$

$\begin{array}{ll}\text { Appendix } & 98\end{array}$ 


\title{
Public Goods: A Survey of Experimental Research
}

\author{
John O. Ledyard*
}

\begin{abstract}
Environments with public goods are a wonderful playground for those interested in delicate experimental problems, serious theoretical challenges, and difficult mechanism design issues. In this chapter I will look at one small but fundamental part of the rapidly expanding experimental research. In Section 1, I describe a very simple public good experiment - what it is, what some theories predict, what usually happens, and why we should care - and then provide a methodological and theoretical background for the rest of the chapter. In Section 2, I look at the fundamental question: are people selfish or cooperative in volunteering to contribute to public good production? We look at five important early experiments that have laid the foundations for much that has followed. In Section 3, I look at the range of experimental research which tries to identify and study those factors which increase cooperation. In order to help those new to experimental work I have tried to focus on specific experimental designs in Section 2 and on general results and knowledge in Section 3. The reader will find that the public goods environment is a very sensitive one with much that can affect outcomes but are difficult to control. The many factors interact with each other in unknown ways. Nothing is known for sure. Environments with public goods present a serious challenge even to skilled experimentalists and many opportunities for imaginative work.
\end{abstract}

\section{Introduction}

Some of the most fundamental questions about the organization of society center around issues raised by the presence of public goods. Can markets provide optimal allocations

${ }^{*}$ I thank the Flight Projects Office of the Jet Propulsion Laboratory of NASA for their financial support. For their intellectual help and advice, I thank Peter Bohm, Don Coursey, Robyn Dawes, Roy Gardner, Mark Johnson, John Kagel, Jamie Brown-Kruse, Susan Laury, Gerald Marwell, Rosemarie Nagel, John Orbell, Elinor Ostrom, Tom Palfrey, Charles Plott, Amnon Rapoport, Al Roth, Tatsuyoshi Saijo, Steve Slutsky, Richard Thaler, James Walker, most of the participants in the Conference on Experimental Research on the Provision of Public Goods and Common-Property Resources at the Workshop in Political Theory and Policy Analysis at Indiana University, and especially Mark Isaac without whom I would not have gotten even this far. Some of these strongly disagree with parts of my commentary. They may be justified. 
of public goods such as air pollution or public health? How well do current political institutions perform in the production and funding of public goods such as space exploration or national defense? How far can volunteerism take us in attempts to solve world environmental problems? If existing institutions, thrown up in the natural evolutionary process of history, do not produce desirable results in the presence of public goods, can we discover other organizational arrangements that would better serve the interests of society? At an even more basic level, public goods raise issues about the very nature of humans. Are people cooperative or selfish? . Do they behave differently when confronting public goods decisions than when making private goods decisions? Are altruism or fairness concepts that a social scientist must come to terms with before solving the organizational problems or can these phenomena be safely ignored? Such questions have been argued throughout history on the basis of much introspection and little evidence. With the development of an experimental methodology for economics, we now enter a new era in the debates.

\subsection{A Simple Public Good Experiment}

Perhaps more than in any other area covered by this handbook, it is difficult to identify a typical experiment. As we will see, there are as many variations in procedures and

treatments as there are research groups. For now, let us look at a design that has some of the basic features of many and is easy to describe and understand.

What does a Public Good Experiment Look Like? Four male undergraduates from a sociology course are brought to a room and seated at a table. They are each given an endowment of $\$ 5$. They are then told that each can choose to invest some or all of their $\$ 5$ in a group project. In particular, each will simultaneously and without discussion put an amount between $\$ 0$ and $\$ 5$ in an envelope. The experimenter will collect the "contributions," total them up, double the amount and then divide this money among the group. The private benefit from the public good, in this case, is one half the total contributions which is what each receives from the group project. No one, except the experimenter, knows others' contributions but all know the total. The procedure is implemented and the subjects are paid. The data collected, beyond the description of the experimental parameters, is simply the amount contributed by each individual.

What Should One Expect to Happen in this Public Goods Experiment? There are many theories. One, the economic/game-theoretic prediction, is that no one will ever contribute anything. Each potential contributor will try to "free ride" on the others. In this theory it is a dominant strategy to choose $\$ 0$ in the experiment because each $\$ 1$ contributed yields only $\$ .50$ to its contributor, no matter what the others $d o$. This is called a public goods problem or a social dilemma because the group would be best off in some sense (taking home $\$ 10$ each) if all contributed $\$ 5$. Each $\$ 1$ contributed yields 
$\$ 1.50$ to the others at no cost to them. From the point of view of this theory, individual self interest is at odds with group interest.

Another theory, which I will call the sociologic-psychologic prediction, is that each subject will contribute something. Although it is hard to find precise statements, it is sometimes claimed that altruism, social norms or group identification will lead each to contribute $\$ 5$, the group optimal outcome. From the point of view of this theory, there is no conflict between individual and group interests.

What does Happen in a Public Goods Experiment? Examination of the data reveals that neither theory is right. In many cases, some contribute $\$ 0$, some contribute $\$ 5$ and some choose a middle course and contribute something less than $\$ 5$.. Generally, total contributions can be expected to lie between $\$ 8$ and $\$ 12$, or $40 \%$ to $60 \%$ of the group optimum. The statement in Dawes and Thaler (1988) is "It is certainly true that there is a 'free rider problem'... On the other hand, the strong free rider prediction is clearly wrong." This lack of precision is disconcerting. They seem to claim that a full range of behavior exists from fully selfish to fully altruistic. If so, outcomes in public goods environments can be almost anything depending on which subjects walk into the room and we can learn no more from further experiments. More likely, the imprecision of results is due to the fact that we have simply not yet achieved sufficient control in our public goods experiments to be able to identify what is really happening. It is only recently that careful experimental work has begun to uncover how changes in payoff parameters and in institutional features can change the amounts contributed for the production of public goods. Being able to change amounts contributed by changing treatments means some measure of control can be achieved. We are thus beginning to understand behavior through better 'control and a growing accumulation of evidence.

Why should We Care about Public Goods Experiments? Both economists and sociologists recognize that the desired outcome is for all to contribute $\$ 5$. The experimental evidence suggests that voluntary contributions will not produce that desired outcome. Economic theory suggests ${ }^{1}$ that it may be possible to change the institutions by which group choices are made in a way that causes the outcome to be closer to the group optimum. To know how to do that, however, requires anticipating how individual choices will change as the institutions change. Since both the economic/game-theoretic and socio-psychologic theoretical predictions are wrong, we need to discover more about behavior not only in the context of voluntary contributions but also in the presence of many institutional designs. Experiments are the only way to do so.

\footnotetext{
${ }^{1}$ See, for example, Groves and Ledyard (1977) or Ledyard and Palfrey (1992).
} 


\subsection{The Art of Experiment: Sensitivity and Control}

The research problem underlying this survey, then, is to understand behavior in the presence of public goods and in the context of many institutions. Once that understanding is achieved, all the other questions we have raised can be answered in a relatively straight-forward manner. On a broader level, the search is really for useful principles of behavior that apply across all environments and institutions. If we are successful as social scientists, we should be able to model behavior in the same.way whether there are private or public goods and whether there are markets or committees. On the surface, this statement is simply a tautology; on deeper examination, it is the heart of what a theorist tries to do. To illustrate, suppose it were shown experimentally that subjects behaved differently when instructions were on green paper than when they were on white paper. To explain this phenomenon, we could add a parameter to our model of behavior, called for example "the color of the paper on which instructions are written." Suppose our original model of behavior is $\mu(e)$; that is, if the experiment is $e$ we will observe $\mu(e)$, and if the experiment is $e^{\prime}$ we will observe $\mu\left(e^{\prime}\right)$. If behavior is $\mu_{g}$ when green paper is used and $\mu_{w}$ when white is used, the new theory is $\mu(e ; x)$ where $\mu(e ; g)=\mu_{g}$ and $\mu(e ; w)=\mu_{w}$. This does not, of course, allow us to predict what will happen when red is used; $\mu(; r)=$ ?. For that we need a set of principles, a set which allows us to say something about behavior for any color. We would ultimately like to be able to say: you give me the details of the environment and a complete description of an institution, then my model of behavior will predict what will happen. Thus, the study of behavior in the presence of public goods should be viewed simply as an extension of the more general study of behavior in groups, examples of which are covered throughout this book. Experimentalists must believe this, if the results of the lab are to tell us anything about behavior in the field. Theorists must believe this, if they are to be able to predict the implications of changes in institutional designs.

One might take this view, that principles of behavior exist independent of environment and institution, to imply that there is nothing special about studying behavior in public goods or dilemma environments. ${ }^{2}$ That would be an incorrect inference. In fact, I think these are exactly the right environments for one simple reason: aggregate results and measurable aspects of behavior seem to be very sensitive to variations in parameters and other treatments. For example, experiments in private good environments, such as the work with Double Auctions (see chapter Sunder (1994)) and bargaining (see chapter Roth (1994)), seem to produce similar predictable results independent of the experimenter, subject pool, and parameters. Demand-supply equilibria arise in simple markets in spite of subject "mistakes" or other characteristics. When one subject errs ${ }^{3}$ in a Double Auction with private goods, another will immediately adjust and take advantage of the

\footnotetext{
${ }^{2}$ There would be something special about studying institutions, though.

${ }^{3}$ It is not always obvious what is an error and what is some subtle form of sophisticated play but for purposes of this example suppose a seller offers to sell a unit at less than her marginal cost. This is either an error (a loss will be incurred) or an altruistic act. We generally treat it as a mistake.
} 
mistake but the rest of the group will not be too severely affected. A buyer may take advantage of a seller's error but the group still achieves near 100 percent efficiencies. Subtleties in behavior are difficult to identify and measure. In public good environments this "averaging" or "smoothing" phenomenon can not happen. A misstep by one is felt by all and can not be easily corrected. Subtleties in behavior are not only identifiable and measurable, they are endemic. Public goods and dilemma experiments appear to be the simplest environment within which to uncover variations in behavior in groups. ${ }^{4}$

Of course the sensitivity of the experimental medium is a double-edged sword. Control is made more difficult. Let me illustrate what I mean. When I was taking freshman physics, I was required to perform a sequence of rather dull laboratory exercises (which may be one reason I became an economic theorist). One standard experiment involved rolling a steel ball down a ramp with a ski jump at the end. The trajectory followed by the ball was to be filmed, using a strobe camera, so we could plot the parabolic arc of the ball and confirm that Newton's Laws were indeed consistent with experimental evidence. In an effort to enliven the proceedings, my lab partner and I substituted a ping-pong ball we had painted silver and, during its trajectory, we gently blew on it. The resulting experimental evidence captured on film, that Newton's Laws appeared to be rejected, was indisputable. Nevertheless, the lab instructor rejected the data as inconsistent with the theory. More correctly, he did not believe they were replicable with the original equipment. Ping-pong balls can allow the experimenter to display effects hidden by the insensitivity of metal balls; but ping-pong balls also allow unintended and uncontrolled intrusions to contaminate and mislead. ${ }^{5}$

Public goods and dilemma experiments are like using ping-pong balls; sensitive enough to be really informative but only with adequate control. For example, the experiment we described in Section 1.1 is neither particularly elegant nor carefully controlled. Even so, at least twelve major choices have been made in creating this design: (1) the number, (2) gender and (3) education of the subjects, (4) whether they are face to face or acting through computer terminals or in isolated rooms, (5) how much endowment to give to each and in what form (cash, tokens, promises, ...), (6) whether discussion is allowed and in what form, (7) whether contributions are private or public, (8) by how much to increase the total contributions, (9) how to divide up the larger pie (for example, in proportion to contribution or to number), (10) whether or when to announce the results, (11) whether to pay subjects publicly or privately and finally (12) whether to run the procedure once or, say, 10 times. Each of these choices represents a potential treatment or control. Each treatment has been shown by at least one experimenter to have a significant effect on the

\footnotetext{
${ }^{4}$ I emphasize groups here since single person decision experiments lack the ability to examine complicated feedback effects from interpersonal interactions.

${ }^{5}$ Using steel balls allows control but is not very illuminating.
} 
rate of contribution. ${ }^{6}$ This means, there are more than $2^{12}$ possible designs. ${ }^{7}$ Further, there still remain uncontrolled phenomena which might affect behavior in the experiment such as the experience of the subjects, whether they are roommates or not, the beliefs and risk-attitudes of the subjects, and the willingness of a subject to trade decision making effort and precision for the dollars to be made in the experiment. In many Double Oral Auction experiments ${ }^{8}$ this lack of control does not seem to be a problem. But, as we will see, it causes serious difficulties in the voluntary provision of public goods.

Experiments with Double Oral Auctions and private goods yield precise replicable patterns of data on exchange prices and quantities: markets are easy to control but provide little insight into individual behavior. ${ }^{9}$ Experiments with voluntary contributions mechanisms and public goods yield imprecise patterns of data on contributions: volunteerism is not very easy to control but, perhaps, yields some insight into individual behavior. This delicate balance between sensitivity and control is a constant challenge to experimentalists. Sometimes the language and theory can be a guide.

\subsection{The Language of Experiment: Mechanisms and Environ- ments}

Modern developments in theory and experimental methods have created a framework and a language within which to study systematically the questions raised at the beginning of this chapter. This new framework, called mechanism design ${ }^{10}$, also provides an outline within which to organize what we know about public goods experiments. The main components featured are environments, outcomes, performance criteria, institutions and models of behavior. To see how these fit together into a coherent and useful framework, let us look at them one at a time.

An environment describes the details of the situation that the analyst takes as given and the experimentalist manipulates; the exogenous variables. Included in the environment are the number of people, or agents, their preferences and endowments, the physical constraints on behavior (biological and physical laws), those aspects of the legal structure (such as property rights) that will be taken as fixed, the structure of information

\footnotetext{
${ }^{6}$ In fact, for most of these variables it is possible to find experimental evidence suggesting a positive effect, evidence suggesting no effect, and evidence suggesting a negative effect. See Section 3.

${ }^{7}$ Variables such as number of subjects and the conversion rate of contributions into public good make the possibilities infinite.

${ }^{8}$ See chapter Sunder (1994).

${ }^{9}$ See Easley and Ledyard (1992) for the extensive range of behaviors which are consistent with the data.

${ }^{10}$ This structure has been developed over many years by many researchers. Examples can be found in Groves and Ledyard (1987), Hurwicz (1972), Myerson (1991), Kiser and Ostrom (1982), Radner (1987), and Smith (1982a). A complete exposition would require another book.
} 
(who knows what and to what extent might that be common knowledge), the technical details and possibilities for production, and so forth. Also included in the environment is a description of the range of possible outcomes of interest to agents.

Outcomes are what the furor is all about. An outcome describes the final distribution of resources and payoffs. How each individual feels about the outcome will depend on the particular environment since an individual's preferences for outcomes are part of the description of an environment. Similarly whether a particular outcome might be good for the group will depend on the details of the environment.

A performance criterion determines, for each environment, a ranking over outcomes. The idea is that in each environment the best outcome is the one which is ranked highest by the performance criterion. A standard performance criterion used in experimental work is a cost/benefit measure ${ }^{11}$ which computes the sum of payoffs received as a percent of the maximum attainable. From a mechanism design point of view, if someone knew all the details of the environment (and were benevolent) we could simply ask them to announce the best outcome for that environment. One problem that might arise would be the difficulty in communicating all relevant details and the complexities in computing it. But one of the main contributions of modern economics is the recognition that information about the environment is dispersed and that individuals may have incentives not to provide the requested information. Further, even if the information is correctly known, self-interested agents may be unwilling to follow the suggested actions. Enforcement is, thus, another possible problem. We cannot readily rely on beneficient omniscience.

Instead, institutions arise to aggregate information and coordinate activities. An institution specifies who should communicate with whom and how, as well as who should take various actions and when. An example of a very simple institution designed to deal with public good production is the Voluntary Contributions Mechanism (without communication) in which each individual is told to contribute an amount of a private good privately and without any information about what others are doing, as in Section 1.1. The level of public good provided then equals that producible with the total private good contributed. The outcome describes the amount of public good produced and the amount of each contribution. Given a set of individuals, their preferences and their endowments, the outcome we observe is the result of both the mechanism rules and the choices made by the agents. Another more complicated institution is the modified Lindahl mechanism in which all agents write down a schedule of their willingness-to-pay (in private good) for various amounts of a public good. The level of public good is chosen to maximize the sum of the willingness-to-pay minus the production cost. Each individual is required to contribute (pay) an amount equal to their marginal willingness to pay (for that amount of the public good) times the amount of the public good. The outcome describes the amount of the public good produced and the amount of each contribution.

\footnotetext{
${ }^{11}$ This is sometimes incorrectly identified as efficiency or Pareto-optimality in environments with income effects.
} 


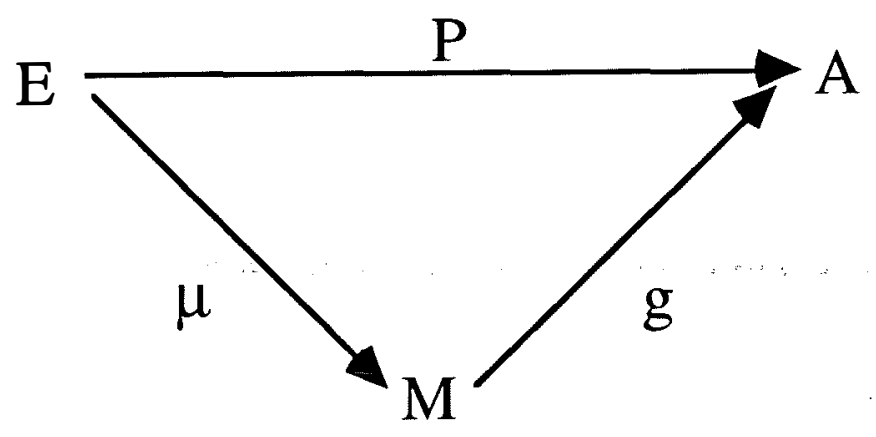

Figure 1:

The possible outcomes for the Lindahl mechanism are exactly the same as those for the voluntary contributions mechanism. But the actual values achieved may be very different because the choices of the agents may differ in the context of different mechanisms.

A particularly interesting question is whether the individuals would be better off with the voluntary contributions mechanism or with the modified Lindahl mechanism. To answer this we must be able to evaluate the performance of these institutions. To evaluate how well an institution performs (according to a particular performance criterion) we need to be able to predict what outcomes will occur in each environment when that institution is used. To do that we need a model of behavior; that is, we need a theory of how individuals respond in each environment to requests for information and action by an institution. In general, the model will predict different responses in different environments to the same institution as well as different responses in the same environment to different institutions.

Figure 1, due to Mount and Reiter (1974), captures all the components of the framework. $E$ is a set of environments and $A$ is a set of outcomes. $P: E \rightarrow A$ is the performance criterion where $P(e)=\{a\}$ is a (possibly set-valued) function which identifies the best outcomes for each environment $e$. The institution is $(M, g)$ where $M$ is the language of communication ${ }^{12}$ and $g\left(m^{1}, \ldots, m^{N}\right)$ specifies the outcomes which are chosen if each individual $i$ responds to the institution with $m^{i}$. The behavioral model is $\mu$ where $\mu(e,(M, g))=\left(m^{1}, \ldots, m^{N}\right)$ specifies how each individual will actually respond if the environment is $e$ and the institution is $(M, g)$.

This structure makes it easy to recast our earlier questions in a more precise form and to identify a variety of other interesting questions. Let us look at three. (1) How

\footnotetext{
${ }^{12}$ This can include iterative procedures, bids and offers, votes, oratory, etc.
} 
does a given institution $(M, g)$ perform and does it perform optimally over a range of environments; that is, what is $\mu[e,(M, g)]$ and does $\mu(e,(M, g)) \epsilon P(e)$ for all $e \epsilon E$ ? Examples of this type of question are: do markets efficiently allocate resources in private goods economies, and how efficient is the allocation of resources in a public goods environment if we rely on voluntary contributions? (2) Is $\mu$ a good theory; that is, do we observe $\mu(e,(M, g))$ as we vary both $e$ and $(M, g)$ ? Examples of these types of questions are: do buyers in a first-price sealed bid auction follow Bayes-Nash strategies, and are agents in a public goods situation selfish or altruistic? (3) Can we design an optimal mechanism for a class of environments; that is, given $(E, P)$ can we find $(M, g)$ such that $\mu(e,(M, g))=P(e)$ for all $e \epsilon E$ ? Examples of this type of question are: how can we fix up problems caused by market failure such as air pollution, how should we organize a firm, and how should we make decisions about public goods so that desirable outcomes occur? If we can simultaneously observe the details of the environment, $e$, the mechanism, $(M, g)$, and the outcome for a wide variety of environments and mechanisms, we have a chance to answer these questions without making arbitrary assumptions about behavior. Experiments provide the opportunity.

\subsection{The Range of Public Goods Environments}

The range of experiments which have a public goods structure is more extensive than most realize. To see why, let me describe some very simple environments with public goods. There are two goods, one private and one public, and $N$ individuals. Each individual $i=1, . ., N$ is endowed with some amount of the private good, $z_{i}$. The public good is produced from the private according to the production function $y=g(t)$ where $t$ is the amount of private good used to produce $y$. An outcome is a level of public good, $y$, and an allocation of the private good for each agent $x^{1}, \ldots, x^{N}$. Each agent values outcomes according to the utility function ${ }^{13} U^{i}\left(x^{i}, y\right)$. Feasible outcomes are $a=\left(y, x^{1}, \ldots, x^{N}\right)$ such that $y=g\left[\sum_{i=1}^{N}\left(z^{i}-x^{i}\right)\right]$. We will call $t^{i}=z^{i}-x^{i}$ the amount of $i$ 's payment for the public good and occasionally restrict the range of possible $t^{i}$. For example, sometimes it is required that $t^{i} \in\left[0, z^{i}\right]$, the endowment is divisible but no one can contribute more than $z^{i}$, nor can they repeat compensation, and sometimes it is required that $t^{i} \in\left\{0, z^{i}\right\}$, either $z^{i}$ is contributed or nothing is contributed. We can summarize the environment as $e=<g, U^{1}, \ldots, U^{N}, z^{1}, \ldots, z^{N}>$.

Virtually any public good or social dilemma experimental environment is a special case of $e$ in which specific forms for $\left(g, U^{1}, \ldots, U^{N}\right)$ and specific values for $z^{1}, \ldots, z^{N}$ are

\footnotetext{
${ }^{13}$ This assumes $i$ is "selfish". We will see later why one might want to relax this assumption. In fact, we will need to go further and distinguish the payoff to subjects, say $p^{i}\left(x^{i}, y\right)$, from the utility they get, $V^{i}=V^{i}\left(p^{i}, \beta^{i}\right)$ where $\beta^{i}$ may be a collection of variables which are difficult to observe or control or $\beta^{i}$ may include the payoffs to others. If we knew $\beta^{i}$ then $U^{i}\left(x^{i}, y\right)=V^{i}\left(p^{i}\left(x^{i}, y\right), \beta^{i}\right)$.
} 
chosen. ${ }^{14} U^{i}$ is then paid to $i$ based on the choices of $x_{1}, \ldots, x_{n}$. One special case, called the linear symmetric variable contribution environment, has been used extensively in experimental research ${ }^{15}$ and is described by $g(t)=\frac{a}{N} t$ and $U^{i}\left(x^{i}, y\right)=p x^{i}+y$. It is called linear because of the assumption that all $U^{i}$ and $g$ are linear functions. It is called symmetric because a renumbering of the agents should change nothing. It is called variable contribution because $x_{i}$ can be any real number. Another environment, called the linear symmetric threshold environment ${ }^{16}$ is described by $g(t)=1$ if $t \geq \bar{t}$ and $g(t)=0$ otherwise, and $U^{i}\left(x^{i}, y\right)=p x^{i}+y$. It is called threshold because of the form of $g$.

There are many other classes of experimental environments which also have the public goods structure. For one example, consider the common property resource problem of Walker, Gardner, and Ostrom (1990). They study problems "that potentially arise whenever multiple appropriators withdraw resource units from a common-pool resource (CPR)." In their experiments, individuals are endowed with $T$ tokens and choose to invest $t_{i}$ tokens. Each $i$ is then paid $h_{i}(t)$ where

$$
h_{i}(t)=5\left(T-t_{i}\right)+\left(t_{i} / \sum t_{k}\right)\left(23 \sum t_{k}-.25\left(\sum t_{k}\right)^{2}\right) .
$$

The idea is that the investment of $t_{i}$ creates a negative externality and lowers the marginal physical product of others' individual investments, $t_{j}$. To see why this can be thought of as a public good environment, let $z_{i}=T, g(t)=23-.25 t$, and $U^{i}\left(x^{i}, y\right)=\left(z_{i}-x_{i}\right) y+5 x_{i}$. Here, $x^{i}=z_{i}-t_{i}$ is the amount of the private good endowment $z^{i}$ which $i$ chooses to retain for consumption. ${ }^{17}$ The fact that $d g / d t<0$ should not deter one from recognizing the public good nature of this environment. We can further transform variables to make the point. Let $y^{*}=g^{*}(t)=.25 t$. Then $d g^{*} / d y^{*}>0$. Let $z_{i}=T$. Let $x^{i}=T-t_{i}=z_{i}-t_{i}$. Let $U^{* i}\left(x^{i}, y^{*}\right)=5 x_{i}+23\left(z_{i}-x_{i}\right)-\left(z_{i}-x_{i}\right) y^{*}$. (In the investment space, one would have $U^{* i}\left(t^{i}, y^{*}\right)=5 z^{i}+18 t_{i}-t^{i} y^{*}$.) Here one might be tempted to call $y^{*}$ a public bad because increases in $y^{*}$ yield decreases in $U^{* i}$. Also there are income effects since

$$
d\left[d U^{* i} / d y / d U^{* i} / d x^{i}\right] / d x^{i}=\frac{1}{y^{*}-18} \neq 0 .
$$

Nevertheless, the fundamental public good structure is revealed by the careful description of the environment. This also illustrates that the same economic environment can be presented to subjects in many apparently unrelated formats. One hopes that behavior would be the same whether $h_{i}(t), U^{i}\left(x_{i}, y\right)$, or $U^{* i}\left(t_{i}, y^{*}\right)$ is used, but this is rarely checked.

\footnotetext{
${ }^{14}$ This point is also made, with graph in Dawes (1975).

${ }^{15}$ This is the basis of Isaac, Walker and Thomas(1984) among others.

${ }^{16}$ See Dawes, Orbell, Simmons, and van de Kragt (1986).

${ }^{17} \mathrm{An}$ equivalent theoretical representation in the space of investments would yield $U^{i}\left(t^{i}, y\right)=t^{i} y-$ $5 t^{i}+5 z^{i}$. In each case the initial endowment is a parameter in the utility function but it is exogenous, fixed and known so that creates no theoretical problems under standard economic and game theories. There may, of course, still be differences in subject behavior when payoffs are presented in the different forms $h_{i}(t), U^{i}\left(t_{i}, y\right)$, and $U^{i}\left(x_{i}, y\right)$. See Section 4 for more on this problem of presentation.
} 
Another example arises in a totally different context. In Cournot Oligopoly models, (see, e.g., chapter Holt (1994)) firms choose quantities $q_{i}$, the market price which depends on the total amount brought to market is $P\left(\Sigma q_{i}\right)$, and firms are paid $\pi_{i}=P\left(\Sigma q_{i}\right) q_{i}-C^{i}\left(q_{i}\right)$ where $C^{i}(\cdot)$ is $i$ 's cost function. Let $g(t)=P(t)$ and $U^{i}\left(x_{i}, y\right)=x^{i} y-C^{i}\left(x^{i}\right)$ to see why this is a public good environment.

I have listed many of the examples I am aware of ${ }^{18}$ and the appropriate references in Appendix A. One may think it is stretching a bit to include all of these as public goods environments, but the advantage gained by recognizing that these are all the same structure is that it brings more experimental data to bear on the really difficult question: what is behavior in the presence of public goods?

\subsection{What Is And Is Not To Be Surveyed}

The contents of a complete survey on public goods experiments would include material from four main categories: (1) experiments with voluntary contributions mechanisms over a wide range of environments, (2) experiments with a wide range of mechanisms over a limited class of economic environments, (3) experiments with mechanisms in political environments, and (4) experiments with applications or policy problems as the focus.

Category (1) includes work by sociologists, social psychologists, political scientists, and economists intended to isolate fundamental aspects of group behavior when voluntary contributions are socially desirable but individually bad. In this paper we will concentrate on this category of work. ${ }^{19}$

Category (2) includes work primarily by economists aimed at identifying those aspects of mechanisms which might lead to socially optimal outcomes even if basic individual incentives operate to foil such goals. Much of this work is motivated by the theoretical findings of Hurwicz (1972) and others. ${ }^{20}$ A good example of early work in this area is found in Smith $(1979 a, 1979 b, 1980)$. A follow-up study to Smith's research can be found in Ferejohn, Forsythe, Noll, and Palfrey (1982). An example of more recent work, is found in Banks, Plott, and Porter (1988). Work from psychology would include Shepperd (1993).

Research in Category (3) has been predominantly generated, as one might expect, by political scientists. In political environments, no compensation is available to ease the group decision making process. As opposed to economic environments in which transfers of the private good from winners can be used to compensate losers, in political environments there is more of a flavor of multilateral bargaining. A classic example of

\footnotetext{
${ }^{18}$ See Schram and Sonnemans (1992) for another involving voter turnout.

${ }^{19}$ I will, however, not survey two-person games.

${ }^{20}$ For a recent survey of the theoretical literature see Groves and Ledyard (1987).
} 
this type of research, focusing on the institution of committees, is found in Fiorina and Plott (1978). A survey of more recent work, including institutions based on elections, can be found in McKelvey and Ordeshook (1990).

The research in Category (4) has more of an applied flavor than that in (1)-(3). Here, the experimental lab serves the mechanism designer in the same way the wind-tunnel does the aeronautical engineer and the towing tank does the naval architect. ${ }^{21}$ Mechanisms which are created from the imagination of designers can be tested in a controlled environment. We need no longer be restricted to studying only those organizations thrown up by the slow evolution of naturally occurring institutions. An early example of this work is Ferejohn and Noll(1976) and Ferejohn, Forsythe, and Noll (1979). A more modern example is Banks, Ledyard, and Porter (1989). Here the basic research in mechanism design meets the world of everyday problems. Airport slot allocation (Grether, Isaac, and Plott (1989), Rassenti, Smith, and Bulfin (1982)), coordinating the use of shared facilities (Banks, Ledyard, and Porter (1989)), managing the development and operations of deep space missions (Olson and Porter (1994)), environmental control through markets (Franciosi et al. (1991), Ledyard and Szakaly (1992)) and siting noxious facilities (Brookshire, Coursey, and Kunreuther (forthcoming), Kunreuther et al. (1986)) are just a few of the complex organizational problems being attacked. Although this is an infant science, I believe that mechanism design and testbedding will ultimately become the foundation of policy analysis.

I do not have space to survey all research across (1)-(4). I have chosen to cover only (1) - behavior in voluntary contributions mechanisms in public goods environments for two main reasons. First, the research, development, and application of mechanisms in (2), (3), and (4) requires a basic understanding of behavior in group situations. The research on voluntary contributions mechanisms is one of the simplest ways to develop that understanding. The experiments are difficult to control but are sensitive revealers of behavior. Second, the research on behavior with public goods has been aggressively multi-disciplinary with excellent programs maintained by ${ }^{22}$ economists, political scientists, psychologists, and sociologists. Many experiments have been created in response to work of others. Several labs have long running programs in which data have been generated by systematically varying environments and institutions. The best results do seem to come from the more systematic efforts. Perhaps more often than in any other area trod by experimental economists ${ }^{23}$, research on voluntary contributions has brought the fundamental beliefs and hypotheses of economics into conflict with those of other fields. The debate has been joined: the resolution, as we will see, remains in doubt.

\footnotetext{
${ }^{21}$ In an early work (1984) for the Jet Propulsion Lab of NASA on space station allocation, I adopted the phrase "testbedding," used by their engineers to describe one phase of spacecraft development, to identify this type of experimental organizational analysis.

${ }^{22}$ Listed alphabetically.

${ }^{23}$ The exception might be in research on decisions under uncertainty (see chapter Camerer (1994)).
} 


\section{Are People Selfish or Cooperative?}

Research on the voluntary provision of public goods must come to grips with this simple but still unanswered question about the fundamental nature of humankind. The debate has been long-standing with much heat and little light. ${ }^{24}$ Economists and game-theorists argue that the hypothesis of selfish behavior is the only viable one as an organizing principle yet they also contribute to public television and vote in elections. Sociologists and political scientists argue that societies are naturally cooperative through the evolution of social norms or altruism. Preconceived notions bordering on the theological have sometimes been rejected by data. But those who are reluctant to part with cherished theories have in turn rejected the data. Disciplinary boundaries have been drawn, breached, and redrawn. It is into this fray that experimentalists have come, trying to generate light where previously there was little.

Although many have contributed to the development of our knowledge, the systematic experimental effort of three research groups has been fundamental. Marwell in Sociology at Wisconsin, ${ }^{25}$ Dawes in Psychology at Oregon and then at Carnegie-Mellon University and Orbell in Political Science at Oregon, ${ }^{26}$ and Isaac and Walker in Economics at Arizona and Indiana ${ }^{27}$ have all carried out sustained efforts to understand whether and why cooperation might occur in public goods problems. Many of these still continue the study. The result of this effort and the sometimes heated interaction has been just what one might hope for; a slowly emerging consensus, which would have been impossible without carefully controlled experiments. Let us see how this has happened by trying to discover what we know now and why.

A reasonable reading of the literature ${ }^{28}$ on voluntary contribution mechanisms and social dilemmas would probably lead one to conclude that the major findings to date are:

1. In one-shot trials and in the initial stages of finitely repeated trials, subjects gen-

\footnotetext{
${ }^{24}$ For an example of the often silly rhetoric of the debate see Mansbridge (1990).

${ }^{25}$ Work from this group includes Marwell and Ames (1979), Marwell and Ames (1980), Alfano and Marwell (1980), Marwell and Ames (1981), and Marwell (1982).

${ }^{26}$ Work from this group includes Dawes, McTavish, and Shaklee (1977), Dawes (1980), Orbell and Dawes (1981), Dawes and Orbell (1982), van de Kragt, Orbell, and Dawes (1983), Dawes, Orbell, and van de Kragt (1985) Orbell, van de Kragt, and Dawes (1988), Dawes, Orbell, Simmons, and van de Kragt (1986), Dawes, van de Kragt; Orbell-(1987); Orbell;-Dawes; and van de Kragt (1990), Orbell and Dawes (1991).

${ }^{27}$ Work from this group includes Isaac and Walker (1983), Isaac, Walker, and Thomas (1984), Isaac, McCue, and Plott (1985), Isaac and Walker (1987), Isaac, Schmidtz, and Walker (1988), Isaac and Walker (1988a), Isaac and Walker (1988b), Fisher, Isaac, Schatzberg, and Walker (1988), Isaac and Walker (1989), Isaac and Walker (1991), Isaac, Walker, and Williams (1990), Walker, Gardner, and Ostrom (1990).

${ }^{28}$ Andreoni (1988b), p. 291. See also Isaac and Walker (1987), Mansbridge (1990), p. 17, and Dawes and Thaler (1988), p. 189, for examples of these claims.
} 
erally provide contributions halfway between the Pareto-efficient level and the free riding level,

2. Contributions decline with repetition, and

3. Face to face communication improves the rate of contribution.

The first finding suggests the public goods problem is not as bad as some economists make it out to be, but that there is still room for improvement. For those interested in creating more desirable outcomes, the second is bad news and the third is good news. But, although these are generally acknowledged stylized facts, they should be viewed with some skepticism. And, perhaps, others should be added. To see why, let us dig deeper.

The public goods problem, that individual incentives are at odds with group interest, has long been recognized at the theoretical level by economists. Lindahl discussed it ${ }^{29}$ as early as 1919, Samuelson (1954) conjectured it, and Ledyard and Roberts provided a proof in 1974. (See Groves and Ledyard (1987) for details). At the same time political scientists recognized it as a problem of collective action (Olson (1971)) and as the tragedy of the commons (Hardin (1968)), while social psychologists called it a social dilemma (Dawes (1980)). But, even though the problem was widely recognized there were few data. This allowed wide disagreement about whether there really was a problem. Lindahl (1919), not recognizing the incentives for misrepresentation, suggested that a bargaining equilibrium would arise that was optimal. For a modern version of the argument that the public good problem is over-exaggerated see Johansen (1977). Most economists believed there was a free rider problem and that voluntary contributions mechanisms would provide very little public goods. Other organizations would be needed. Eventually data were brought to bear on the debate but that is a relatively recent occurrence. For example, Marwell and Ames (1979) note at the time of their work that "No body of experimental research asks explicitly what level of self-denial on behalf of achieving collective goods may be expected from some population, and under what conditions this self-denial may vary." (p.1336) The earliest experiment they acknowledge ${ }^{30}$ was reported by Bohm (1972). We start there.

\subsection{Bohm: Estimating Demand}

In one of the earliest attempts to discover experimentally whether there is a public goods problem, Bohm (1972) set up a well thought out test "involving five different approaches to estimating demand for a public good." His conclusion after the data were analyzed

\footnotetext{
${ }^{29}$ See Bohm (1987).

${ }^{30}$ They identified it as related but not focused on their question of interest.
} 
was that "the well-known risk for misrepresentation of preferences in this context may have been exaggerated" and people may be willing to contribute to the public good even if their own self-interest runs counter. What did Bohm do and was his conclusion correct?

\subsubsection{Procedures}

Let me first describe his experimental procedures and then explain why his study raised more questions than it answered. In his own words:

The test was carried out by the Research Department of the Swedish RadioTV broadcasting company (SR) in November, 1969. A random sample of 605 persons was drawn from the age group 20 to 70 of the population of Stockholm. They were asked to come to the premises of the broadcasting company to answer some questions about TV programs and were promised a fee of $\mathrm{Kr} .50$ (\$10) for a one-hour "interview." Normally, some 35-50\% show up in tests of this kind. (Bohm (1972) p. 118. ${ }^{31}$ )

After dividing the sample,

The persons in each subgroup were placed into a room with two TV-sets and were, for allegedly "practical reasons," immediately given the fees promised them in four ten-Crown bills, one five-Crown bill and small change to make Kr.50. The administrator gave an oral presentation of the test which involved a half-hour program by Hasse Alfredsson and Tage Danielsson, ${ }^{32}$ not yet shown to the public. The subjects were given the impression that there were many groups of the same size simultaneously being asked the same questions in other rooms elsewhere in the broadcasting company. The responses, given in writing by the persons in each subgroup, were taken away and said to be added to the statements from other groups. ... The main part of the instructions given to groups I to $\mathrm{V}$ was as follows: Try to estimate in money terms how much you find it worth at a maximum to watch this half-hour program in this room in a little while, i.e. what is the largest sum you are willing to pay to watch it... If the sum of the stated amounts of all the participants covers the costs (Kr. 500) of showing the program on closedcircuit TV, the program will be shown; and you will have to pay

\footnotetext{
${ }^{31}$ I would like to thank Elsevier Science Publishers for permission to quote from this report.

${ }^{32}$ Well-known Swedish comedians.
} 
(to group I) the amount you have stated,

(to group II) some percentage (as explained) of the amount you have stated,

(to group III) either the amount you have stated or a percentage (as explained) of this amount, or Kr. 5 or nothing, to be determined later by a lottery you can witness

(to group IV) Kr. 5,

(to group V) nothing. In this case the participants were informed that the costs were to be paid by the SR, i.e. the taxpayers in general.

"Counter-strategic" arguments (see below in Section 2.1.3) were added to instructions I, II, IV and V.

The subjects in group VI, who received instructions which differed from the instructions to the first five groups, were simply asked how much they found the program to be worth at a maximum. In a second round, these people were asked to give their highest bids for a seat to watch the program and were told that the 10 highest bidders out of an alleged group of some 100 persons were to pay the amount they had bid and see the program. (Bohm (1972) pp. 118-119.)

The design of the experiment was intended to test whether, as economists might have predicted, group I would understate their willingness to pay and groups IV and V would overstate.

\subsubsection{Results}

The data Bohm found are summarized in Table 1.

They imply that no significant differences (at the $5 \%$ level) could be found between any pair of instructions I to IV. (Bohm (1972) p. 120.)

\subsubsection{Comments}

There are three aspects of the design which deserve mention because they suggest a lack of control. First, Bohm does not know and cannot directly measure the true willingnessto-pay of his subjects to see a specific television show. Since he did not control this variable (subjects were not paid but would get to watch the show) he is forced to make 
Table 1: Amounts stated at instructions I-VI: 2.

\begin{tabular}{|c|c|c|c|c|c|c|c|c|}
\hline $\mathrm{Kr}$. & I & II & III & IV & V & VI:1 & VI:2 & \\
\hline $0-0.50$ & & & & 1 & 1 & 2 & 5 & \\
\hline $0.60-2.5$ & 2 & 2 & & 4 & 3 & 4 & 4 & \\
\hline $2.60-4.50$ & 4 & 5 & 2 & 1 & 4 & 4 & & \\
\hline $4.60-6.50$ & 8 & 6 & 15 & 13 & 8 & 10 & 10 & 55 out of 70 stating Kr. 5 \\
\hline $6.60-8.50$ & 4 & 3 & 2 & 6 & 7 & 3 & 3 & \\
\hline $8.60-10.50$ & 1 & 7 & 9 & 4 & 8 & 13 & 12 & All 54 stating $\mathrm{Kr} .10$ \\
\hline $10.60-12.50$ & & 1 & & 1 & 1 & 3 & 1 & \\
\hline $12.60-17.50$ & 3 & 1 & & 6 & 3 & 11 & 12 & 35 out of 36 stating Kr. 15 \\
\hline $17.60-22.50$ & & 3 & & 1 & 1 & 1 & 4 & All 10 stating Kr. 20 \\
\hline $22.60-27.50$ & & 1 & 1 & & 3 & 2 & 2 & 8 out of 9 stating Kr. 25 \\
\hline $27.60-32.50$ & 1 & & & & & & 1 & Both stating Kr. 30 \\
\hline 50 & & & & & & 1 & & \\
\hline Number & 23 & 29 & 29 & 37 & 39 & 54 & 54 & \\
\hline Mean & 7.61 & 8.84 & 7.29 & 7.73 & 8.78 & 10.19 & 10.33 & \\
\hline Standard Deviation & 6.11 & 5.84 & 4.11 & 4.68 & 6.24 & 7.79 & 6.84 & \\
\hline Median & 5 & 7 & 5 & 6.5 & 7 & 10 & 10 & \\
\hline
\end{tabular}


probabilistic statements across groups. ${ }^{33}$ Further, it is impossible for him to distinguish between two key hypotheses: no misrepresentation of preferences and simple irresponsible responses. He notes that "the reactions received from different groups are compatible with the possibility of getting identical (emphasis is his) responses to instructions I to V" (p. 124). He also remarks, in discussing group VI but with relevance to group V, that "the results are of course compatible with the general view that, when no payments and/or formal decisions are involved, people respond in an "irresponsible" fashion. In other words, this result may be. seen as still another reason to doubt the usefulness of responses to hypothetical questions ..." (p.125). The lack of direct control over the fundamental parameter, willingness-to-pay, creates a serious difficulty in knowing what to conclude without a significantly large number of experiments with randomly assigned subjects so that statistical procedures can substitute for direct control. ${ }^{34}$

Second, because he wanted to study the effect of large groups and because he did not have much money, Bohm misrepresented the true situation to the subjects. There were no other "groups of the same size simultaneously being asked the same questions" and in fact the program was always shown no matter what the answers were. The experimenter may hope the subjects believe that the group is large, but control may have been lost. Bohm is not the only one to adapt this strategy in order to save money. In Section 3.3.2 I will discuss the problems of doing experiments with large numbers and one of the creative attempts at solution. The problem remains open.

Third, "the use of Counter-strategic" arguments in experiments is clearly controversial. Instructions IV and $\mathrm{V}$ say

It is easy to see that it would pay for any one of you who really wanted to watch this program to state a much higher amount than he actually would be willing to pay. In this way the total sum of the amounts stated would increase and so would the changes of having the program shown here. But this would of course make it impossible for us to find out just how much you really think watching this program is worth to you. It could also be said that such an overstatement would indicate a lack of solidarity or respect for the views of your neighbors, who may be called upon to pay for something that is not really desired by all of you together. In other words, it should be seen as something of a "duty" to state the amount you actually find it worth to see the program. (pp. 128-129.)

Instructions I and II say,

\footnotetext{
${ }^{33}$ We need to develop an econometrics of experiments to deal with the estimation and identification of uncontrolled variables.

${ }^{34}$ Other early experiments also had this problem. For example, Schneider and Pommerehne (1981b) used students as subjects and the public good was the purchase of the professor's forthcoming book: see the discussion of this experiment in Chapter 1.
} 
... it could pay for you to give an understatement of your maximum willingness to pay. But, if all or many of you behave in this way, the sum won't reach Kr. 500 and the program won't be shown to you. (p. 128)

It is well known now that subjects may actually be trying to do what they think the experimentalist thinks they should be doing. Even subtle cues in the instructions can cause subjects' decisions to vary. Strong moral imperatives such as those used by Bohm are equivalent to blowing on ping-pong balls. There may be economic principles involved but we will never find them this way. We might, however, find out whether such mechanisms can increase contributions. I will take up a discussion about the role of moral suasion in Section 3.5.

Bohm's imaginative study was, for its time, a major advance in the attempt to identify the extent of voluntary behavior in the presence of public goods. Although he tentatively concluded that that misrepresentation of preferences was less a problem than believed by economists, his experiment was seriously flawed in at least three ways. As a result, the data were not convincing and he was forced to conclude correctly that "the test would seem to encourage further work in the field of experimental economics." The question of cooperative vs. selfish behavior remained open.

\subsection{Dawes et al.: Social Dilemmas}

While economists were struggling to get their experiments under control, social psychologists were independently studying a phenomenon which, I would argue, is a special case of public goods; social dilemmas. One of the best and most persistent groups has included Robyn Dawes and John Orbell. Let us look at Dawes, McTavish, and Shaklee (1977) for an example of this type of work that avoids many of the flaws of Bohm.

\subsubsection{Procedures}

The experiment is simple. ${ }^{35}$ Eight person groups were created although sometimes less showed up. A total of 284 subjects were used in 40 groups. Each individual in each group marked an $X$ or an $O$ on a card in private. They were told ${ }^{36}$

If you choose an $O$, you will earn $\$ 2.50$ minus a $\$ 1.50$ fine for every person who chooses $X$. If you choose $X$, you will earn $\$ 2.50$ plus $\$ 9.50$ minus $\$ 1.50$

\footnotetext{
${ }^{35}$ Simplicity is a good feature of experiments. You are more likely to understand what you have learned.

${ }^{36}$ The subjects were also asked to indicate beliefs about others' choices. We will comment on this aspect of their experiments later in Section 3.4.2.
} 
fine for each person, including yourself, who chooses $X$. (Dawes-McTavishShaklee (1977) pp.4-5. ${ }^{37}$ )

Subjects were also presented the payoffs in the form of one half of Table 2. Some groups faced the loss condition: Some groups faced the no-loss condition.

Table 2. Payoff Matrix

\begin{tabular}{|c|c|c|c|c|c|c|c|}
\hline \multicolumn{3}{|c|}{ Number Choosing } & \multirow[b]{2}{*}{$\begin{array}{r}\text { Payoff } \\
\text { to } \mathrm{O}\end{array}$} & \multicolumn{4}{|c|}{ Number Choosing } \\
\hline $\begin{array}{c}\text { Payoff } \\
\text { to } \mathrm{X}\end{array}$ & $X$ & $\mathrm{O}$ & & $\begin{array}{c}\text { Payoff } \\
\text { to } \mathrm{X}\end{array}$ & $\mathrm{X}$ & $\mathrm{O}$ & $\begin{array}{c}\text { Payoff } \\
\text { to } \mathrm{O}\end{array}$ \\
\hline \multicolumn{4}{|c|}{ Loss condition } & \multicolumn{4}{|c|}{ No-loss condition } \\
\hline - & 0 & 8 & 2.50 & - & 0 & 8 & 2.50 \\
\hline 10.50 & 1 & 7 & 1.00 & 10.50 & 1 & 7 & 1.00 \\
\hline 9.00 & 2 & 6 & -.50 & 9.00 & 2 & 6 & 0 \\
\hline 7.50 & 3 & 5 & -2.00 & 7.50 & 3 & 5 & 0 \\
\hline 6.00 & 4 & 4 & -3.50 & 6.00 & 4 & 4 & 0 \\
\hline 4.50 & 5 & 3 & -5.00 & 4.50 & 5 & 3 & 0 \\
\hline 3.00 & 6 & 2 & -6.50 & 3.00 & 6 & 2 & 0 \\
\hline 1.50 & 7 & 1 & -8.00 & 1.50 & 7 & 1 & 0 \\
\hline .00 & 8 & 0 & - & .00 & 8 & 0 & - \\
\hline
\end{tabular}

Four communication conditions were tried, the details on which can be found in Section 3.3.3. After discussions, subjects made a single choice, received nominal payoffs in private (but, as shown below, dollar payoffs were determined on the basis of total earnings from their friendship group), and were dismissed separately.

A peculiar aspect of the experimental design is centered around trying not to force subjects to take a loss while at the same time maintaining the standard social dilemma structure. Students were recruited in (friendship) groups of 4. This worked as follows.

Friendship groups met initially with an experimenter who informed them that each person would go to a different decision group where she or he would make a decision with seven other people. The four friends would then return to their friendship group, pool their earnings, and divide them equally among themselves. If the total were negative, no member of the friendship group would receive anything (although people who did not win at least $\$ 2.00$ were contacted later and paid from $\$ 1.00$ to $\$ 2.50$ depending on their initial

\footnotetext{
${ }^{37}$ I would like to thank the American Psychological Association for permission to quote from this report.
} 
earnings). One member from each friendship group was sent to each of the four communication conditions. Two went to groups in which it was possible to lose money (the loss condition), two to groups in which negative payoffs were truncated at zero (the no-loss condition). Thus the eight groups of four friends separated and formed four groups of eight strangers to play the commons dilemma game. (Dawes-McTavish-Shaklee (1977) p.4.)

The design was intended to identify, among other things, the effect of communication on contributions.

\subsubsection{Results}

The data on non-contributions $(\mathrm{X})$ is displayed in Table 3 .

Table 3. Non-Contribution (frequency of choosing $X$ )

\begin{tabular}{ccccc}
\hline & \multicolumn{4}{c}{ Condition } \\
\cline { 2 - 5 } Condition & $\begin{array}{c}\text { No } \\
\text { Communication }\end{array}$ & $\begin{array}{c}\text { Irrelevant } \\
\text { Communication }\end{array}$ & $\begin{array}{c}\text { Unrestricted } \\
\text { Communication }\end{array}$ & $\begin{array}{c}\text { Communication } \\
\text { Plus Vote }\end{array}$ \\
\hline Loss & .73 & .65 & .26 & .16 \\
No Loss & .67 & .70 & .30 & .42 \\
\hline \multicolumn{4}{c}{ (Dawes-McTavish-Shaklee (1977) p.5.) }
\end{tabular}

The main result appears to be (see Dawes (1980)) that only $31 \%$ contribute without communication or with irrelevant communication while $72 \%$ contribute when relevant communication occurs. A secondary but puzzling result is that the no-loss treatment had apparently no effect.

\subsubsection{Comments}

The first thing to notice is that this really is a public good environment as described in Section 1.4. Let $z_{i}$, the initial endowment, be 0 . Require that $t_{i} \in\{0,9.50\}$. Let $g(t)=[(12 / 9.5) t] / 8$.. Finally, let $U^{i}\left(t_{i}, y\right)=z_{i}-t_{i}+g(t)$. Then, for example, if 2 individuals contribute, their $t=9.50$, and 6 do not, their $t=0$, then contributers receive $U^{i}=0-9.50+[(12 / 9.5)(2 \times 9.50) / 8]=-6.50$ and non-contributers receive $U^{i}=0-0+(12 / 9.50)(2 \times 9.50) / 8=3.00$. Compare this to Table 2 under the loss condition.

A second observation concerns the lack of impact of the no-loss treatment. Let us look first at the structure of the problem. In the loss condition (ignoring for now the 
complication created by membership in a friendship group), a decision to defect gains a subject $\$ 8$ and costs everyone else $\$ 1.50$. Alternatively spending $\$ 9.50$ by cooperating generates $\$ 1.50 /$ person, no matter what others decide to do. In the no-loss condition, the situation is very different. The marginal cost and gain of a decision to defect by choosing $X$ now depends on the number of other defectors choosing $X$. This is calculated in Table 4.

Table 4.

$\begin{array}{cccc}\begin{array}{c}\text { \# defectors } \\ \text { other than you }\end{array} & \begin{array}{c}\text { marginal cost } \\ \text { to other defectors }\end{array} & \begin{array}{c}\text { marginal cost } \\ \text { to other cooperators }\end{array} & \begin{array}{c}\text { marginal gain } \\ \text { to you }\end{array} \\ 0 & 1.50 & 1.50 & 8.00 \\ 1 & 1.50 & 1.00 & 8.00 \\ 2 & 1.50 & 0 & 7.50 \\ 3 & 1.50 & 0 & 6.00 \\ 4 & 1.50 & 0 & 4.50 \\ 5 & 1.50 & 0 & 3.00 \\ 6 & 1.50 & 0 & 1.50 \\ 7 & 1.50 & 0 & 0\end{array}$

Thus in the no-loss condition the marginal cost a subject imposes on others by defecting is no larger than in the loss condition and is much less on cooperators. One should expect this to induce more defection ceteris paribus. But the marginal benefit to a subject from defecting is also reduced if at least 2 others defect. This would induce, perhaps, less defection ceteris paribus. One way to understand the puzzling fact that the no-loss treatment had no effect is to realize that for the subjects in these experiments the two countervailing effects could easily have cancelled each other.

Another way to measure the tension between the selfish gain from defecting and the public gain from contributing is to calculate the per subject return from switching $\$ 1$ to contributions. $^{38}$ For these experiments this is simply $\partial u^{i} / \partial t_{i}$ or, in the loss condition, 1.5/9.5. In the no loss condition the algebra is somewhat different. If there are, say, 5 other defectors, then if I contribute I lose $\$ 3$ and those 5 gain 1.5 each. Other contributors gain nothing. Therefore the per capita gain per $\$$ is $\frac{5 \cdot 1 \cdot 5}{8} \cdot \frac{1}{3}$. These calculations are made in Table 5.

Thus if the subject expects the number of other defectors to be less than 4 , then the no-loss condition should raise the incentive to defect by lowering the marginal gain from cooperating. Similarly, if the subject expects more than 3 other defectors, the no-loss

\footnotetext{
${ }^{38}$ Isaac, Walker, and Thomas (1984) call this the marginal per capita return (MPCR) and were the first to identify this very important parameter. More on this later in Section 3.3.1.
} 
Table 5.

\begin{tabular}{ccl}
$\begin{array}{c}\text { \# other } \\
\text { defectors }\end{array}$ & $\begin{array}{c}\text { loss } \\
\text { return on } \$ 1\end{array}$ & $\begin{array}{c}\text { no loss } \\
\text { return on } \$ 1\end{array}$ \\
\hline 0 & .158 & .158 \\
1 & .158 & .12 \\
2 & .158 & .05 \\
3 & .158 & .093 \\
4 & .158 & .16 \\
5 & .158 & .3 \\
6 & .158 & .75 \\
7 & .158 & $\infty$
\end{tabular}

condition should lower the incentive to defect by raising the marginal benefit of contributing. ${ }^{39}$ As can be seen the incentive effects of the no-loss treatment are complex and out of control. This should give experimentalists reason to pause. A relatively simple appearing alteration in the payoff structure, replacing negative numbers with zeros, creates a very complex change in the incentive structure because the direction of the effect depends on the subjects' expectations which are not controlled by the experimenter. ${ }^{40}$

A third observation is that the fear of losses on the part of the experimenters that led them to create friendship groups and no-loss conditions could have been avoided by recognizing that the experiment is almost identical to that described in Section 1.1 if an initial endowment of $\$ 9.50 /$ subject had been provided. Of course that would have cost an additional $\$ 9.50 \times 284$ or about $\$ 2,700$. An alternative way to save money and to avoid forcing subjects into losses would have been to add $\$ 9.50$ to each entry (so all payoffs are non-negative) and then divide all entries by some number to lower the total paid out. ${ }^{41}$

\footnotetext{
${ }^{39}$ In the extreme case if 7 others plan to defect then each subject faces no cost from contributing but can provide 1.50 to the others by doing so.

${ }^{40} \mathrm{I}$ have not had the time to figure out in what way this might explain the data on predictions of others' behavior. Dawes et al. claim defectors expected more defection than did cooperators. But the incentive structure suggests that the no-loss incentives would lead those who expect defection by others to defect less often than those who expect more cooperation. It is further claimed by Dawes et al. that

The possible loss manipulation was not only ineffective in eliciting differential cooperation, it was ineffective in eliciting differential predictions about others' behavior as well. (DawesMcTavish-Shaklee (1977) p. 5.)

I remain suspicious and believe this needs more investigation.

${ }^{41}$ For example, a rough calculation for these Dawes experiments suggests a payoff of $\$ 3.75$ to 5.5 defectors and $-\$ 5.75$ to $2.5(=.3 \times 8)$ contributors for a total of $\$ 52.50$. A similar calculation for communication suggests $\$ 1.25$ to $5.5(=.7 \times 8)$ contributors and $\$ 8.25$ to 2.5 defectors for a total of $\$ 137.50$. Adding $\$ 9.50$ to each of 8 payoffs would yield a cost for each trial of $76+137.50=\$ 223.50$. Dividing by 2 would then
} 
A modicum of salience is lost, but one avoids the lack of control from treatments such as the no loss payoff table or the use of friendship groups to "average" payoffs across trials. Budget constraints force experimentalists to make these choices all the time, and the ability to control payoffs, allows one to analyze the potential impact of the choices.

The last observation concerns the most obvious and least informative result: relevant talking matters a lot, but although four different types of communication were tried the data provide little information as to why. Just letting subjects talk in an uncontrolled framework opens up the chances for all sorts of contamination and unintended effects. Are facial expressions important? Which ones? Would one get the same effect if each subject just could say "zero" or "one" once and simultaneously? Would it matter if "zero" were changed to "I won't contribute" and "one" were changed to "I will contribute"? If we are to understand the role of communication in encouraging voluntary contributions, we need better control and precision in our experimental designs. This remains an open problem. The state of the art is described in Section 3.3.3.

\subsection{Marwell et al.: The Free Rider Problem}

During the same time as and independently from Dawes, McTavish and Shaklee (1977), Gerald Marwell was initiating the first systematic experimental research program on the determinants of the voluntary provision of public goods - or as he put it on "a fundamental sociological question: when will a collectivity act to maximize its collective interest even though such behavior conflicts with a course of action that would maximize the short-term interests of each individual separately." Not just trying to demonstrate that "the effects of free-riding were much weaker than would be predicted from most economic theory," the Marwell group tried to determine what affects the rate of contribution. In the process, they tested the distribution of resources, group size, heterogeneity of benefits, provision points, strength of induced preferences, experience of subjects, the divisibility of the public good, and the economics training of the subjects. This was a carefully thought out research program focused on an important phenomenon. The data generated could not be ignored. In fact it was in response to this study that experimental economists finally began laying the groundwork needed to study free riding. No longer would provision of public goods be just a theoretical debate.

\subsubsection{Procedures}

High school students were contacted by telephone and given tokens which could be invested in a private exchange yielding $1 \phi /$ token or in a public exchange yielding an amount

have cost on average $\$ 111.75$ for communication trials and $\$ 64.25$ for non-communication trials. The total for each pair would then be $\$ 176$, a saving as opposed to the original $\$ 190$. Table 2 would then have entries such as a payoff to $X=7.25$ and a payoff to $O=3.00$ if $X=4$ and $O=4$. 
depending on the total contribution to the public exchange. In the words of the experimenters:

The experiment was conducted during a single summer and fall using 256 high school students between the ages of 15 and 17. Subjects were divided into 64 four-person groups, resulting in eight groups assigned to each treatment condition ... Since each group contained two female and two male subjects, each cell contained 16 males and 16 females $^{42}$ High school-age subjects were selected for study because we felt that the amount of money at stake in their decision (about $\$ 5.00$ ) would be most meaningful to young people and that at the same time these subjects would be old enough to understand the investment decision they had to make. (Marwell-Ames (1979) p. 1341. ${ }^{43}$ )

The study was performed in a "natural" setting, in that all interaction with the subjects was by telephone and mail, with subjects remaining in their normal environments throughout the course of the research.

After willingness to participate had been established by phone, the subject was mailed a set of instructions appropriate to the experimental condition to which he or she was assigned ...

Within a few days an experimenter telephoned the subject to go over each point in the mailed instructions. This discussion usually lasted 15-20 minutes ... An appointment was then made for another telephone conversation the next day (or as soon as possible), in which the subject could invest the study tokens.

In this next telephone call the subject invested the tokens in either of two exchanges (which are explained below) or split them between the two. (MarwellAmes (1979) pp. 1342-43)

The payoff table, given to the subjects, for a large group ${ }^{44}$ of 80 with unequal benefits (designated blue and green) and unequal resources is provided in Table 6 .

One unusual feature (corrected and tested in Marwell-Ames (1980)) about this induced valuation structure is the peak at 7;999 total tokens. At all other levels the marginal benefit from contributing 1 more token (worth $1 \phi$ ) is less than $1 \phi$ whereas at

\footnotetext{
${ }^{42}$ This is a Marwell-Ames footnote: "One male subject named Chris was inadvertently classified as female and the mistake was not discovered until long after completion of the experiment. Thus, one group was composed of three males and one female. Deletion of this group or this subject makes no meaningful change in the results."

${ }^{43}$ I would like to thank the University of Chicago Press for permission to quote from this report.

${ }^{44}$ How a group of 4 becomes a group of 80 is discussed below.
} 
Table 6. Payoff from Group Exchange in Large, Unequal-Interest, Unequal-Resource Groups

\begin{tabular}{|c|c|c|c|}
\hline \multirow[b]{2}{*}{$\begin{array}{l}\text { If The Total Tokens Invested } \\
\text { In The Group Exchange By } \\
\text { All Group Members Is }\end{array}$} & \multirow[b]{2}{*}{$\begin{array}{l}\text { Total Money } \\
\text { Earned By The } \\
\text { Group Is }(\$)\end{array}$} & \multicolumn{2}{|c|}{$\begin{array}{l}\text { How Much Money You Get } \\
\text { If You Are (\$) }\end{array}$} \\
\hline & & $\begin{array}{c}\text { Blue } \\
\cdot\left(2 \frac{1}{4} \phi \text { of Each }\right. \\
\text { Group Dollar })\end{array}$ & $\begin{array}{c}\text { Green } \\
\text { (9/10 } \notin \text { of Each } \\
\text { Group Dollar) }\end{array}$ \\
\hline Between: & & & \\
\hline 0 and 1,999 tokens & 0 & 0 & 0 \\
\hline 2,000 and 3,999 & 14.00 & .32 & .13 \\
\hline 4,000 and 5,999 & 32.00 & .72 & .29 \\
\hline 6,000 and 7,999 & 54.00 & 1.22 & .49 \\
\hline 8,000 and 9,999 & 320.00 & 7.20 & 2.93 \\
\hline 10,000 and 11,999 & 350.00 & 7.88 & 3.21 \\
\hline 12,000 and 13,999 & 390.00 & 8.78 & 3.57 \\
\hline 14,000 and 15,999 & 420.00 & 9.45 & 3.85 \\
\hline 16,000 and 17,999 & 440.00 & 9.90 & 4.03 \\
\hline 18,000 & 450.00 & 10.13 & 4.12 \\
\hline
\end{tabular}

7,999 the marginal benefit is about $6 \phi$. This means there are multiple Nash equilibria. One at which no one contributes (the strong free rider hypothesis) and a bunch where everyone contributes partially. For example, if all contribute $4 / 9$ of their tokens then a total of 8,000 from 18,000 is contributed. If the initial endowment is equally distributed then each begins with 225 tokens so each is contributing 100 tokens at a cost of $\$ 1$ and receiving a marginal return $\$ 5.98$. Because of this feature, which Marwell and Ames call a provision point, not contributing is no longer a dominant strategy and, at least in the equal distribution case, contributing $44 \%$ on average is an obvious focal point.

Group size was varied between 4 and 80 . In small groups there were a total of 900 tokens and in large groups there were a total of 18,000 tokens. In some small groups one individual might have as many tokens as the provision point and everyone knew this. ${ }^{45}$ But as in the Bohm experiments some of this was a fiction.

Group size was specified as "small" when there were four members in the group and "large" when there were 80 members. However, no individual was actually a member of a group of 80 persons. All groups contained just four real subjects. Because group members never interacted with one another it was

\footnotetext{
${ }^{45}$ Theory suggests in this case that one Nash equilibrium involves only that person contributing.
} 
possible to tell them that there were any number of members in their group and have them make their investment decisions in terms of this assumption. Telling half our subjects that they were in large, 80-person groups was the only element of deception in this experiment. (Marwell-Ames (1979) p. 1345.

\subsubsection{Results}

The finding claimed by Marwell and Ames was "a lack of support for ... the strong free rider ${ }^{46}$." Approximately $57 \%$ of available resources are invested in the public good. If those subjects whose endowments are greater than the provision point are excluded, then the contribution rate is $41 \%$.

In all, tests of the hypotheses derived more or less directly from the economic theory support a very weak free-rider hypothesis, with the proviso that groups containing a member whose interest is greater than the cost of provision invest substantially more in public goods than do other groups. No other hypothesized process demonstrated a substantial effect on group investment. (Marwell-Ames (1979) p. 1352)

A second finding which we will examine more closely in Section 3.4.1. was that the rate of contribution was less if initial endowments were unequal.

\subsubsection{Comments}

A number of issues are raised by this study. Many have since been addressed either by Marwell's group (see Marwell and Ames (1980), Alfano and Marwell (1980), and Marwell and Ames (1981)) or by the economists who initially thought something must be wrong if there was so much contribution.

The existence of a provision point could quite obviously have increased contributions to $44 \%$. But in a later study by Marwell and Ames (1980) the provision point was removed as in Table 7.

The result reported after the change was that "the subjects averaged 113 tokens invested in the group exchange or approximately $51 \%$ of the tokens they had available." (p. 932) This would seem to blunt the criticism that subjects were focused on a focal point equilibrium. However, notice that multiple Nash equilibria still exist at positive levels of contribution. For example at $1,999,3,999$, etc. a $1 \phi$ contribution yields a personal return

\footnotetext{
${ }^{46}$ The strong free-rider hypothesis is that everyone contributes zero to the public good
} 
Table 7. Payoffs from Group Exchange

\begin{tabular}{|c|c|c|c|c|}
\hline \multirow{5}{*}{$\begin{array}{l}\text { If The Total Tokens } \\
\text { Invested In The } \\
\text { Group Exchange By All } \\
\text { Group Members Is Between: }\end{array}$} & \multicolumn{2}{|c|}{$\begin{array}{l}\text { Previous Study } \\
\text { Provision Point }\end{array}$} & \multicolumn{2}{|c|}{$\begin{array}{c}\text { Present Study: } \\
\text { No Provision Point }\end{array}$} \\
\hline & & How Much & & How Much \\
\hline & Total Money & Money You Get & Total Money & Money You Get \\
\hline & Earned by & $\left(1 \frac{1}{4} \phi\right.$ of Each & Earned by & $\left(1 \frac{1}{4} \phi\right.$ of Each \\
\hline & The Group Is & Group Dollar) & the Group Is & Group Dollar) \\
\hline 0 and 1,999 & 0 & 0 & 0 & 0 \\
\hline 2,000 and 3,999 & 14.00 & .18 & 44.00 & .55 \\
\hline 4,000 and 5,999 & 32.00 & .40 & 88.00 & 1.10 \\
\hline 6,000 and 7,999 & 54.00 & .68 & 132.00 & 1.65 \\
\hline 8,000 and 9,999 & 320.00 & 4.00 & 176.00 & 2.20 \\
\hline 10,000 and 11,999 & 350.00 & 4.38 & 220.00 & 2.75 \\
\hline 12,000 and 13,999 & 390.00 & 4.88 & 264.00 & 3.30 \\
\hline 14,000 and 15,999 & 420.00 & 5.25 & 308.00 & 3.85 \\
\hline 16,000 and 17,999 & 440.00 & 5.50 & 352.00 & 4.40 \\
\hline 18,000 & 450.00 & 5.63 & 396.00 & 4.95 \\
\hline
\end{tabular}

(Marwell-Ames (1980) p. 931)

of $55 \phi$. So if the others contribute some amount between 1,946 and 1,999 or 3,946 and 3,999 , etc., it pays one to contribute up to 54 tokens. That means there can be many equilibria. Of course, this still does not explain why individuals are contributing 113 on average instead of something between 1 and 54 .

A smoother, more continuous payoff schedule would not have this property but would, perhaps, be harder to explain to the subjects. An extremely important methodological question for experimentalists concerns the presentation of the payoffs to the subjects. Does the form matter? Are tables better than graphical presentation? Are functions impossible to use? What if there are four dimensions and graphs and tables become unwieldy? I do not know of any systematic study of these issues ${ }^{47}$ although it is widely recognized, for example, that changes in the placement of information on a computer screen, the amount and form of feedback, and the complexity of instructions all can lead to changes in behavior. It is vitally important to understand these effects if one wants to control induced valuations. The sensitivity of the public goods environment strongly highlights these presentation "effects.

A second observation echoes one I made in Section 2.1 on Bohm's research. Even though groups were actually of size 4 , half of the subjects were told they were in a group

\footnotetext{
${ }^{47}$ One study that suggests this is important is Saijo and Yamaguchi (1992) which is discussed in more detail in Section 4. I have also learned recently of the work of Schwartz-Shea and Simmons (1987) but have not had time to incorporate it into this paper.
} 
of 80. Since all of the experimental interaction was over a phone, no subject could know for sure what the group size was other than relying on the veracity of the experimenter. How do we know for sure what the subject believed? Since the experimenter was deceptive about $N=80$, why not about $N=4$ ? It is believed by many undergraduates that psychologists are intentionally deceptive in most experiments. If undergraduates believe the same about economists, we have lost control. It is for this reason that modern experimental economists have been carefully nurturing a reputation for absolute honesty in all their experiments. This may require costlier experiments where not just 4 subjects but 80 are paid. It may require more clever procedures to get 80 subjects together at one time. But if the data are to be valid, honesty in procedures is absolutely crucial. Any deception can be discovered and contaminate a subject pool not only for that experimenter but for others. Honesty is a methodological public good and deception is equivalent to not contributing. It is important for the profession to remember this, especially since, as John Kagel pointed out to me, it is conventional wisdom that economists free ride.

\subsection{Economists Begin to React}

The work of Marwell and Ames described in section 2.3 provided stark and clean evidence against the standard economic predictions: data confirmed that subjects contribute and do not all fee ride. The research caught the attention of the new economic experimentalists who had been focusing on markets and who felt sure that the study by sociologists must be flawed. Theory could not be that wrong, could it?

In this section we will look at two studies which were created in direct response to Marwell and Ames. Indeed the purpose of both Kim and Walker (1984) and Isaac, McCue, and Plott (1985) was to show that Marwell and Ames were wrong and "to explore the behavior of groups within a set of conditions where we expected the traditional model would work with reasonable accuracy." (Isaac, McCue, and Plott (1985) p. 51.) By this they mean they expected to find free-riding and underprovision of the public good, a finding that would be at odds with Marwell and Ames $(1979,1980)$ and Dawes, McTavish, Shaklee (1977).

\subsubsection{Procedures}

The main divergence of both Isaac, McCue, and Plott and Kim and Walker from Marwell and Ames was the introduction of repetition; that is, subjects faced the same decision process for a series of periods rather than just making their decisions once. We will describe the Isaac, McCue, and Plott experiment. ${ }^{48}$

\footnotetext{
${ }^{48} \mathrm{Kim}$ and Walker is covered in Section 2.4.3.
} 
A total of nine experiments were conducted ...

Subjects were guaranteed a minimum of $\$ 5.00$ for participating. Before the instructions were read, subjects were endowed with the $\$ 5.00$ and told that all earnings in the experiment would be paid in addition to that initial amount. ...Each subject was assigned one of the two payoff conditions ... called 'high' and 'low' payoff condition ... The earnings of a subject in a period was the individual's payoff as determined by the level of public good provided that period and the individual's payoff chart minus the amount the individual contributed toward the provision of the public good that period. Thus, the total earnings of an individual during the experiment was the initial payment guarantee plus the sum over all periods of the earnings for each period.

... there were ten subjects in each experiment (except experiments 4 and 9) half of which had the high payoff condition and the other half had the low payoff condition. the public good was supplied at a constant marginal cost of $\$ 1.30$. (Isaac-McCue-Plott (1985) p.53. ${ }^{49}$ )

Subjects were given a table which indicated both their marginal payoff and total payoff at each level of the public good from 0 to 40 . The functions which generated these marginal payoffs, where $q$ is the amount of the public good actually chosen, were $\$ .44$ $0.011 \mathrm{q}$ for the high types and $\$ .276-0.008 \mathrm{q}$ for the low types. Given this environment the optimal group allocation, which maximizes total payoff, is at $q=23$ or 24 . The Nash equilibrium is $q=0$ and it is a single-period dominant strategy for both types not to contribute.

The decision process for the primary voluntary contributions process proceeds as follows. At the beginning of a period each subject privately wrote on a slip of paper the amount (s)he wished to contribute to the jointly provided public good that period. The paper was collected by the experimenter. The sum of these contributions by the subjects was calculated by the experimenter and was divided by the (constant) cost of the units to obtain the level of the project funded. The level of the project thus funded was announced and used to determine each individual subject's monetary payoff from the payoff chart. This payoff determination was made privately by each individual. The subjects recorded the payoff amount on a form provided as a part of the instructions. The earnings for a subject were calculated as the difference between the monetary payoff determined by the level of the public good and the contribution made by the subject for the provision of the good. A brief period was allowed for the computation of this profit before the next period began.

\footnotetext{
${ }^{49}$ I would like to thank Elsevier Science Publishers for permission to quote from this report.
} 
There were two standard rules regarding the information of participants: first, the subjects were not allowed to communicate with one another during the experiment. Secondly, the individuals had no knowledge about the nature of any payoff charts other than their own. In a technical sense it was public information that no one had information about other subject preferences. Furthermore, it was public information that the final period was known with certainty to no one. (Isaac-McCue-Plott (1985) p. 57.)

\subsubsection{Results}

Did Isaac et al. find evidence that contradicts the Marwell-Ames results? The answer is yes and no. In the first period decisions, contributions strongly resemble those observed by Marwell-Ames. On average first period contributions yield a public good level of 8.8 which yields a group payoff of $50 \%$ of the maximum possible. So the first decisions of subjects are similar in both studies. However, by the fifth period the average number of units provided has dropped to 2.1 for a group payoff which is $9 \%$ of the maximum. So, after repetition, one can observe significant underprovision and the free-riding phenomenon.

\subsubsection{Comments}

The relatively high initial contribution rate which declines with repetition has been found by others and is discussed in more detail in Section 3.2. Kim and Walker (1984) with a similar design found contributions provided $41 \%$ of the maximal group payoff in the first period and declined to $11 \%$ by the third period. I have not emphasized their study more because, although they were extremely careful to try to eliminate nine experimental design features of earlier studies which they argued might be invalidating factors, ${ }^{50}$ they misled their 5 subjects hoping they would think there were actually 100 subjects. ${ }^{51}$ Whether the subjects believed that or not is unknowable.

An innovative feature of both the Isaac-McCue-Plott and Kim-Walker experiments was the use of a declining marginal payoff curve (in the public good) for each subject and no constraint on contributions within a period imposed by an initial endowment of tokens (just a total capital constraint across all periods). Such a payoff structure means that the private incentives not to contribute increase as the others' contributions increase. Let us look at that incentive. For the high types, contributing one dollar more to public good provision yields $\frac{1}{1.30}$ units of the good which yields an extra benefit, to that individual, of $m=[.44-.011 q] \frac{1}{1.30}$. When $q=0, m=.3385$, when $q=10, m=.25$, and when $q=24$ (the group maximal amount) $m=.13$. For low types we have $m=.2123$ when $q=0$,

\footnotetext{
50 "Factors which, if they intrude into the experimental situation, will render the theory ... inapplicable" (p. 11). Such factors involve a loss of control by the experimenter.

${ }^{51}$ I have indicated in Section 2.3.3 how I feel about this design to save money.
} 
$m=.158$ when $q=10$ and $m=.0646$ at $q=24$. Since $m<1$ for all $q$ it is a dominant strategy not to contribute. $m-1$ measures the marginal gain from contributing $\$ 1,1-m$ measures the marginal gain from withholding $\$ 1$. We will see in the next section that $m$ is an important variable ${ }^{52}$ in determining the extent of contributions. To see whether .34 is large, let us compute the similar statistic for Dawes et al. (in Section 2.2). ${ }^{53}$ Under the loss condition (see Table 2) contributing by choosing $O$ instead of $X$ is equivalent to spending $\$ 9.50$ privately to gain an extra $\$ 1.50 /$ person. Thus, $m=1.5 / 9.5=.158$. Equivalent numbers are computed for the no-loss condition in Table 5. Isaac, McCue, and Plott do not seem to have chosen parameters with incentives not to contribute any stronger than Dawes et al. One might, therefore, conclude that the low contribution rate is attributable to repetition.

That leads to a final comment. The fact that repetition is an important treatment is good to know but there is no way to know why it is from this paper. ${ }^{54}$ Are subjects learning? If so, are they learning how to compute dominant strategies or how to interpret the payoff tables or whether the others are "fair" or ...? Maybe the decline in contributions is simply the result of complicated strategic decisions and/or attempts at signaling. ${ }^{55}$ Repetition confounds the one period gains from contribution with the multiple-period gains from communicating. Controls must be created to disentangle strategic and learning effects from each other. Finally, one might wonder whether the decline in contributions is an attempt to punish "unfair" behavior by others, but one must also then wonder how that could be proven. We will take up some of these issues in Section 3.2.

\subsection{Isaac et al.: Systematic Study by Economists}

By 1981, the results of Dawes et al., Marwell-Ames, Kim-Walker, and Isaac-McCuePlott were fairly well known. The work of the first two groups suggested that free riding was at best a weak phenomenon in single decision situations; the work of the last two groups seemed to suggest that free-riding was an important and strong phenomenon in repeated situations. It was time to try to figure out what was really happening. One of the first systematic studies truly designed to reconcile and understand the reasons for the range of seemingly divergent experimental results was that of Isaac, Walker, and

\footnotetext{
${ }^{52}$ Isaac, Walker, Thomas (1984) were the first to identify and study this effect systematically. Their work is described in Section 2.5.

${ }^{53}$ In Marwell-Ames (1980) there is not a smooth marginal contribution function, so it is not obvious what the appropriate $m$ would be. One might compute an average where every 2,000 tokens yields $.55 /$ person so $m=.0275$. This seems very small but it did not deter contributions.

${ }^{54} \mathrm{~A}$ similar comment applied to communication in the Dawes et al. experiment described in Section 2.2 .

${ }^{55}$ Isaac-McCue-Plott point to a phenomenon they call "pulsing" - a contribution larger than in a previous period - and conjecture it may be an attempt to get others to cooperate. No one knows for sure as "pulsing" has never been systematically isolated and studied.
} 
Thomas (1984). Isaac and Walker continue today in systematic efforts to understand behavior in voluntary contributions situations. I include a description of their first work here because of the craftsmanship with which it was designed. But even with a careful design they were left with many unanswered questions. In particular they conclude that "free riding is neither absolutely all pervasive nor always nonexistent ... The extremes of strong free riding and near-Lindahl optimal behavior can and do occur." (p. 140.) So we still do not know what to expect - anything can happen.

Nevertheless because of the care taken, we do learn something about the existence of

"... systematic effects of attributes of the decision setting upon the existence of free riding ... General theories about the importance of free riding are not failing because of some inexplicable randomness in previous experiments." (Isaac-Walker-Thomas (1984) p. 125.)

\subsubsection{Procedures}

Four undergraduate students at the University of Arizona were brought into a room and each was assigned to a (PLATO) computer terminal. All communication, including instructions to the subjects, was done through the terminals. As they indicate

One feature of this set of experiments that differs from the previously cited experiments is the use of the Plato computer system for conducting the experiments. This system allows for minimal experimenter-subject interaction during experimental sessions as well as insuring that all subjects see identical programmed instructions and examples for a given experimental design. The use of the computer system also facilitates the accounting process that occurs in each decision period and minimizes subject's transactions costs in making decisions and recalling information from previous decisions. (Isaac-WalkerThomas (1984) p. 116.)

Continuing the description:

The programmed instructions described to the participants the following decision problem: given a specific endowment of resources (tokens) participants faced the decision of allocating them between an individual exchange (private good) and a group exchange (public good). The individual exchange was described as an investment which paid to the investor $\$ .01$ for each token invested. ... The group exchange was explained to the participants as an 
investment which yielded a specific return per token to the individual as well as the same return to all other participants. ... The payoff from the group exchange was reported to each participant in the form of a table which gave group and individual returns from the group exchange for various investment levels (from zero up to the total tokens owned by the group.)

The information position of each participant can be described as follows: First, each participant knew his own endowment of tokens for each decision trial and the total tokens for the group. He did not know the specific allocation of tokens to other participants. Second, participants knew the exact size of the group and that each participant return from the group exchange was identical. Each participant knew with certainty his own return from the private exchange. Participants were not informed that all other participants received the same return per token from their contributions to the private exchange. Third, each participant knew there would be 10 decision trials and his endowment for each trial would be equal. Finally, it was explained that the monetary gains from each trial were binding and total payments to the participant equaled the sum of his return for the group and individual exchanges totaled over all ten trials. At the end of each trial the participant received information on his return from the individual and group exchange. They were also told the total number of tokens contributed by the group to the group exchange. Before making an investment decision in any one trial, a participant could obtain this same information for all previous trials. (Isaac, Walker, and Thomas (1984), p117.)

Isaac, Walker, and Thomas were interested in identifying factors which increased or decreased free-riding and they chose four particular ones: repetition, group size, marginal payoff and experience. They, of course, hoped to control for all else.

Here each participant knew there would be exactly 10 periods and the participants' endowments and payoffs would remain constant across the repetitions. Group size was easy to control: They chose $N=4$ and $N=10$. But keeping all other possible effects constant proved more challenging. In particular, they discovered that keeping the marginal individual payoff (a measure of selfish gain) constant and simultaneously keeping the marginal group payoff (a measure of altruistic gain) constant was impossible. Algebraically, the payoffs in this experiment were $u^{i}=p\left(z-c_{i}\right)+\frac{a}{N}\left(\sum c^{k}\right)$. The marginal individual gain from contributing a token is $\frac{a}{N}$. Normalize by the cost, $p$ and get $\frac{a}{p N}=M$. This is simply the marginal rate of substitution of the private for the public good, $y=\sum c^{k}$. That is $M=-\frac{\partial u^{i} / \partial y}{\partial u^{i} / \partial c_{i}}$. Isaac and Walker call this the marginal per capita return. ${ }^{56}$ The marginal group return, computed from $\sum u^{i}=p\left(N z-\sum c^{i}\right)+a\left(\sum c^{i}\right)$ is $\frac{a}{p}$. If we increase $N$ and change nothing else then the incentives for individual interest increase relative to the

${ }^{56} \mathrm{We}$ saw this variable in Section 2.4.3. 
incentives for the group interest. If we increase $N$ but keep $M$ constant by increasing $a$ then the incentives for the group interest increase relative to the incentives for individual interest. It does not seem possible to change $N$ without changing the incentives between group and self interest. Isaac, Walker, and Thomas deal cleverly with this by considering a $2 \times 2$ design with $N=4$ or 10 and $M=.3$ or .75 . Always $p=1$. Then, since $a=N M$, we have four parameter choices $(N, M, a):(4, .3,1.2),(4, .75,3),(10, .3,3)$, and $(10, .75,7.5)$. These allow comparing a change in $N$ keeping $M$ constant (for both $M=.3$ and $M=.75$ ) and comparing a change in $N$ keeping $a=3$ constant.

Finally, experience is measured as previous participation in similar experimental sessions.

\subsubsection{Results}

The only extant formal theory at the time of these experiments predicts no contributions. That is clearly false as can be seen in Table 8 and Figure 2 .

Ave. $\%$ contributions for

$\mathrm{N}=$\begin{tabular}{|c|c|c|}
\hline & \multicolumn{3}{|c|}{$\mathrm{M}=$} \\
\hline & .3 & .75 \\
\hline 4 & 19 & 57 \\
\hline 10 & 33 & 59 \\
\hline
\end{tabular}

Figure 2 .

Table 8. Data for IWT (1984)

\begin{tabular}{lllllllllll|l} 
& \multicolumn{10}{c}{ Period } \\
& 1 & 2 & 3 & 4 & 5 & 6 & 7 & 8 & 9 & 10 & Ave. \\
\% contrib. (all) & 51.1 & 47.2 & 44.1 & 47.4 & 46.7 & 38.1 & 40.6 & 35.2 & 35.8 & 37.3 & 42.4 \\
\% contr.( $M=.3)$ & 43 & 35 & 28 & 32 & 26 & 25 & 20 & 17 & 20 & 17 & 26 \\
\% contr.( $M=.75)$ & 60 & 59 & 60 & 63 & 67 & 51 & 61 & 53 & 52 & 57 & 58 \\
$\%$ contr.(inexper.) & 53 & 53 & 45 & 50 & 55 & 43 & 50 & 41 & 39 & 44 & 47 \\
$\%$ contr.(exper.) & 49 & 41 & 43 & 45 & 38 & 33 & 31 & 30 & 33 & 30 & 37 \\
$\%$ contr. $(N=4)$ & 50 & 50 & 38 & 40 & 38 & 30 & 36 & 32 & 38 & 30 & 38 \\
$\%$ contr. $(N=10)$ & 56 & 50 & 40 & 41 & 41 & 34 & 32 & 33 & 37 & 35 & 40
\end{tabular}

The average $\%$ contribution across all treatments is $42 \%$ and the average across first periods is $51 \%$. These look very much like Dawes et al. and Marwell-Ames. But the variance is high, with contributions ranging from $0 \%$ (period 8 with $M=.3, N=4$, experienced subjects) to $83 \%$ (period 5 with $M=.75, N=4$, and inexperienced subjects). 
So something more than just $40-60 \%$ contribution is going on. There are three obvious conclusions. First, increasing $M$ from .3 to .75 increases the rate of contribution in all cases. The effect is dramatic and strong and in the direction one should expect when the strength of the private (selfish) incentive is reduced relative to the public (altruistic) incentive. Second, experience matters with inexperienced subjects contributing more. This suggests that some form of learning may be occurring. Finally, repetition decreases and group size increases contributions for low $M=.3$ but neither seem to have any effect if $M=.75$.

\subsubsection{Comments}

This experiment epitomizes the difficulties in doing experimental research in public goods. One can identify general effects which cause free riding but there are always cases which contradict the general finding. For example, the strongest effect seen in this experiment was that a decrease in $M$ will cause contributions to drop yet in the first period of $N=10, M=.3$ and experienced subjects there were $46 \%$ contributions whereas in the first period of $N=10, M=.75$ and experienced subjects there were only $44 \%$ contributions. The change in $M$ had no effect. This may say more about the random nature of first period play than it does about the systematic effect of $M$, but we do not have enough evidence to know for sure. The experimental design is really carefully thought out, one of the best, an attempt is made to control the obvious confounding variables and yet the data are not that precise and conclusions are hard to draw out. The lack of any helpful theory beyond calculation of marginal rates of substitution prevents a precise analysis of the obvious interaction effects between variables. One experiment will not be enough; a history of comparable efforts may be needed before we fully understand what helps or hinders volunteerism.

A second comment foreshadows the rest of this chapter. The fact that repetition and group size have a noticeable effect when $M=.3$ but not when $M=.75$ signals a real difficulty with public goods experiments and our ability as economists to extract useful information from these experiments. To see why, let me try to summarize what we know to here.

\subsubsection{A Summary to this Point}

We have looked at six major experiments that have studied behavior in public goods environments. Three ${ }^{57}$ claim to have established that selfishness is not as rampant as we might have expected while three ${ }^{58}$ claim to have established that altruism has no staying

\footnotetext{
${ }^{57}$ Bohm (1972), Dawes, McTavish, and Shaklee (1977), and Marwell and Ames (1979).

${ }^{58}$ Isaac, McCue, and Plott (1985), Kim and Walker (1984), and Isaac, Walker, and Thomas (1984).
} 
power. It seems pretty easy to demonstrate that subjects contribute. All experiments have periods with at least $40 \%$ contributions. But determined experimenters also seem to be easily able to extinguish most but not all of the altruistic impulse (if that is what it is) through low marginal payoffs and repetition. We need to better understand the causes of these observations. But none of these experiments is truly comparable with any of the others. Look at the summary of the designs and results in Table 9. At least two features, sometimes more, change between any two experiments.

Table 9. Summary of Designs and Results

\begin{tabular}{l|c|c|c|c|c|c}
\hline & $\mathrm{B}$ & DMS & MA & IMP & KW & IWT \\
\hline Numbers & $? *$ & 8 & $4,80 *$ & 10 & $100 *$ & 4,10 \\
Marginal Payoff & $?$ & $.16, .16-.75$ & non-linear & $.34^{b}-.06$ & $.02^{b}, .05$, & $.3, .75$ \\
& & & & & .07 & \\
Repetition & no & no & no & yes $^{c}$ & yes $^{c}$ & yes \\
Provision Point & yes & no & yes & no & no & no \\
Tokens & no & $1 /$ person & yes & no & no & yes \\
Heterogeneity & $?$ & no & no, yes & yes & no & no \\
Experience & no & no & no & no & no & yes, no \\
Communication & no & yes, no & no & no & no & no \\
Moral suasion & yes & no & no & no & no & no \\
$\begin{array}{l}\text { \% contributions } \\
\text { initial period }\end{array}$ & NA & $31 \%{ }^{a}$ & $41 \%$ & $50 \%$ & $68 \%$ & $51 \%$ \\
last period & NA & NA & NA & $9 \%$ & $8 \%$ & $19 \%$ \\
\hline
\end{tabular}

$*=$ deception played a role.

$?=$ uncontrolled.

$\mathrm{a}=\mathrm{w} / \mathrm{o}$ communication. (It was $71 \%$ with communication.)

$\mathrm{b}=$ declines as $q$ increases.

$\mathrm{c}=$ subjects did not know number of repetitions.

Note $=$ Two entries mean both treatments were tried.

$$
\begin{array}{ll}
\mathrm{B}= & \text { Bohm (1972) } \\
\mathrm{DMS}= & \text { Dawes, McTavish, and Shaklee (1977) } \\
\mathrm{MA}= & \text { Marwell and Ames (1979) } \\
\mathrm{IMP}= & \text { Isaac, McCue, and Plott (1985) } \\
\mathrm{KW}= & \text { Kim and Walker (1984) } \\
\mathrm{IWT}= & \text { Isaac, Walker, and Thomas (1984) }
\end{array}
$$

The two closest designs may be Marwell and Ames (1979) and Isaac, Walker, and Thomas (1984) but even they differ in marginal payoff, provision point, and repetition. The difference in designs implies that sometimes subjects contribute and sometimes they 
do not. The research problem is to discover when and why. I suppose that if one had all the data from these six studies one could do some complex multivariate statistical analysis, but experiments are supposed to free economists from that necessity. ${ }^{59}$

Our task would be easier if there were significant comparability across experiments and experimentors. However as we will see in Section 3, there is precious little and, perhaps as a result, a lot of uncertainty still remains about behavior in public good environments.

\section{What Improves Cooperation?}

In Section 2 we looked at some of the pioneering efforts in the experimental analysis of behavior in the presence of public goods. We found that not everyone free rides all the time. That subjects would voluntarily provide public goods in some situations is amply demonstrated by Dawes et al., Marwell et al., and the early periods of Isaac et al. This early work also identified two factors which seemed to improve cooperation: relevant communication (by Dawes et al.) and increases in the marginal payoff for contributing (by Isaac et al.). One factor which seemed to decrease cooperation, repetition, was also identified (by Isaac, McCue, and Plott). As one can see from Table 9 in Section 2, there were at least six other factors which were deemed potential influences on behavior: numbers, provision points, number of tokens, heterogeneity of payoffs and endowments, experience, and moral suasion. Of course one might think of many other factors and the next cohort of experimentalists have done just that. It is time now to try to understand the state of the art today. In Section 2 I tried to give the reader an idea about how experiments with public goods have been conducted; in this section I am going to concentrate on what modern experimental research has discovered and, therefore, where the next work might begin. ${ }^{60}$ The reader is strongly encouraged to consult the original papers if they want to know the details of the experimental designs.

One of the major goals of research on public goods is to discover the nature of the relationship $\mu(e,(M, g))=\{a\}$ : that is, contributions $=\mu$ (environment, mechanism). The issue is not so much honest revelation of preferences as it is what level of public goods will be provided by subjects and how is that affected by environment and mechanism. In Table 10, I have listed 19 variables various researchers have identified as having an effect on the level of contributions. I have found it useful to group the variables identified

\footnotetext{
${ }^{59}$ In an extremely interesting paper, Sally (1992) took 130 treatments from 37 studies and ran a regression with $\%$ contribution as the dependent variable. He found significant positive coefficients for moral suasion, frequency of discussion, solicitation of promises by the experimenter, and (perhaps surprisingly) whether players earned money. He found a significant negative effect for marginal payoffs. His $R^{2}$ were about .7 to .8 . However, I think he missed some interesting experiments and variables.

${ }^{60} \mathrm{I}$ cover about 40 papers in this section. I apologize to the authors I leave out. I just ran out of time and space.
} 
by existing research into three main categories: the environment (numbers, strength of incentives, extent of homogeneity, thresholds imposed by the production technology, initial information structure, gender, ...), systemic variables (fairness concepts, altruism, risk attitudes, beliefs, ...), and design variables (such as unanimity rules, structured communication, and moral suasion). The variables in the first two categories are aspects of what I have called the environment: I have split them into two parts to emphasize that some are more easily controllable with current experimental technologies. In particular, those identified as environmental are relatively straightforward to control, while those listed as systemic are currently more difficult. The variables in the category, labeled design variables, are factors identified by experimentalists which should be more properly thought of as aspects of institutional design. These variables are amenable to change and the mechanism designer can use them to improve solutions to the free rider problem.

In Table 10, I summarize what seems to be the consensus of experimentalists about the effect of a change in one of these variables on the change in total contributions as a percent of the efficient level. Some effects are more certain than others, in that replication has confirmed initial findings. Understanding behavior would be easier if each of these variables had a separable and identifiable effect on contributions. ${ }^{61}$ Unfortunately that is not true: the details of the environment seem to matter. Left unexplained in the table are what I call cross-effects. The latter are very important and not well tracked in the literature. ${ }^{62}$ In some cases, cross-effects may even reverse the direction of effect of a variable. We will see this below.

I organize the rest of this chapter as follows. In Section 3.1, I describe a very important structural feature in environments with public goods which must be tracked in order to make comparisons across experiments. In Section 3.2, I take up results dealing with repetition and the related issues of learning and experience. In 3.3, I cover the strong effects of marginal payoff (and its related problem of numbers) and communication. In 3.4 , I turn to weak effects. In 3.5, I discuss some of the factors which may be important but of which little is known primarily because an inability to control their impact on an experiment. In Section 4, I conclude with some final thoughts on what we really know and where we might go.

\footnotetext{
${ }^{61}$ I have in mind here something like the robustness of the supply-demand equilibrium with private goods. (See chapter Holt (1994)).

${ }^{62}$ For example, the effects of changes in the marginal per capita return seem to vary depending on group size. See Isaac and Walker(1988b) and Isaac, Walker, and Williams (1990).
} 
Table 10. Stylized Facts

I. ENVIRONMENT - easy to control

Effect on \%C Section

MPCR (marginal per capita return)

Numbers

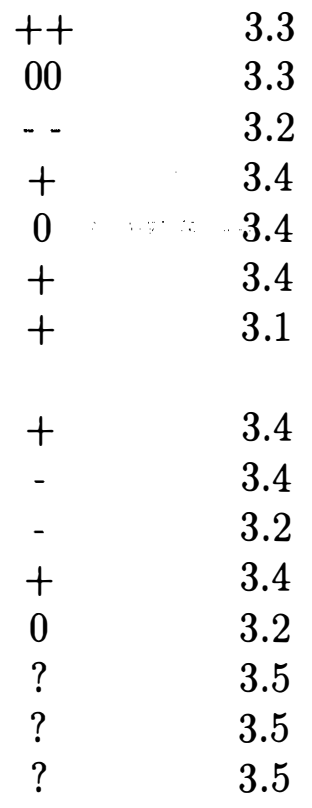

Repetition

Common knowledge

Gender

Homogeneity (symmetry)

Thresholds

II. SYSTEMIC - difficult to control

Beliefs

Economics Training

Experience

Friendship/Group identification

Learning

Altruism, fairness

Effort

Risk Aversion

$++$

3.3

Communication

+
+

3.3

Unanimity

$-$

Moral Suasion

?

3.4

3.5

* + means increase, 0 means no effect, - means decrease, and ? means that I do not believe these have even been measured yet. A double symbol means the effect is strong and apparently replicable. A single symbol, other than?, means the effect is apparently there but weak and difficult to replicate.

\subsection{Thresholds and Provision Points}

To compare data across experiments one must recognize that there is a fundamental difference in the structure of incentives when a threshold or provision point exists from when it does not. Without a threshold the voluntary contributions mechanism is usually a Prisoner's dilemma game; with a threshold it becomes a game of Chicken. See Table 11. In the former it is a dominant strategy ${ }^{63}$ not to cooperate and there is (usually) a unique non-cooperative equilibrium which is not Pareto-optimal. In the game of Chicken there

\footnotetext{
${ }^{63} \mathrm{~A}$ strategy is dominant if it maximizes the return to an individual no matter what his opponents do. That is, if player $i$ 's strategy is $s$ and the others' strategies are $x$ and $i$ 's payoff is $u(s, x)$ then the strategy $c$ is dominant if and only if $c$ solves $\max u(c, s)$ for all possible $s$.
} 
are generally many non-cooperative equilibria, each of which may be optimal, and none of which is dominant, and the task of the players is to coordinate their actions to select one. The environments of Dawes et al. (1977) and of Isaac and Walker (1988b) are of the prisoners' dilemma variety. The environment of Marwell and Ames (1979) is more like a game of chicken. It is not surprising that we see different results in these two types of environments. For example, if the players can talk one might suspect that in the game of Chicken they would correlate their strategies. This is even easier in repeated play because they can then try to equalize sacrifice. But one might expect that communication would have a lesser effect in dilemma games since there is no problem of coordination.

Table $11 .^{64}$

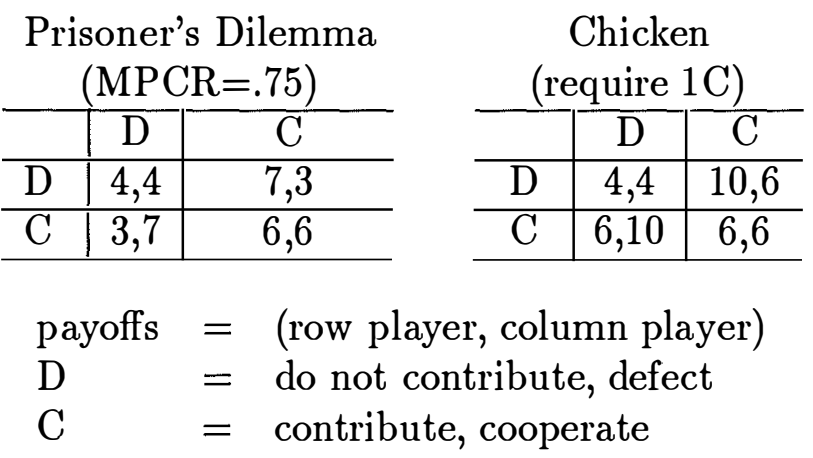

For now let us address the simpler problem: do thresholds cause contributions to increase, ceteris paribus. One often sees campaign targets set when raising funds for charities or university endowments. Do these work? We do not have much evidence but what there is seems to suggest that increases in thresholds increase contributions but also increase the probability the target will not be reached ${ }^{65}$ There are many papers reporting on experiments with thresholds but six actually vary the threshold to determine its effect. ${ }^{66}$ Marwell and Ames (1980) actually compare contributions with and without the provision point discussed in Section 2.3. They found no significant difference. However, as we mentioned in Section 2.3.3 there remained a problem: while they did eliminate the major jump in payoff at 8,000 tokens, in their no-provision point design there are still actually 9 provision points since the payoff is constant across 2,000 token intervals. (See Table 7 in Section 2.3.) What changed was marginal payoff at each provision point: some

\footnotetext{
${ }^{64}$ In the Prisoner's dilemma, each player's dominant strategy is D. There is one Nash equilibrium: (D,D). In Chicken, there are two Nash equilibria: $(D, C)$ and $(C, D)$. There are no dominant strategies. See Chapter 1 for an early history of these experiments.

${ }^{65}$ So if you are running a campaign you want a high enough target to encourage contribution increases but low enough to prevent failure to attain the goal. This is the fund-raiser's art.

${ }^{66}$ These are Marwell and Ames (1980), Dawes, Orbell, Simmons, and van de Kragt (1986), Isaac, Schmidtz, and Walker (1988), Rapoport and Suleiman (1993), Suleiman and Rapoport (1992), and Palfrey and Rosenthal (1991a).
} 
increased and some decreased. So it is not obvious in what direction the provision points are moving. Isaac, Schmidtz, and Walker (1988) provides a better study of this problem in the context of the Isaac, Walker, and Thomas (1984) design described in Section 2.5. They consider three different provision point levels and keep all else constant, such as repetition and marginal payoff. This is done by paying subjects $p^{i}\left(z^{i}-c^{i}\right)+A \cdot \frac{a}{N}\left(\sum c^{j}\right)$ where $A=0$ if $\sum c^{i}<T, A=1$ if $\sum c^{i} \geq T$ and $T$ is the threshold or provision point. They find that increases in $T$ increase contributions but also increase the proportion of times that $\sum c^{i}<T$. They also find that the increase in contributions disappears with repetition so the failure of provision because $\sum c_{i}<T$ eventually dominates. Suleiman and Rapoport (1992) confirm this with a similar study. The main difference is that they provide a payoff of $u^{i}=p_{i}\left(z_{i}-c_{i}\right)+A r$; that is, the return from the public $\operatorname{good}^{67}$ is independent of the total contributions. They also found contributions increased with $T$ and the probability of provision decreased. ${ }^{68}$ The numbers are reported in Table 12 . It is not obvious from these data what the efficiency, $\sum u^{i}$ divided by the max possible, levels were. Dawes, Orbell, Simmons, and van de Kragt (1986) report similar results when subjects make an all or none contribution one time only. ${ }^{69}$ Here everyone could contribute $\$ 5$ or $\$ 0$. If at least $K$ of 7 contributed, everyone got $\$ 10$ : contributors end up with $\$ 10$, non-contributors receive $\$ 15$. They find that for $K=3,51 \%$ contribute and for $K=5,64 \%$ contribute. I could not calculate the provision proportions from the data reported.

Table 12.

\begin{tabular}{rr|c|c}
\hline & & ave. contributions & provision \% \\
\hline \multirow{3}{*}{ Threshold } & 10 & $53 \%$ & $85 \%$ \\
& 15 & $66 \%$ & $80 \%$ \\
& 20 & $73 \%$ & $39 \%$ \\
\hline
\end{tabular}

So increases in thresholds seem to increase the percent contributed and lower the probability of provision. But in a followup study Rapoport and Suleiman (1993) report results that could cause one to worry about accepting this proposition too quickly. Changing the experiment by randomly assigning the endowments $z_{i}$ to be $3,4,5,6$, and 7 , they found that changes in the threshold had no significant effect on the percent contributed. With $N=5$, the average individual contributions were $54 \%, 63 \%$, and $60 \%$ for $T=10,15$, and 20 respectively. ${ }^{70}$ The provision percentages were $80 \%, 65 \%$ and $12 \%$ respectively. Palfrey

\footnotetext{
${ }^{67}$ In the experiments reported $r=10, z_{i}=5$, and $T=10,15$, or $20 . \quad N=5$.

${ }^{68}$ They also had repetitive trials but since no information or feedback was provided between trials, the repetition had no apparent effect.

${ }^{69}$ Suleiman and Rapoport (1992) actually test whether requiring an all or none payment affects the rate of contribution. They find that contributions increase if $c_{i}$ is not restricted to be all or none. Palfrey and Prisbrey (1993) have a similar finding for a non-threshold environment.

${ }^{70}$ What did have an effect on the average contributed was the introduction of heterogeneity. More on this in Section 3.4.
} 
and Rosenthal (1991a) find similar ambiguities in a heterogeneous environment. There $N=3$, marginal payoffs are heterogeneous, and each agent has one token. The threshold is $K$ of $N$. They find that \% contributions increase as $K$ is increased from 1 to 2 but decrease as $K$ is increased from 2 to 3 .

In the Palfrey and Rosenthal (1991a) framework, pure strategy Bayesian equilibrium theory predicts a decrease from $K=1$ to 2 and from $K=2$ to 3 for their parameters. However, a careful look at mixed strategy equilibria for these environments with thresholds suggests that game theory would predict that changes in the threshold can have an ambiguous effect on changes in contributions. See, e.g., Palfrey and Rosenthal (1988). The ambiguity is resolved only when specific parameters are known. The theory is telling us we should not expect a definitive answer to "does an increase in threshold increase contributions" which is independent of other factors. The data are supporting that view.

\subsection{Experience, Repetition, and Learning}

A natural explanation for the large rate of contribution in many voluntary contribution experiments can be found in the inexperience of the subjects. Perhaps a $40-60 \%$ contribution rate occurs simply because if one must contribute a number between 0 and $\mathrm{Z}$ and does not understand the implications of the act then a natural choice is somewhere in the middle. ${ }^{71}$ This would be especially true of experiments such as Isaac-Walker in which payoffs are linear. Clearly it is important to be able to discover whether the data are simply the result of confusion and inexperience or the result of some more purposeful behavior. One way to do this is to create payoffs such that the two key points of interest, the dominant strategy contribution and the group optimum contribution are moved to the interior of $[0,100]$. That is discussed in Section 4 . We explore another way here.

Repetition (not replication) has become a common feature ${ }^{72}$ of much research in experimental economics in an effort to eliminate or control for at least two types of experience effects: learning how to play the particular class of games, such as what keys to press in a computerized continuous auction or how to read a particular payoff schedule, and learning about the specific game one is in, such as what the environment is and what the other subjects are like. One can easily control for the first type of experience by simply bringing back subjects who have previously participated in similar experiments. This has not been done as often as one might suspect. The data from Isaac, Walker, and Thomas (1984) and Palfrey and Prisbrey (1993) suggest that subjects who have previously been in a voluntary contributions experiment contribute less than those who are first-timers

\footnotetext{
${ }^{71} \mathrm{An}$ alternative yielding the same data would be to randomize between contributing 0 and contributing $z$. This, however, does not appear to be supported by individual data. But I am not sure whether a more diffuse contribution strategy based on random behavior can be rejected since one only sees realizations and not the strategy itself.

${ }^{72}$ At least 25 of the 40 or so papers reported here have used this technique.
} 
but still more than zero. Palfrey and Prisbrey (1993) suggest that experience does not actually have a significant effect on the $\%$ of contributions, because, although experienced subjects contribute less, they also make fewer errors. They also find that experienced subjects are more responsive to MPCR. Two other studies which control for experience this way (Marwell and Ames (1980) and Isaac, Schmidtz, and Walker (1988)) however find no significant effect. There was a threshold in the latter two and not in the former. Does that explain the different data? We do not know. ${ }^{73}$

Significant decreases from repetition in non-threshold environments are reported by Isaac, Walker, and Thomas (1984), Isaac, McCue, and Plott (1985), Isaac, Walker, and Williams (1990) for $N=4$ and 10, Brookshire, Coursey, and Redington (1989a), Kim and Walker (1984), Brown-Kruse and Hummels (1992), Banks, Plott, and Porter (1988), Sell and Wilson (1990), Andreoni (1988b), and Isaac and Walker (1987). Experiments in which repetition had no effect ${ }^{74}$ and there was no threshold are reported by Isaac, Walker, and Williams (1990) for $N=40$ and $N=100$ and by Palfrey and Prisbrey (1993). In experiments with thresholds the results are considerably more mixed. Bagnoli and McKee (1991) report a positive effect on contributions, Palfrey and Rosenthal (1991a) report a small drift towards Nash equilibrium, and Suleiman and Rapoport (1992) and Isaac, Schmidtz, and Walker (1988) report a negative effect. From a theoretical perspective the natural question is not whether contributions decline but rather whether convergence to Bayes-Nash equilibrium is occurring. With no threshold, the equilibrium is zero contribution and convergence seems to be empirically verified (at least for small $N)$. With a threshold, there are usually multiple Nash equilibria so the convergence question is more clouded: we need to look at details other than simple increases or decreases. Since the data and theory for the no threshold environments are more straightforward let us concentrate on those for now.

The data suggest there is a deterioration in contributions after some number of iterations. Is this due to strategy or experience? From a theoretical point of view, one must consider significantly different models depending on which is really happening. It is possible to construct a model in which there is a very small probability that some subjects are not fully rational (i.e., they use dominated strategies) and in which even fully rational selfishly maximizing subjects, even perhaps economists, would contribute all or most tokens - at least in the early periods. Towards the last iteration, the rational players will not contribute. Thus, one should observe the development of a bimodal distribution in contributions as iteration continues. Isaac, Walker, and Williams (1990) have data somewhat like this in large groups of 100. Such a theory can be found in Kreps et al. (1982) and McKelvey and Palfrey (1992). If, on the other hand, subjects are simply trying to learn (by some suitable groping process) what the appropriate one-trial

\footnotetext{
${ }^{73}$ In another attempt to control for inexperience Dawes and Orbell (1982) let some subjects think about the problem for a day. It did not matter. There was no threshold. See Section 3.5.

${ }^{74}$ Saijo and Yamaguchi (1992) report both decreases and no effect depending on the details of the payoff schedules. More on this in Section 4.
} 
strategy is, given this environment and this collection of subjects, then a better model would be something like a learning algorithm found in Miller and Andreoni (1991), Boylan (1990), Crawford and Haller (1990), or Kalai and Lehrer (1990). If everyone learns, then one should observe the contributions converge to the non-cooperative equilibrium after enough periods. This seems to happen after 10 iterations in small groups. We do not know how long it would take in large groups. ${ }^{75}$

The experimental puzzle is to develop designs which allow separation of these two types of temporal phenomena and help us identify those aspects of the institution which speed learning or channel strategy when that is desirable. Andreoni (1988b) represents a good start on this complicated problem. In a unique design he compared two treatments called Strangers and Partners in an Isaac-Walker environment with $p=1, \frac{a}{N}=.5, N=5$, and $z_{i}=50$ all of which were known to everyone. The Partners played repeatedly 10 times just as in Isaac, Walker, and Thomas (1984). The Strangers were 20 subjects randomly reassigned by computer to groups of 5 after each repetition. The idea was to separate strategic play by Partners from no strategic play with Strangers. Thus one should see only learning in the Strangers condition but see learning and strategy in the Partners condition. The data are in Table 13. (Andreoni $(1988 b)^{76}$ )

Table 13. Average Investment in Public Good per Subject

\begin{tabular}{|c|c|c|c|c|c|c|c|c|c|c|c|}
\hline & \multicolumn{11}{|c|}{ Round } \\
\hline & 1 & 2 & 3 & 4 & 5 & 6 & 7 & 8 & 9 & 10 & All \\
\hline Partners & 24.1 & 22.9 & 21.5 & 18.8 & 18.4 & 16.8 & 12.8 & 11.2 & 13.7 & 5.8 & 16.6 \\
\hline Strangers & 25.4 & 26.6 & 24.3 & 22.2 & 23.1 & 21.9 & 17.8 & 19.7 & 14.0 & 12.2 & 20.7 \\
\hline Difference & -1.3 & -3.7 & -2.8 & -3.4 & -4.7 & -5.1 & -5.0 & -8.5 & -0.3 & -6.4 & -4.1 \\
\hline
\end{tabular}

Surprisingly, contrary to received strategic theory, Partners contribute less than Strangers and the difference increases over time. Andreoni further argues that since there is no reason Strangers should learn slower than Partners, learning alone is not responsible for the observed decay in contributions. But strangers are in a noisier environment and, therefore, may indeed learn more slowly. A strategic hypothesis, that giving occurs early because it generates more later, appears to be inconsistent with the data. A learning hypothesis may be ok. That decay in contributions occurs with repetition in environments with a zero dominant strategy is indisputable. What explains the phenomenon remains to be found. Follow up research is needed.

\footnotetext{
${ }^{75}$ Isaac, Walker, and Williams are apparently now running some experiments for up to 60 decision rounds which may provide some answers.

${ }^{76}$ I would like to thank Elsevier Science Publishers for permission to quote from this report.
} 


\subsection{Strong Effects}

In this section I want to concentrate on identifying those factors which, like repetition, have a well documented effect on contributions in the voluntary provision of public goods. There are really just two factors that fall into this category: one environmental, marginal payoffs, and one institutional, communication. I will, however, include a discussion of numbers and rebates since their effects are virtually impossible to disentangle from those of marginal payoffs.

\subsubsection{Marginal Payoffs and Rebates}

Two of the variables most easily controlled in public goods experiments are the marginal benefit of the public good relative to the private and the number of subjects in a group. In terms of our general model, an agent's payoff is $u^{i}\left(w^{i}-t^{i}, g\left(\Sigma t_{j}\right)\right)$. To see the incentives for contributing, differentiate with respect to $t^{i}$, and get $-u_{x}^{i}+u_{y}^{i} g_{z}$. Normalizing by $u_{x}^{i}$ yields $-1+\left(\frac{u_{y}^{i}}{u_{x}^{i}}\right) g_{z}$. It is the product of the marginal rate of substitution, $\left(u_{y}^{i} / u_{x}^{i}\right)$, and the marginal rate of transformation, $g_{z}$, which determines the marginal incentive to contribute. Isaac, Walker, and Thomas (1984) called this product the marginal per capita return, MPCR. For their environment, $u=p(w-t)+y$ and $g\left(\Sigma t_{j}\right)=\frac{a}{N}\left(\Sigma t_{j}\right)$ and, therefore, $\mathrm{MPCR}=\left(\frac{1}{p}\right)\left(\frac{a}{N}\right)$. In Isaac, Walker, and Thomas (1984) and Isaac and Walker (1988b) they began a systematic exploration of the effect of changes in MPCR on rates of contribution. As was evident from the data presented earlier in Section 2.4, Table 8, increasing the MPCR from .3 to .75 increases the rate of contribution independent of $N$ for $N=4$ or 10 . Thus, although the strong game-theoretic prediction of free riding is false, subjects do appear to respond to incentives in a predictable and systematic fashion. Does other research confirm this? Unfortunately not very many other experimentors have controlled the marginal payoff (MPCR) to assess its effect on contributions. But those that have generally find observations consistent with the hypothesis that marginal incentives matter. ${ }^{77} \mathrm{Kim}$ and Walker (1984) increase marginal payoffs, in the midst of their experiment, after repetitions 3 and 11. Their MPCR changes from .02 to .05 to .07 . Each change is accompanied by a significant increase in contributions. Brown-Kruse and Hummels (1992) confirm the effect for MPCR=.5 and .3. Saijo and Yamaguchi (1992) confirm the effect for MPCR $=.7$ and $1.43 .^{78}$

\footnotetext{
${ }^{77}$ I use marginal incentives here to contrast it with what has been called the strength or salience of payoffs. That would mean increasing the rate at which subjects are paid while keeping the marginal payoffs constant. For the Isaac and Walker environments this would mean increasing $a$ and $p$ while keeping $\frac{a}{p}$ constant.

${ }^{78} \mathrm{At} .7$ it is a dominant strategy to contribute nothing. At. 1.43 it is a dominant strategy to contribute everything. Neither happens in this experiment but an increase in contributions (on average from $27 \%$ to $40 \%$ ) does occur with the increase in MPCR. These puzzling data will be discussed in more detail in Section 4 below.
} 
We can also get some indirect evidence on the effect of marginal payoffs from two other sources; experiments with asymmetric payoffs and experiments with rebates. An example of the former can be found in Section 2.4 where Isaac, McCue, and Plott (1985) found (conclusion 7 p. 64) that "individuals in the high payoff condition contribute more than individuals in the low payoff condition." Marwell and Ames (1979) also report more contributions from "high interest" (blue) subjects (see Figure 6 Section 2.3 for the payoffs) than "low interest" (green) subjects. Other confirming evidence with asymmetric payoffs can be found in Brookshire, Coursey, and Redington (1989a), Fisher, Isaac, Schatzberg, and Walker (1988), Palfrey and Rosenthal (1991a), and Rapoport and Suleiman (1993). One of the more powerful sets of supporting data is in Palfrey and Prisbrey (1993) who mimic the Isaac and Walker framework but allow the private value to be asymmetric across subjects. In particular $u^{i}=P_{i}\left(z-c_{i}\right)+a \sum c_{i}$ where $P_{i}$ is private information, drawn randomly and uniformly from the set $\{1,2, \ldots, 20\}$. Here it is a dominant strategy to contribute if $P_{i}<a$ and to not contribute if $P_{i}>a$. They used a total of 64 subjects in four different experimental sessions involving 4 person groups. A very simple probit model, Probability $($ contribute $)=\mathrm{f}\left(\right.$ constant $\left.+\alpha\left(\frac{a}{p}\right)\right)$ is able to correctly predict $83 \%$ of the observations. ${ }^{79}$

Clearly, the marginal payoff $\frac{a}{p}$ is an important effect. ${ }^{80}$ This is true whether thresholds are present or not. Indeed one other source of confirming data comes from the analysis of rebates in threshold situations. Dawes, Orbell, Simmons, and van de Kragt (1986) study two changes in their simple payoff structure, both of which increase the marginal payoff to contributing ceteris paribus. In their baseline condition each subject could contribute or keep $\$ 5$. If at least $K$ of $N$ contribute, then all get $\$ 10$. In a "no fear" condition all contributors get their $\$ 5$ back if less than $K$ contribute. In a "no greed" condition subjects who do not contribute only get $\$ 5$ more if at least $K$ contribute. The data are in Ta.ble 14. In another study with thresholds Isaac, Schmidtz, and Walker (1988) also find a significant effect for rebates.

Table 14. \% Contributing

\begin{tabular}{c|c|c}
\hline & $K=3$ of 7 & $K=5$ of 7 \\
\hline baseline & $51 \%$ & $64 \%$ \\
\hline no fear & $61 \%$ & $65 \%$ \\
\hline no greed & $86 \%$ & $93 \%$ \\
\hline
\end{tabular}

The only report which might cast any doubts on the strong effect of increasing marginal payoffs can be found in Isaac, Walker, and Williams (1990). Here they begin to explore the effect of large numbers $(N=40$ and 100) without the deception which

\footnotetext{
${ }^{79}$ The $t$ statistic on the estimated coefficient $\alpha$ is 86.358.

${ }^{80}$ For additional work see Carter et al. (1992).
} 
characterized others' earlier attempts. They found, with these large numbers, that varying MPCR between .3 and .75 had no significant effect on percentage contributions. In fact, it was not until MPCR dropped from .3 to .03 that any significant decline in contributions occurred. Either increasing numbers has a dampening second order effect on the effect of marginal payoffs or there was something else in their experimental design which caused the effect to be eliminated. Let us see what we can find out about numbers.

\subsubsection{Numbers}

The second variable that is most easy to control is the number of subjects. One of the longest running debates among theorists, other than whether contributions will occur at all, is whether contributions increase or decrease with group size. ${ }^{81}$ Those arguing for a decrease in $\Sigma t_{i}$ as $N$ increases generally believe that, in larger groups, non-cooperative behavior is more difficult to detect and, therefore, self-interested subjects will be more willing not to contribute. The argument that an increase in $\Sigma t_{i}$ will occur as $N$ increases usually relies on the fact that the marginal effect on $\sum_{i} u^{i}$ with respect to $t_{i}$ increases as $N$ increases and, therefore, any tendency toward altruism should be reinforced as $\mathrm{N}$ increases. In the Isaac and Walker environments $u^{i}=p_{i}\left(z_{i}-c_{i}\right)+\frac{a}{N}\left(\sum_{j} c_{j}\right)$. The marginal (selfish) incentive to contribute is $\frac{a}{p_{i} N}=M P C R$. The marginal (selfish) incentive not to contribute is $\frac{p_{i} N}{a}$. The group benefit if $p_{i}=p$ for all $i$ is $\sum u^{i}=p\left(\sum z_{i}-\sum c_{i}\right)+a\left(\sum_{j} c_{j}\right)$, so the marginal (altruistic) incentive to cooperate is $\frac{a}{p}$. If we keep $a$ and $p$ constant but increase group size, we increase the marginal selfish incentive not to contribute relative to the marginal altruistic incentive to contribute; causing contributions to decrease with N. If we keep $\frac{a}{N}$ and $p$ constant and increase $N$, we cause the marginal altruistic incentive to contribute to increase relative to the marginal selfish incentive not to contribute and cause contributions to increase. Does that happen? What do the data say?

While there are many experiments with different numbers, and different MPCRs, there are only a small number which systematically vary $N$ as one of the treatments. Of those, only Isaac and Walker's group recognized the intimate relationship between MPCR and $N$. Three studies by Marwell and Ames (1979), Chamberlin (1978), and Bagnoli and McKee (1991) involved provision points. Marwell and Ames (1979), see Section 2.3, found no effect from varying numbers. They did, however, adjust payoffs between large and small groups.

... keeping the situations of subjects in large and small groups otherwise comparable also required keeping mean interest $\left(\bar{V}_{i}\right)$ and resources constant over groups. This meant that for large groups the total resources and interest had to be 20 times as large as in small groups. For this reason cutting points

\footnotetext{
${ }^{81}$ Olson (1971) is usually cited as arguing for the decrease. Chamberlin (1974) provides conditions under which there might be an increase.
} 
for changes in payoffs were also kept proportionate, so that, for example, 20 times as many tokens had to be invested by the large group before the payoffs became larger than one cent per token. Thus, the mean contributions were required to be identical for identical effects. (Marwell and Ames (1979), p. 1346.)

I think this means that $\frac{a}{N}$ was held constant as $N$ increased but I cannot really tell from their description. Chamberlin (1978) found a negative effect on contributions as $N$ increased. Bagnoli and McKee (1991) also found a negative effect particularly in early periods. They conjecture "individuals in a larger group may find it more difficult to focus on a particular equilibrium vector of contributions. ${ }^{82}$

I find the Isaac-Walker experiments without thresholds most revealing because they attempt to control for the purely private incentives (measured by MPCR) in order to isolate the effect of numbers and they have tried large numbers without deception. Initially they used groups of 4 and 10 and MPCRs of .3 and .75. Those data were displayed in Section 2.4, Table 8. They found that MPCR mattered and $N$ did not. The only way $N$ mattered was if $a$ were held constant causing a crowding effect where $M P C R=\frac{a}{p N}$ declines as $N$ increases. Believing they had discovered a systemic relation between contribution and numbers, they then designed with Williams an experiment for $N=40$ and $N=100$. In doing so they had to overcome several methodological difficulties. To avoid the extremely high cost of such experiments, they developed a new method for rewarding their subjects. In their own words:

As explained in the class handout, subject $i$ 's experimental dollar earnings were converted into the following "performance index" prior to being converted into extra-credit points:

i's Actual Earnings - i's Minimum Possible Earnings

i's Maximum Possible Earnings - i's Minimum Possible Earnings

which can range from 0 to 1 for each individual. At the end of the final round, this fraction was computed for each individual (based on earnings in all rounds), multiplied by 3 , and added to the subject's final grade average. Thus, the range of possible extra-credit points was $[0,3]$. The performance index was used so that the maximum and minimum possible extra-credit earnings did not depend upon the design cell assignment. All classes from which subjects were drawn utilized a 100-point scale and, with minor modifications, used a standard mapping of point totals into letter grades $(A=90$ 's, $B=80$ 's, etc.).

\footnotetext{
${ }^{82}$ One other interesting set of experiments with Cournot oligopoly, reported in Morrison and Kamarei (1990), finds no effect from numbers. As with thresholds there is an interior equilibrium but unlike with thresholds it is unique.
} 
Furthermore, Indiana University allows + and - letter grades, so a unique letter grade typically comprised a 3 to 4 point interval.

We have spent a great deal of time considering questions of practicability and fairness in the use of extra-credit points as a motivator. On the issue of fairness, we can report that of the hundreds of subjects who participated in the VCM-MS-XC experiments, ${ }^{83}$ we do not know of a single grade appeal in which these extra credit points were an issue. (Isaac, Walker, and Williams (1990) pp.6-7. ${ }^{84}$ )

A second methodological innovation for $N=40$ and 100 involved a technique which allowed subjects to make decisions when not all 100 were in the same room at the same time. In particular, each decision-making round lasted several days, rather than a few minutes, so students could access the experiment on a network and make their decisions. This contrasts with the typical single session which usually lasts only an hour or two. As they note on p. 6:

The experimental procedures outlined above represent a logical link between standard single-session laboratory experiments and actual field experiments. Certainly some experimental control is lost relative to a strictly controlled laboratory setting, however, the gain in feasible group sizes, the real time between allocation decisions, and the more "natural" communication opportunities available in this environment add an element of parallelism with nonexperimental settings that could have important methodological and behavioral ramifications. (Isaac, Walker, and Williams (1990) p.6.)

Both innovations are clever and important advances in the methodology of experimental economics, and if their innovations are valid, Isaac, Walker, and Williams have found a very inexpensive way to do experimental economics. They did run control sessions in order to check validity. In a comparison to their earlier results with cash payments they claim "For a specific group size and MPCR, the aggregate pattern of token allocations ... are very similar." A significant difference (through a t-test) in the percentage of tokens contributed is found in only one round.

Contrary to most economists' expectations, not only were contributions higher with large $N$ but the effect of MPCR was significantly diluted. In particular they make three observations based on their data with large $N$. (Isaac et al. p.13.)

\footnotetext{
${ }^{83} \mathrm{My}$ footnote: VCM-MS-XC means "voluntary contribution mechanism-multiple session-extra credit."

${ }^{84}$ I would like to thank R.M. Isaac for permission to quote from this report.
} 
First, the impact from variations in the magnitude of the marginal percapita return from the public good (MPCR) appears to vanish over the range $[0.30,0.75]$. Second, with an MPCR of .30 , groups of size 40 and 100 provide the public good at higher levels of efficiency than groups of size 4 and 10. Third, with an MPCR of .75, there is no significant difference in efficiency due to group size. (Isaac, Walker, and Williams (1990) p.13.)

Finally, in an attempt to rescue the "MPCR effect" they ran three single session 40 person experiments with money (at a cost of about $\$ 900$ each) and an MPCR $=.3$. They found no deterioration in contributions but, in fact, a slight increase over the "no money" experiments. Continuing their rescue attempt they ran 4 experimental sessions with $N=40$ but MPCR=.03, three with credit points and multiple sessions and one with money and a single session. Here they finally found contribution rates that looked more like the $N=4, \mathrm{MPCR}=.3$ experiments. Instead of using large numbers to hide one's selfishness, subjects actually seem to become more cooperative in the larger groups. This would be consistent with the existence of the selfish vs. altruistic tradeoff described earlier where holding $\frac{a}{N p}$ constant and increasing $N$ increases contributions. But another possible implication of all this is that voluntary contributions experiments with public goods, as many do them, are yielding data which are not very sensitive to the incentives provided by the experimentalists.

What do we now know and what do we need to find out? Clearly, subjects appear to respond positively to increases in their MPCR although the effect is diluted in large groups. To really pin down the relationship between contributions, MPCR, and $N$ will cost a lot of money and effort since we need to fill in data between $N=10,40$, and 100 . We also need observations for more values of MPCR than just .03, .3, and .75. There are many other observations on various pairs of MPCR and N in the literature but they need to be extracted and tabulated. ${ }^{85}$ This would be, to me, a very interesting subject for a dissertation.

Also, can we now conclude altruism is at work? Rather than running a very large number of experiments, one could try to leap to an understanding by creating a new theory which explains or predicts a relationship $\left(\Sigma t_{i} / N\right)=f[M P C R, N, \alpha]$ where $\Sigma t_{i}$ are total contributions, $N=$ number of subjects, and $\alpha$ are, perhaps uncontrolled and unobserved, parameters. The development of such a theory would also point to new experiments which might require new theory, and so forth. Let us see how this might work.

Standard game theory predicts, for the Isaac-Walker environment that

$$
\left(\Sigma t_{i}\right) / N=0=f(M, N, \alpha)
$$

\footnotetext{
${ }^{85}$ One of the problems a theorist faces in trying to decide what we know is the fact that many experimentalists make very little effort to relate their results to others.
} 
for all $M<1$ where $M=M P C R=\frac{a}{p N}$. Try as they might, however, experimental economists have been unable to support that theory in the lab. Based on their own experiments, Isaac-Walker-Williams suggest ${ }^{86}$ a theory based on the concept of a successful group effort. The idea is that those who contribute are happy to do so if at least those who do are better off than at the initial endowment. This will be true if and only if $\left[\left(\Sigma t_{i}\right) / N\right] a>p$. This means there is a minimally sized successful group $S=\frac{1}{M P C R}$ so that if at least $S$ contribute then those who do are satisfied. This effectively creates a threshold payoff in utility as opposed to dollars. Keeping MPCR fixed as $N$ grows, $S$ becomes a smaller percentage and, presumably, more likely to occur so agents are more likely to risk contributing. One can formalize this and generate an equation for the expected \% contribution

$$
E\left[\left(\Sigma t_{i}\right) / N\right]=\Pi[p Z, M P C R, N]
$$

where the form of $\Pi$ depends on the, unknown and uncontrolled, distribution of the subjects' tastes for success. But $\Pi(\cdot)$ is estimable from enough data. It can be shown that $\partial \Pi / \partial M>0, \partial \Pi / \partial p<0$, and $\partial \Pi / \partial z<0$, independently of that distribution. One other implication is that if payoffs are increased, that is if $u=\lambda\left[p(z-t)+\frac{a}{N} \Sigma t\right]$ where $\lambda>1$, then (since this does not change the MPCR but does increase $p z$ ) we should see contributions decline. All implications are testable in the lab.

Another theory, based on the idea that subjects trade off selfish payments against altruism would suggest a personal utility payoff of $V^{i}\left[u^{i}, \Sigma u^{k}\right]$ where $u^{i}$ is paid to $i$ and $\Sigma u^{k}$ is the total paid to all subjects. Approximating $V^{i}$ linearly yields $u^{i}+\beta \Sigma_{k} u^{k}$. For the Isaac-Walker environment

$$
V^{i}=\left[p\left(z-t^{i}\right)+\frac{a}{N} \Sigma t^{k}\right]+\beta\left[p\left(N z-\Sigma t^{n}\right)+a \Sigma t^{k}\right] .
$$

Thus, $i$ will contribute if and only if $\beta \geq \frac{1-M}{N M-1}$. For this theory, the distribution of $\beta$ is uncontrolled and unobservable, but the predictions are that ${ }^{87}$

$$
E\left[\left(\Sigma t_{i}\right) / N\right]=\gamma\left[\frac{1-M}{N M-1}\right]
$$

where $\gamma \prime<0$. Thus $\partial \gamma / \partial N>0, \partial \gamma / \partial p z=0$, and $\partial \gamma / \partial M>0$. As opposed to the model based on minimally sized successful groups, this model predicts no change in $\%$ contribution if payoffs are. increased since.M. will not change.

\footnotetext{
${ }^{86}$ They have since provided some detail based on expectations about the effects of signaling. Their model predicts that contributions will decrease with $\left[\frac{1-M}{M} \cdot \frac{1}{N-1}\right]$ and will not change with a multiplicative increase in payoffs.

${ }^{87} \gamma$ is $1-F(\cdot)$ where $F$ is the population cumulative distribution function of $\beta$, a sample of which appears in the lab. Under the maintained hypothesis that the theory is correct, $\gamma$ can be estimated from the data.
} 
A third theory, based on the idea that subjects care about fairness or equality, would have $V^{i}=u^{i}+\delta \frac{1}{N}\left(\sum_{j}\left(u_{j}-\bar{u}\right)^{2}\right]$ where $\bar{u}=\frac{1}{N} \sum_{j} u^{j}$, and $\delta<0$. When $u^{i}=p\left(z-t^{i}\right)+$ $\frac{a}{N} \sum_{j} t_{j}$ then

$$
V^{i}=p\left(z-t^{i}\right)+a \bar{t}+\frac{\delta}{N} \sum_{j}\left[p^{2}\left(\bar{t}-t^{j}\right)^{2}\right]
$$

where $\bar{t}=\frac{1}{N} \sum_{j} t_{j}$. Differentiate $V^{i}$ with respect to $t_{i}$, set it equal to zero and get

$$
-p+\frac{a}{N}-2 \frac{\delta}{N} p^{2}\left(\bar{t}-t_{i}\right)=0
$$

or

$$
t_{i}=\bar{t}+\frac{N(1-M)}{2 \delta p} .
$$

The expected $\%$ contribution is therefore

$$
E[\% C]=E\left(\frac{\sum t_{i}}{N}\right)=\frac{\sum_{j} \bar{t}^{j}}{N}+\frac{N(M-1)}{2 p} E\left(\frac{-1}{\delta}\right)
$$

where $\bar{t}^{j}$ is j's belief about others expected contributions. ${ }^{88}$ Therefore

$$
E(\% C)=\sigma\left[E(\bar{t}), \frac{N(M-1)}{p} E\left(\frac{-1}{2 \delta}\right)\right]
$$

where $\partial \sigma / \partial p>0$ and $\partial \sigma / \partial N<0$ since $M<1$. If payoffs are increased then $E(\% C)$ decreases since $N, M$ stay constant but $p$ increases.

We now have three theories based on three different uncontrollable and unobservable parameters. Each is consistent with the finding that increases in $M$ increase contributions. Each yields different predictions for the comparative statics of $N, P$, and $z$ and they can, therefore in principle, be separated in the lab even if full control is not possible. At least two should be demonstrably incorrect based on data. Maybe the third is also. ${ }^{89}$ The next round belongs to the experimentalists.

${ }^{88}$ Since $M<1, t_{i}<\bar{t}^{i}$ so, strictly speaking, $t_{i}=0$ if $\bar{t}^{i}+\frac{N(M-1)}{2 \delta^{i} p} \leq 0$. Thus $E(\% C)$ is an overestimate of the correct number. This does not affect the comparative statics below. Also it does provide a somewhat ad hoc explanation for a decline in contributions with repetition since if subjects use last periods contributions to estimate this periods $\bar{t}^{i}$ then contributions will follow the time path given by

$$
\% C_{\tau}=\% C_{\tau-1}+k\left(\frac{N(M-1)}{p}\right)
$$

where $k$ is a subject pool specific constant.

${ }^{89}$ Since none predicts splitting of tokens, a well-known fact, all are technically deficient. See Chen (1993) for a theory which might explain splitting. 


\subsubsection{Communication}

In Section 2.2 we saw that Dawes, McTavish, and Shaklee (1977) were able to demonstrate that relevant communication increased contributions in $\mathrm{N}$-person dilemma experiments. This seems to be a consistent, replicable, and strong finding, especially for environments without thresholds. What does theory say? As it turns out, not much. Preplay communication, however structured, in the language of modern game theory is simply cheap talk. If there is a unique dominant strategy equilibrium, as is true of most experiments without thresholds, then talking should have no effect on rates of contribution: We should see none. If there are multiple Nash equilibria as is often the case with thresholds, cheap talk generally expands the number of equilibria but might lead to better coordination by subjects. This might raise the efficiency of the voluntary contributions mechanisms.

What do the data say? Let us look first at non-threshold environments. At least nine papers report an obvious and significant increase in group payoffs when communication is allowed prior to play. Dawes, McTavish, and Shaklee (1977) report an increase in payoffs from $31 \%$ to $72 \%$ when relevant communication occurs. (See Table 3 in Section 2.2.) Isaac, McCue, and Plott (1985) report ${ }^{90}$ that "communication increases the level of contribution (and efficiencies). The increase is small but it appears to be stable." (p. 67.) Isaac and Walker (1988a) report"91 "our results document the significant impact of group communication in the reduction of free riding behavior." Their four groups average greater than $80 \%$ contributions. In a follow-up study Isaac and Walker (1991) designed an experiment to make communication costly. In fact it was made a threshold public good. ${ }^{92}$ In spite of the cost of communication the groups still achieved an efficiency level higher than $91 \%$ in six of ten periods.

One interesting aspect of these results is that repetition seems to increase the rate of contribution with communication rather than inhibit it. The Dawes et al. results are for one-shot decisions and yield $70 \%$ levels while the Isaac-Walker results are for 10 or more periods and yield $90 \%$. There are of course other differences in their experiments so the comparison is somewhat tenuous. But Sell and Wilson (1990) have tested this comparison directly. Groups of 6 subjects with 40 tokens each contributed to an Isaac-Walker type public good with MPCR=.3 under a $2 \times 2$ treatment design. What was varied was (a) whether subjects were told what others did in past decisions or not and (b) whether subjects could announce whether they intended to contribute or not in the next decision. The idea is that no information-no announcement is like a one-shot experiment, information-no announcement is like the Isaac-Walker-Thomas experiments without communication and information-announcement is like Isaac-Walker with very limited communication. The results are given in Table 15. I am not sure what to make of this. Communication without verification (announcement only) seems

\footnotetext{
${ }^{90}$ See Section 2.4 for a description of their experimental design.

${ }^{91}$ Their environment is described in Section 2.4. Here they used an MPCR of .3.

${ }^{92}$ If at least 4 of 6 contributed $10 \phi$, all could talk. There were no rebates.
} 


\begin{tabular}{lcccc}
\multicolumn{4}{c}{ Table 15. Duncan's Multiple Range Test for Contributions } \\
Treatment & Mean & $\mathrm{N}$ & Duncan Grouping \\
No Information, No Announcement & 60.3 & 72 & $\mathrm{~A}$ \\
Information, Announcement & 59.3 & 72 & $\mathrm{~A}$ \\
Information Only & 46.0 & 72 & $\mathrm{~B}$ \\
Announcement Only & 34.0 & 72 & $\mathrm{C}$
\end{tabular}

Note: Means with the same letter are not significantly different at .05

Sell and Wilson (1990) p.23. (I would like to thank J. Sell for permission to quote from this report.)

to reduce contributions. With verification it helps $(59.3 \%$ vs. $46.0 \%)$. But no information or communication, the one-shot equivalent, yields the same rate of contribution as information and communication, the repetition and communication equivalent. Sell and Wilson state:

Our results are consistent with other reported results using a voluntary contribution mechanism. Everywhere we observe a consistent decay in provisioning that extends over the periods ... Where individuals are able to make announcements and check on one another's behavior, they are somewhat less likely to lie in their announcements (the Pearson's correlation coefficient between one's announcement and contribution is .34, compared with .10 under the Announcement Only condition).

But they also admit that they are "far from capturing the essence of communication."

Dawes and Orbell have been systematically studying communication in dilemmas, trying to identify that essence. Experiments without thresholds are reported in Dawes, van de Kragt, and Orbell (1987), Orbell, van de Kragt, and Dawes (1988), and Orbell, Dawes, and van de Kragt (1990). Their present position seems to be that communication "works either because it provides an occasion for (multilateral) promises or because it generates group identity - or, possibly some combination of those two hypotheses." (Orbell, Dawes, and van de Kragt (1990) p.619, footnote 7.) They also note that multilateral promising only goes so far. In their words

Perhaps the psychology of multilateral promising reduces to the psychology of a set of bilateral promises - perhaps, that is, people in our experiment felt they were making promises, as Hobbes put it, "every one apart, and Man by Man." But the straightforward interpretation of our data is that people do revert to what we have called multilateral promising and that, when they do, 
it can work. As this article has suggested, the interesting problem is that when people do revert to multilateral promising, there is no fully satisfactory rule for specifying when one's announced willingness to accept the proposed terms of multilateral exchange becomes an ethical obligation actually to do so. Our data are consistent with their adopting in practice a rule saying that promises are not ethically binding until everyone in the group has promised. This rule is as simple as the analogous rule that works nicely in the bilateral case and is attractive to that extent. But the conditions under which it can produce satisfactory multilateral exchanges are quite restrictive. It only requires a single individual to withhold a promise for whatever reason, and the effort at multilateral promising collapses. We note that, for many $N$-person prisoner's dilemma configurations, losses from such a failure could be quite substantial.

Short of further empirical investigation, we do not know whether the unanimity requirement is progressively relaxed as size increases so that some proportion or number less than everyone promising is sufficient to trigger ethical obligation. It is, nevertheless, instructive that, among our relatively small fourteen-person groups, only about half managed to meet the obligationinvoking unanimity criterion - and to capture the benefits that came with that. (Orbell, Dawes, and van de Kragt (1990) p.627. ${ }^{93}$ )

We see that communication increases contributions in no-threshold environments with small $(N<15)$ groups. We do not know why. We also do not know what would happen in large groups.

For completeness we should consider environments with thresholds. Here the evidence is mixed although the theory suggests there should be even more group gains from communication than in the dilemma environment. van de Kragt, Orbell, and Dawes (1983) report communication increases efficiency and contribution while Chamberlin (1978) and Palfrey and Rosenthal (1991b) report no discernible effect. This needs more study.

\subsection{Weak Effects}

In this section I will briefly identify and describe a variety of additional phenomena which experimentalists have pointed to as possible explanations for behavior observed in voluntary contributions games. I separate these into environmental, systemic, and institutional effects as was done in Table 10. Each effect has some evidence supporting its importance, but I have called these weak effects because there does not yet appear to me to be enough evidence for acceptance. In many cases there is apparently conflicting evidence. Future research will determine whether any one of these effects should be included among those in Section 3.3.

\footnotetext{
${ }^{93}$ I would like to thank the University of Chicago Press for permission to quote from this report.
} 


\subsubsection{Environment}

Homogeneity and Information In many of the early experiments with voluntary contributions, all subjects were given the same preferences and endowments. ${ }^{94}$ There is now reason to believe that such homogeneity in the environment has a positive effect on contributions. Isaac, McCue, and Plott (1985) conjectured this in their attempt to reduce contributions, and included asymmetries in payoffs. But they did not control for the effect by also studying their environment without asymmetries.

We have already seen that contribution rates are responsive to marginal payoffs. See Section 3.2. What is at issue here is whether there is an additional effect due to heterogeneity in payoffs or endowments. For example, suppose if everyone is the same, contributions are $60 \%$ with $\mathrm{MPCR}=.75$ and $30 \%$ with $\mathrm{MPCR}=.3$. Now suppose we have an environment with half MPCR's $=.75$ and half $=.3$. Is the aggregate contribution rate $45 \%$ ? Or are the contribution rates of the high MPCR types now less than $60 \%$ since they can safely mimic the behavior of the low MPCR types? Theory is no help since it predicts contributions of 0 no matter what. What do the data say?

In Table 16, I provide a summary of five papers which compare ceteris paribus contributions in homogeneous environments to contributions in heterogeneous environments. Looking only at the last column would lead one to conclude that heterogeneity lowers contributions. But the effect can clearly be dampened by a lack of information and/or a lack of repetition (or repetition without reports of previous outcomes). Can we separate these effects? Let us look at the role and impact of alternative information structures.

Table 16.

Threshold Repetition Complete $^{c}$ More Heterogeneity

Bagnoli and McKee (1991)

Brookshire et al. (1989a)

Fisher et al. (1988)

\begin{tabular}{|c|c|c|c|}
\hline & & Information & Implies \% Contribution \\
\hline $\mathrm{Y}$ & $\mathrm{Y}$ & $\mathrm{Y}$ & decrease \\
\hline $\mathrm{N}$ & $\mathrm{Y}$ & $\mathrm{Y}$ and $\mathrm{N}$ & decrease \\
\hline $\mathrm{N}$ & $\mathrm{Y}$ & $\mathrm{N}^{a}$ & $\begin{array}{l}\text { decrease in } \\
\text { first } 10 \text { periods }\end{array}$ \\
\hline $\mathrm{Y}$ & $\mathrm{N}$ & $\mathrm{N}$ & no effect \\
\hline Y & $\mathrm{Y}^{b}$ & $\mathrm{Y}$ & $\begin{array}{l}\text { decrease only } \\
\text { at high threshold }\end{array}$ \\
\hline
\end{tabular}

Marwell and Ames $(1979,1980)$

Rapoport and Suleiman (1993)

a Subjects were told values "might not be the same" and all values were changed at period 10.

$b$ Repetition occurred but no information about previous contributions of others was provided.

c Complete information means subjects know the ex ante distribution of possible types.

\footnotetext{
${ }^{94}$ This is true of Dawes, McTavish, and Shaklee (1977), Isaac, Walker, and Thomas (1984), and some of Marwell and Ames (1979).
} 
An important environmental treatment which can be controlled by the experimentalist is what subjects know about the environment and about the actions of others. As early as Fouraker and Siegel (1963) it was recognized by experimentalists that this information structure was important. Even the usually predictable behavior of subjects in Double Oral Auction Markets becomes more volatile and less responsive to the Law of Supply and Demand if subjects know each other's payoffs. See Smith and Williams (1990). Unfortunately, however, there have been only two studies of this easily controlled effect. Brookshire et al. (1989a) provide two information structures - one: (called incomplete) in which each subject knows only her own payoff and endowment and another (called complete ${ }^{95}$ ) in which each subject knows the list of others' payoffs and endowments but do not know who has which one. They check 5 different payoff structures and find that contributions tend to be less under complete information than under incomplete information in all environments except the one, in which all subjects were identical. In that homogeneous case information had no effect. Isaac and Walker (1989) studied only the homogeneous case and found no effect on contributions from changing the information conditions. So the studies are consistent but hardly conclusive and it is not easy to find other experimental evidence to provide support. For example, although the evidence from experiments with asymmetric payoffs and common knowledge of the possible types that Palfrey and Rosenthal (1991b) and Palfrey and Prisbrey (1993) conducted suggest lower contributions than those of Dawes, McTavish, and Shaklee (1977) and Isaac, Walker, and Thomas (1984), it is only a suggestion and not a controlled experiment. We can make several tentative conjectures but nonetheless they need considerably more testing before they become "stylized facts". 96 First, heterogeneity lowers the rate of contribution unless there is incomplete information and no repetition. Second, complete information leads to less contribution than with incomplete information - unless there is homogeneity. The existence of a threshold does not seem to play an interactive role with heterogeneity. See Chan et al. (1993) for additional work with heterogeneous endowments.

Gender One of the most obvious but easiest to control ${ }^{97}$ aspects of the environment is gender. The question is simple: does gender affect the rate of contribution and how? There are 5 relevant studies but the evidence is nevertheless still inconclusive. On the one side, there are two studies which purport to find that females tend to contribute more than males. Dawes, McTavish, and Shaklee (1977) find this in one experiment but are quick to point out that it occurred only in the relevant communication condition and that (see their footnote 5 p. 10) "we have never "been able to replicate the sex effect." Mason, Phillips, and Redington (1991) find, for two person games, that "at the beginning

\footnotetext{
${ }^{95}$ In the language of modern game theory, the distribution of types is common knowledge. Information is complete but imperfect.

${ }^{96}$ For example Brookshire et al. (1989a) suggest that the effect of heterogeneity depends on the range of alternative types - how many and how different. This needs more exploration.

${ }^{97}$ This is still not perfectly controlled always. See, for example, footnote 42 in Section 2.3 for a problem encountered by Marwell and Ames.
} 
of experiments women tend to be more cooperative than men and have a higher variance of choices." But they also note that "after 25 periods these differences vanish." In the middle, finding no effect, are Isaac, McCue, and Plott (1985), Poppe and Utens (1986), and Orbell, Schwartz-Shea, Dawes, and Elvin (1992). On the other side, there is the only experiment designed specifically to isolate and identify a gender effect in a public goods experiment with more than two players. Brown-Kruse and Hummels (1992) used an Isaac-Walker design with $N=4$ and MPCR's of .3 and .5. They also varied a condition they called "community", a group identity phenomena discussed further in Section 3.4.2. They found first that there were no significant differences in the way that men and women responded to the community or multiplier (MPCR) treatments, nor in the way they contributed by period. But they also found significant gender differences in contribution rates. "... males contributed at higher rates than did women" (p.12). Men's initial contributions rates are higher but their comparative statics are the same. So are there gender differences? I think the question remains open. ${ }^{98}$

\subsubsection{Systemic}

In this section we consider three explanatory variables that may be important determinants of cooperative behavior but which are difficult to measure and control.

Economics Training In Marwell and Ames (1981) a tongue-in-cheek, but still provocative, question was raised: are economists the only free riders? They reported finding that contributions were significantly lower if and only if the subjects were graduate students in economics at Wisconsin. Isaac, McCue, and Plott (1985) took exception to this and used students in an undergraduate sociology course at Pasadena City College and students from undergraduate economics courses at Caltech. They found, under repetition, that "the tendency for erosion of contributions is not unique to societies populated by economists ... Our single experiment with sociology subjects yielded substantially the same results as other subject pools, including economists." I find neither set of data particularly convincing. It is not obvious what is being measured by participation in a class: Experience, training, self-selection, or propensity to contribute? Are high school, 2-year college, 4-year college, and graduate classes different? Is the effect large enough (if it exists at all) to be found across a large number of very sensitive environments? The effect of training and/or self-selection on cooperation remains a wide-open problem. ${ }^{99}$

\footnotetext{
${ }^{98}$ Robyn Dawes has suggested to me that a "wild speculation would be that men cooperate more when the experimenter is female" and vice versa. This can be tested.

${ }^{99}$ In research on ultimatum games, a 2-person situation, Carter and Irons (1991) find that economists are more selfish. Frank, Gilovich, and Regan (1993) have a similar finding for 2-person prisoner dilemmas. Kagel, Kim, and Moser (1992) do not support the Carter and Irons result. I know of no other work specifically designed to isolate an "economist" effect than these three, but see Schram and Sonnemans (1992) for additional work in this area.
} 
Beliefs It is not surprising that some researchers have tried to explain contributions, when not contributing is a dominant strategy, as mistakes. One systematic way to do this is by assuming subjects arrive in the lab with beliefs about the world, that these beliefs affect their behavior, and that these are not controlled in the experiments. Indeed not only are they not controlled they may be only indirectly measurable. Three approaches have been taken: two with thresholds, one without. Let us look at the threshold environments first. Rapoport (1985) introduced the notion of strategic uncertainty or a subject's probability belief that the sum of contributions of other players is less than or equal to $X$, call it $F_{j}(X)$. So when $j$ 's payoff is

$$
\left\{\begin{array}{rll}
r+z_{j}-t_{j} & \text { if } \quad \sum t_{i} \geq T \\
z_{j}-t_{j} & \text { if } \quad \sum t_{i}<T
\end{array}\right.
$$

and $j$ maximizes expected payoff, $j$ will choose $t_{j}$ to

$$
\max \left(r+z_{j}-t_{j}\right)\left(1-F_{j}\left(T-t_{j}\right)\right)+\left(z_{j}-t_{j}\right) F_{j}\left(T-t_{j}\right)
$$

or

$$
\max r\left[1-F_{j}\left(T-t_{j}\right)\right]+z_{j}-t_{j}
$$

From a theorist's point of view this is very straightforward. From an experimentalist's point of view the problem is that the subject brings the function $F_{j}(\cdot)$ to the lab. Suleiman and Rapoport try to discover what $F_{j}$ is by asking questions of the subjects. No payments were made contingent on their answers. ${ }^{100}$ Using the estimated $F_{j}$ Suleiman and Rapoport can predict $t_{j}$ from the maximization problem and then compare it to the actual contributions. Although this approach seems to have some explanatory power, ${ }^{101}$ in their most recent paper Rapoport and Suleiman, (1993), conclude "although we have achieved limited success in accounting for the contribution decisions of some of the subjects, our results show that neither the cooperative nor the expected utility model account for the behavior of the majority of the subjects." (p.30). I would suggest that perhaps the (survey) data on beliefs and risk attitudes are unreliable and that before one rejects those models one should try to find better ways to measure what is needed. Perhaps some of the techniques discussed in chapter Camerer (1994) would be of help.

An alternative approach is devised by Palfrey and Rosenthal (1991a) who consider misspecified priors and in a more complete game-theoretic framework. This allows a much clearer test of the expected utility approach using only the actual decisions of the

\footnotetext{
${ }^{100}$ This yields a rather peculiar juxtaposition of strong control of payoffs and absolutely no control over the data on beliefs.

${ }^{101}$ The interested reader can check the data analysis in Suleiman and Rapoport (1992) and Rapoport and Suleiman (1993). They also generalize the model above by assuming subjects have expected utility functions of the form $u(x)=k x^{c}$. They estimate $c$ by fitting $k x^{c}$ to nine responses of each subject about two alternative gambles and their certainty equivalents. No payments were contingent on the responses so one must be careful about the quality of these data.
} 
subjects (for which they were paid). By changing the experiment so that (1) contributions are all or none and (2) the public good is provided if at least $K$ of $N$ contribute, it is easy to show that a subject contributes if and only if $r P_{j}^{K-1} \geq z^{j}$ where $P_{j}^{K-1}$ is $j$ 's belief (probability) that exactly $K-1$ others will contribute. If $z^{j}$ is randomly chosen from a $c d f G(\cdot)$ then at a Bayes Equilibrium ${ }^{102}$ each expected payoff maximizing subject contributes if and only if $z_{i} \leq z^{*}$, the probability any one subject contributes is $G\left(z^{*}\right)$, and $z^{*}$ satisfies

$$
\frac{1}{r} z^{*}=\left(\begin{array}{c}
N-1 \\
k-1
\end{array}\right) G\left(z^{*}\right)^{K-1}\left(1-G\left(z^{*}\right)\right)^{N-K} .
$$

Palfrey and Rosenthal carefully induce the payoffs and $G$. In their words:

At the beginning of each experiment, subjects were told $K, N, r$ in "francs," ... and all other relevant information about the experimental procedures. They were also told how many cents per franc they would receive at the conclusion of the session. These values were held constant throughout an experiment. Subjects earned between $\$ 10$ and $\$ 20$ during each session. Sessions lasted between forty-five minutes and an hour and a half.

In each round, subjects were each given a single indivisible "token" (endowment). Token values in franc increments between 1 and either 90 or 204 were independently drawn with replacement from identical uniform distributions and randomly assigned to subjects, and this was carefully explained to the subjects in the instructions. ... Then each subject was told the value of his or her token, but not told the values of the tokens of other subjects. Subjects were then asked to enter their decisions (spend or not spend the token).

The results were very striking. First using the predicted $z^{*}(K, N)$ and varying $K$ and $N,(N=3$ and $4, K=1,2$, and 3$)$, one can get a prediction of subjects earnings in the Bayes equilibrium. The regression of predicted on actual yields

actual earnings $=-.054+1.045 z^{*}$ predicted with $n=33$ and $R^{2}=.95$.

The intercept is not statistically different from 0 and the slope is not different from 1 . But individual behavior "differs substantially from that predicted by the model: contribute when $z^{i} \leq z^{*}(K, N)$. Palfrey and Rosenthal consider four alternative models: biased probabilities, risk aversion, other non-linear utility forms including altruism and the Rapoport model, and cooperation. They show that these yield different predictions about how contributions change with $K$ and $N$. They then proceed to show that the data support only the hypothesis that subjects' priors about $G\left(z^{*}(K, N)\right)$ are biased

\footnotetext{
${ }^{102}$ See Palfrey and Rosenthal (1991a) for the details.
} 
upward - that is subjects expect a slightly higher rate of contribution than is consistent with an unbiased Bayes-Nash equilibrium. Whether this methodological approach would yield similar results for the complete information world of Dawes, Orbell, Simmons, and van de Kragt (1986) remains an open question.

It is important to recognize the methodological differences between Rapoport and Palfrey and Rosenthal. The latter use a standard economic approach to data analysis computing comparative statics predictions from theory and then comparing those predictions to the data using standard hypothesis tests. In many cases this circumvents the need to measure utility functions and/or priors directly because the indirect predictions are independent of the precise details of those functions. Survey data ${ }^{103}$ in an experimental context are unreliable so it is important to find ways to avoid their use. Indeed, that is the purpose of the lab. Theory, comparative statics, and statistical procedures can allow us to test and identify, using indirect evidence, the existence of effects which are otherwise unmeasurable and, perhaps, uncontrollable.

Beliefs have also been used as an explanation for contributions in experiments without thresholds. The data can be found as early as Dawes, McTavish, and Shaklee (1977); a theory for two-person dilemmas can be found in Orbell and Dawes ${ }^{104}$ (1991). In their $N$ person dilemma experiments, described earlier in Section 2.2, they also asked subjects about their expectations of others' behavior. They report that

One of our most consistent findings throughout these studies - a finding replicated by others' work - is that cooperators expect significantly more cooperation than do defectors. This result has been found both when payoffs are "step-level" (when contributions from a subset of $k$ subjects ensure provision of a benefit to all) and when they are "symmetric" (when all contributions ensure a constant benefit to all). (Orbell and Dawes (1991) p.518. ${ }^{105}$ )

The data on beliefs are the results of surveys but there does seem to be something systematic; subjects with a propensity to cooperate (for whatever reason) also tend to believe others are more likely to cooperate. Dawes, McTavish and Shaklee (1977) go farther and claim that it is choice causing beliefs and not vice versa. ${ }^{106}$ In Orbell and

\footnotetext{
${ }^{103}$ I use this term to identify data collected by asking subjects questions for which there is nothing at stake. This includes standard debriefing such as "What were you doing?" 'As a classroom exercise, I have often asked students to describe their strategy after an experiment. In the overwhelming majority of cases the data generated in that experiment reject the subjects' own hypotheses about their own behavior. I now tend to ignore any ex post anecdotal evidence from surveys.

${ }^{104} \mathrm{~A}$ critique and response can be found in McLean, Orbell, and Dawes (1991).

${ }^{105}$ I would like to thank the American Political Science Association for permission to quote from this report.

${ }^{106}$ They survey both subjects who were decision makers and subjects who were (unseen) observers. The variance of responses of the former was larger suggesting that choice affected beliefs.
} 
Dawes (1991) they use this as one assumption in a model which purports to explain the evolution of cooperation and, presumably therefore, the tendency to cooperate in the one-shot experiments. I think these ideas deserve to be explored further especially in a way that provides more reliability in the responses to questions about beliefs. Scoring rules or payments to the subject whose predicted percentage cooperation is closest to the actual percentage might tighten up the data. It would also be interesting to see how repetition affects predictions and how prediction affects behavior. ${ }^{107}$

Friends, Group Solidarity Two experimentalists have tried to discover whether some form of group identity might cause contributions to increase. Both have indicated the answer is yes. Orbell, van de Kragt, and Dawes (1988) report the results of an experiment similar to the Dawes, McTavish, and Shaklee (1977) experiments described in Section 2.2. One difference was that some groups were told their contributions would provide a public good, not for those in their own room, but for a similar group in another room. Although the payoff structure is identical in both treatments, cooperation is significantly higher (almost twice as high) when the public good accrues to subjects in one's own room. The data are in Table 17. The effect is magnified by discussion although, somewhat surprisingly to me, discussion increases contributions even when the benefits go to others. ${ }^{108}$

Table 17. \% Contributions

\begin{tabular}{|l|c|c|}
\hline & \multicolumn{2}{|c|}{ Give to } \\
& Own Group & Other Group \\
\hline No Discussion & 37.5 & 19.6 \\
\hline Discussion & 78.6 & 30.4 \\
\hline
\end{tabular}

Brown-Kruse and Hummels (1992) also try to control for group identity by using a community versus non-community treatment. In their words:

In the community v. noncommunity treatment, we controlled the nature of pre-experiment communication. By filling out a required questionnaire, subjects in the community setting were encouraged to meet, talk, and learn something about each other. Our goal was to arouse a sense of membership in a group. (Brown-Kruse and Hummels (1992) p.6. ${ }^{109}$ )

\footnotetext{
${ }^{107}$ That is, does the mere act of asking for predictions affect the rate of contribution?

${ }^{108}$ They provide a second set of data, which shows that the opportunity of promising may be an important part in explaining the effect of discussion. This is further discussed in Orbell, Dawes, and van de Kragt (1990).

${ }^{109}$ I would like to thank J. Brown-Kruse for permission to quote from this report.
} 
This is very similar to the irrelevant communications treatment of Dawes, McTavish and Shaklee (1977). Although only a small direct effect was found for community, the hypothesis of no effect can be rejected with only about $80 \%$ probability. A significant interaction was found with marginal payoffs. When the MPCR was high contribution rates did not depend at all on the community treatment: When the MPCR was low, contribution rates depended strongly on the presence of the community treatment. Brown-Kruse and Hummels explain this using the concepts of trust and risk. Higher MPCRs mean lower risk, more community means more trust, and low risk means trust is unimportant while high risk means trust is important.

We are left with the undefined and unmeasured concepts of discussion induced group solidarity (Orbell, van de Kragt and Dawes (1988)) and trust (Brown-Kruse and Hummels (1992)) to explain part of the rate of contribution. There may be something here but it has not yet been isolated, measured and controlled.

\subsubsection{Institutional}

Unanimity Building on an idea from Wicksell (1958), Smith (1977, 1979a) identifies unanimity as a potentially important driving principle in generating contributions towards public goods. ${ }^{110}$ The idea is that after contributions are proposed a vote is taken. A single no vote means contributions are returned and no public good is provided. These votes are more than just talk since they change the Nash equilibrium of the game. The hope is that this raises contributions since one can potentially contribute a lot but then veto if others do not contribute enough and so get one's money back. Banks, Plott, and Porter (1988) subjected these ideas to a very rigorous test in response to a proposal to use a mechanism like Smith's public good auction to allocate resources on Space Station Freedom. This research is a nice example of the use of experiments to test the limits of a potentially useful idea for a new institution in a way that would be difficult if one were only able to use field data. Using the Isaac, McCue, and Plott environment, described earlier in Section 2.4, Banks, Plott, and Porter generated the data in Table 18.

Table 18. Average Efficiencies

\begin{tabular}{l|c|c|c} 
& For All Periods & $\begin{array}{c}\text { For Early Periods } \\
1 \text { and } 2\end{array}$ & $\begin{array}{c}\text { For Later Periods } \\
\geq 3 .\end{array}$ \\
\hline with unanimity & $8 \%$ & $7 \%$ & $8 \%$ \\
without $^{a}$ unanimity & $32 \%$ & $53 \%$ & $21 \%$
\end{tabular}

${ }^{a}$ These data are from Isaac, McCue, and Plott (1985)

The effect of unanimity is large and apparently obvious; efficiencies are way down and the effect of repetition disappears. A closer examination of the data reveal some clues. From

\footnotetext{
${ }^{110} \mathrm{~A}$ recent theoretical analysis is Bigman (1992).
} 
the data in Table 19 we see that unanimity does increase contributions if there are no vetos but there are so few success periods $(13 \%)$ that the gain in potential contributions is outweighed by the failures. This effect is very similar to the effect of increases in thresholds observed in Section 3.1. Since there is only this one study ${ }^{111}$, one must be careful about leaping to conclusions but it seems likely that unanimity is not desirable as an institutional device to increase contributions, a fact that would have been impossible to discover with theory or field data.

Table 19.

\begin{tabular}{l|c|c} 
& $\begin{array}{c}\text { Table 19. } \\
\text { Efficiencies in } \\
\text { Success Periods }^{a}\end{array}$ & \% Success Periods \\
\hline with unanimity & 57.5 & 13 \\
without unanimity & 32 & 100
\end{tabular}

${ }^{a}$ A success period is one in which no veto occurs.

Revision and Sequence Two other institutional variations may have a more positive effect on cooperation than unanimity. One, sequencing, ${ }^{112}$ has been tested in a threshold environment and one, revision, has been tested across different environments including an Isaac-Walker environment and a threshold environment. They each deserve further exploration.

The idea of sequencing is not new ${ }^{113}$ but one of the first studies of its properties in public goods environments seems to be in Erev and Rapoport (1990). Sequencing allows or requires participants to make their decisions sequentially with complete information about previous decisions in the sequence. When there is a threshold this significantly changes the theoretical properties of the game. If one applies the modern notions of subgame perfection to a game in which the monetary public good is provided if and only if $K$ of $N$ contribute then the theory predicts the last $K$ in the sequence will contribute and the good will always be provided efficiently. The data lend limited support to this conclusion. Using an environment similar to van de Kragt, Orbell, and Dawes (1983) requiring 3 of 5 contributors, Erev and Rapoport found that the percentage of cooperation was essentially the same whether decisions were sequential $(45.3 \%)$ or simultaneous $(42.9 \%)$. However, under the sequential protocol the public good was provided $66.7 \%$ of the time

\footnotetext{
${ }^{111}$ There have been other -mechanisms tested -with unanimity. Banks et al. (1988) also test Smith's auction process and obtain data similar to that in Tables 18 and 19. Smith et al. (1982) tested Oral Double Auctions with unanimity and found that the extramarginal units which were rationed out by the price system - as they should be - tended to veto the allocations and significantly reduce efficiencies.

${ }^{112}$ This variation is clearly related to sequential protocols in bargaining such as ultimatum games. See chapter Roth (1994).

${ }^{113}$ See, for example, the work of Harstad and Marrese $(1978,1981,1982)$, or Cremer and Riordan (1982).
} 
whereas it was provided only $14 \%$ under the simultaneous protocol. ${ }^{114}$ A sequential choice mechanism does not increase cooperation in this threshold environment but it does solve some of the coordination problem. Of 75 subject choices in the sequential mechanism, 20 or $27 \%$ violated the predictions of game theory. ${ }^{115}$ No one knows why although the fact that most errors occurred in the early decisions $(75 \%$ of the decisions which violate the theory were made by the first 3 movers) suggests that backward induction may be difficult for the subjects. ${ }^{116}$ Other possibilities are that early movers may anticipate mistakes by later movers or late movers may be spiteful. The explanation-here must be somehow related to that of behavior in centipede games. (See McKelvey and Palfrey (1992).) Sequential protocols are a possible solution to coordination problems with small numbers. They should be studied more.

The idea of revision is also not new since it can be found in one of the oldest market institutions, the English Auction. Dorsey (1992), using the Isaac, Walker, and Thomas (1984) design, with $\mathrm{MPCR}=.3$ and $\mathrm{N}=4$, made one change and allowed subjects to adjust their planned contributions in real time. Only the final contribution levels were binding. He found $11.5 \%$ contribution rates when allowing both increases and decreases (compared to Isaac, Walker, and Thomas who found 26\%). Allowing increases only - a form of partial commitment - Dorsey found contribution rates of $23 \%$. It is not obvious that revisions are helping in this public goods environment. ${ }^{117}$ In fact, they seem to give subjects an opportunity to discover others' less than fully cooperative behavior and to lower contributions upon that discovery. But more needs to be done before definite conclusions are possible.

\subsection{Unknown Effects}

There are a number of other possible treatments or phenomena which might affect contributions or cooperation and which, as far as I know, have not been fully tested. Three of these are decision costs, attitudes of fairness, and moral suasion. Each is usually presented as a motivation beyond monetary gain which might cause the decisions of subjects to be different from those predicted by reward maximizing models.

\footnotetext{
${ }^{114}$ Notice that the average (or \% of) cooperation will not be the same as the $\%$ of time the good is provided. If cooperation is efficient and exactly 3 of 5 contribute each time then (3/2)(\% cooperation) $=\%$ provision.

${ }^{115} \mathrm{E}$.g. if exactly 2 of 5 have cooperated and you are the 5 th to move; you should cooperate.

${ }^{116} \mathrm{John}$ Kagel points out that "these results contrast to sequential games requiring 1 out of 2 to contribute to the public good - where, with experience, subgame perfection works almost perfectly (Harrison and Hirschleifer (1989). This supports the notion of the failure of backward induction argument, as these games involve only two moves compared to 5."

${ }^{117}$ Banks, Ledyard, and Porter (1989) found revisions very helpful in a private good, coordination problem.
} 
Decision Costs Decision costs are related to bounded rationality and computational and informational complexity. Generally the idea is that precise optimization carries cognitive processing costs which are traded off by subjects against rewards: The lower the rewards the more errors in computation. While Smith and Walker (1992) address some of the issues in the context of private goods, it is difficult to identify any systematic study in the context of public goods. Two papers are vaguely related. Dawes and Orbell (1982) report the results of an experiment using one of their standard dilemma designs with no threshold, with no communication and with losses truncated at zero in which they tried to check whether communication causes increases in contributions because it facilitates thinking. They allowed some subjects only 5 minutes to think about their choice and allowed others 24 hours. The results were clear and unequivocal: cooperation rates were $35.6 \%$ for 5 minutes and $35.9 \%$ for 24 hours. "Thinking time per se does not help." (p.172.) In a second study related to decision costs, Saijo and Yamaguchi (1992) compare rates of contribution in an Isaac and Walker type design with MPCR $=.7$ and $1 / .7$ and with $N=7$. They provide two different payoff tables to different subjects. One they call rough, similar to that provided by Isaac and Walker, provides two columns of data: "Total contributions" in increments of 10 and "Your (public good) Payoff." In the format they call detailed they provide a $61 \times 11$ matrix whose rows are "sum of others contributions" including all integers ranging from 0 to 60 and "your contribution" ranging from 0 to 10. The entries are "your (total) payoff." They obtain considerably different results with the detailed table than with the rough. Using the rough table and MPCR $=.7$, the rates of contribution and the decline with repetition mimic those in Isaac, Walker, and Thomas (1984) (see Section 2.5): more than 30\% contribution early with decay towards $10 \%$. With the detailed table "the mean investment for all ten periods is significantly less $(19.6 \%$ vs. $34.1 \%)$ than the previous experiments and no specific decay toward period 10 is observed." (p.10.) It seems from Saijo and Yamaguchi (1992) that reducing cognitive processing costs by providing the detailed table ${ }^{118}$ reduces contributions and eliminates the decline with repetition. This is consistent with a hypothesis that some subjects make errors (which are one-sided at 0 ) that they correct with repetition or with detail. This is a wide open area of research at the edge between psychology and economics. It is related to the issue of presentation raised in footnote 16. It certainly seems to me to be worth a lot more careful research.

Fairness It is often claimed that non-reward maximizing behavior arises because of subjects' concerns for fairness. There has been a lot of 'study or at least claims of this in bargaining experiments (see chapter Roth (1994)) but very little has been done in the context of public goods. Marwell and Ames (1979) administered a survey as part of their experiment (see Section 2.3) and they suggest that the answers to that "suggests one major theme - the consideration of 'fairness' as a mediating factor in investment

${ }^{118}$ The detail table eliminates computation and interpolation but increases informational size from $2 \times 11$ entries to $61 \times 11$ entries. Does this increase or decrease decision costs? 
decisions." (p.1357.) However, they also recognize that "... investment in the public good did not vary with definitions of fairness" (p. 1357) where definition means what is a fair \% of contribution. However, contributions did vary with a "concern for fairness."

Those who were not so concerned were markedly concentrated in the lowest levels of investment. For these people, at least, "being fair" may be driven out by greed. If the stakes are high enough, almost everyone may opt for profit over fairness. But this would still deny the strong free-rider hypothesis for a large range of meaningful economic conditions.

So here again is a possible explanation for contributions above those maximizing personal payoff. I am uncomfortable with the use of survey data and the fact that "concern for fairness" is not measurable, but nevertheless I think there is something which deserves to be followed up. One way would follow up on the theory presented in Section 3.3.2.

Moral Suasion I include a final class of phenomena which are possible explanations for non-maximizing behavior under a general heading of moral suasion. We have already seen, in Section 2.1, how instructions in Bohm's experiments included what he called "counter-strategic arguments." These are simply an extreme form of an effect which may lead subjects to make decisions as they think the experimenter wants them to. The existence of such an effect has seemingly been demonstrated weakly by Hoffman and Spitzer (1985) and by Hoffman, McCabe, Shachat, and Smith (1992) in the context of 2 person bargaining experiments. ${ }^{119}$ The latter state in their abstract: "we conducted dictator experiments ${ }^{120}$ in which individual subject decisions could not be known either by the experimenter or by anyone else except the decision maker. The results yielded by far our largest observed proportion of self-regarding offers." The conjecture is that even if the experimenter can prevent subjects from knowing what each other do, the fact that the experimenter knows can still lead subjects to entertain other-regarding behavior. It would be interesting to know whether such protection from the experimenter (and not just from each other) is really important and whether it would significantly reduce contributions in any of the public goods situations we have described in this paper.

Finally, one should notice that each of the three phenomena mentioned (decision costs, fairness, moral suasion) trades off against the private stakes. All experimenters including psychologists like Dawes and sociologists like Marwell recognize that "if the stakes are high enough almost everyone may opt for profit." It is indeed a systematic if not often replicated fact in experimental data that increasing the stakes (that is, for

\footnotetext{
${ }^{119}$ These are discussed in chapter Roth (1994).

${ }^{120}$ Dictator experiments allow a subject to divide $\$ 10$ between themselves and another. The other must accept the division.
} 
example, doubling the value of each unit of endowment and doubling the value of each unit of the public good) reduces the contribution rate in dilemmas. ${ }^{121}$ This is a matter of control.

It is obvious that subjects bring motivations beliefs and capabilities to the lab that may be vastly different from those assumed in standard game-theoretic models. Some experimental situations such as Double Oral Auctions appear to be very robust against such variations. No control is needed. Some experimental situations such as voluntary contributions mechanisms with public goods are very sensitive to such variations. That sensitivity can be controlled with high payoffs but little is learned. The hard problem is to isolate and measure the effects of the variations. This will keep experimentalists busy for a long time.

\section{$4 \quad$ Final Thoughts}

What do we know about behavior in public goods environments? In particular, are subjects naturally cooperative, contributors, and altruistic? Conventional wisdom is based on the data generated by Marwell and Ames, Dawes and Orbell, Isaac and Walker, and others in environments without thresholds. These suggest that in public goods experiments where the dominant payoff maximizing strategy is to give nothing and where the group optimum is to give everything, in one-shot decisions or in the early rounds of repetitive decisions contributions from $30 \%$ to $70 \%$ occur. ${ }^{122}$ There are at least two explanations for the data: (a) subjects trade off altruistic and cooperative responses against personal payoffs or (b) subjects make mistakes, do not care, are bored, and choose their allocations randomly. How can we tell the difference? Let us look at four recent papers which, I think, provide a clue. Two use environments which retain a dominant strategy feature but test the hypothesis of natural cooperation by eliminating the conflict between group and self-interest. ${ }^{123}$ Two others study an environment with an interior Nash and interior social optimum so mistakes can be made by both contributing too much and contributing too little. ${ }^{124}$

In Palfrey and Prisbrey (1993) and Saijo and Yamaguchi (1992) each subject faces an Isaac-Walker type payoff of $u^{i}=p^{i}\left(z-t_{i}\right)+b^{i}\left(\sum_{j} t_{j}\right)$. Sometimes $b^{i}<p^{i}<N b^{i}$, so self-interest suggests $t_{i}=0$ and group interest suggests $t_{i}=z$. But sometimes $p^{i}<b^{i}$ so both group and self regarding behavior would suggest $t_{i}=z$ : Palfrey and Prisbrey use an asymmetric information environment in which each subject has a different value

\footnotetext{
${ }^{121}$ See, for example, Marwell and Ames (1980), Palfrey and Prisbrey (1993), and McKelvey and Palfrey (1992), who test this hypothesis directly.

${ }^{122} \mathrm{See}$, for example, Table 9.

${ }^{123}$ See Andreoni (1993a) and (1993b) for additional work like this.

${ }^{124}$ In Dawes et al., Marwell et al., and Isaac et al., etc. the dominant strategy was $t=0$. Only mistakes such that $t>0$ are possible.
} 
of $b / p$ but each knows the common distribution that generates these values. Saijo and Yamaguchi use a complete information homogeneous environment where all subjects have the same $b / p$, all know it, and all are provided very detailed information on payoffs. The results, nevertheless, are remarkably similar. If we classify subjects as Nash players (a Palfrey and Prisbrey approach) if they contribute when $b^{i}>p^{i}$ and do not contribute when $p^{i}>b^{i}$ and if we allow some error, ${ }^{125}$ then Palfrey and Prisbrey find $49 \%$ Nash players. In Saijo and Yamaguchi in the first period of play $50 \%$ of the decisions (in the detailed treatment) are Nash. This increases to $62 \%$ by the last period. ${ }^{126}$. At least half the subjects are very close to behaving as self-payoff maximizing game theory would predict.

What about the others? Are they cooperative? Again Saijo and Yamaguchi (1992) provides some clues. They used homogeneous groups of 7 with MPCR of .7 sometimes and 1.4 other times. They also used a rough payoff table (similar to Isaac and Walker) and a very detailed table. The rates of contribution are listed in Table 20.

\begin{tabular}{l|c|c}
\multicolumn{3}{c}{ Table 20. Approx. \% Contributions (1st period, 10th period, Average) } \\
\hline \multirow{3}{*}{ MPCR $=1.4$} & Rough Payoff Table & Detailed Payoff Table \\
\cline { 2 - 3 } MPCR $=.7$ & $50,45,50$ & $75,70,72$ \\
\hline
\end{tabular}

The rough payoff data with $\mathrm{MPCR}=.7$ are similar to previous data of Isaac and Walker and others. What is surprising is the rough payoff data for MPCR=1.4. If one wants to interpret the $40 \%$ contribution with $\mathrm{MPCR}=.7$ as contributory and the result of natural altruism or some other group regarding behavior, then one must also interpret the $50 \%$ lack of contribution with MPCR $=1.4$ as non-contributory and the result of natural spitefulness. The alternative, that there are a lot of mistakes and inattention to payoff detail, seems more plausible to me. The $20 \%$ and $75 \%$ early rates of contribution, when payoffs are better explained to the subjects, supports that view but still leaves about $20 \%-25 \%$ of the aggregate contributions unexplained. ${ }^{127}$ What has not been controlled?

\footnotetext{
${ }^{125}$ Palfrey and Prisbrey use a score maximizing procedure to do this. In Saijo and Yamaguchi, $z=10$ and I have arbitrarily allowed errors of 1 ; that is, $t_{i}=0$ or 1 is not giving and $t_{i}=9$ or 10 is giving.

${ }^{126}$ Two other interesting observations can also be made. First, initially there are $33 \%$ more Nash responses when MPCR $=.7$ and Nash is anti-group behavior than when MPCR $=1 / .7$ and Nash is exactly progroup behavior. This suggests to me that the explanation for contributions in one shot experiments with $M P C R<1$ is not altruism. Second, classifying 10 and 9 when MPCR=.7 and 0 and 1 when MPCR $=1 / 0.7$ as absolutely not $\mathrm{Nash}$, we see $12 \%$ responses, with no decline, which are of this type evenly distributed between both values of MPCR. This suggests to me that, on average, about $10 \%$ of laboratory subjects may be simply immune to the control that experimenters try to exert by paying them.

${ }^{127}$ As I indicated in Section 3.3.1, Palfrey and Prisbrey (1993) provide a probit estimation of individual decisions and suggest that $80 \%$ of the decisions can be explained by expected contribution $=f\left[\alpha_{o}+\right.$ $\alpha_{1}(M P C R)$ ]. This also leaves about $20 \%$ unexplained.
} 
Another approach to separating errors from altruism places the non-cooperative equilibrium in the interior of $[0, z]$ and separates that equilibrium from the group optimum. Both Andreoni (1993b) and Walker, Gardner, and Ostrom (1990) do this by introducing income effects. ${ }^{128}$ Andreoni (1993b) wanted to study whether government funding of the public good would crowd-out private contributions. He recognized that to do so required an environment with an interior non-cooperative equilibrium. He created an environment in which an individual's payoff is $u=\alpha \ln \left(z-t_{i}\right)+(1-\alpha) \ln (y), y=\Sigma_{i} t_{i}$, and $0 \leq t_{i} \leq z_{i}$. The first thing to note about this world is that the non-cooperative equilibrium (that generated by perfectly selfish game-theoretic behavior) is

$$
t^{*}=\frac{(1-\alpha)}{1+\alpha(N-1)} z
$$

so that for $0<\alpha<1,0<t^{*}<z$. The second thing to notice is that the marginal per capita return (MPCR) to contributing is

$$
\left(u_{y}^{i} / u_{x}^{i}\right)=\frac{1-\alpha}{\alpha} \cdot \frac{x}{y}=\frac{1-\alpha}{\alpha} \frac{z-t}{y}
$$

which is not constant in $z$. This is what is meant by income effects. At the noncooperative equilibrium, ${ }^{129} t^{*}, M P C R=1$, so if the subjects' cooperative nature is similar to that in the linear world of Isaac and Walker, we should expect to see contributions greater than $t^{*}$. If everyone is symmetric, we can identify a group optimum ${ }^{130}$ as that $\hat{t}$ which maximizes $\alpha \ln (z-t)+(1-\alpha) \ln N t$. Thus $\hat{t}=(1-\alpha) z$. Notice that, for $0<\alpha<1$ and $N>1,0<t^{*}<\hat{t}<z$, and the MPCR at $\hat{t}$ is $\frac{1}{N}$ for all subjects. ${ }^{131}$ With this design it is possible for an experimentor to manipulate $t^{*}$ and $\hat{t}$ to see whether subjects respond or not. Andreoni's data suggest that they do. Although he only used one set of parameters with $z=7, t *=3$, and $\hat{t}=6$, contributions averaged 2.84 over a number of periods and were bounded between 2.11 and 3.33 in each period. This is clearly near the non-cooperative equilibrium, is less than altruism would suggest, and is nowhere near the optimum. Although I have not analyzed these data to separate out the percentage of Nash players, this is certainly additional evidence supporting the conventional wisdom that average rates of contribution are $50 \%$ may be the unintended result

\footnotetext{
${ }^{128} \mathrm{~A}$ simple theoretical exercise which would provide an interesting environment for an experiment is to determine an environment where every subject has a dominant strategy to contribute $t_{i}^{*}$ where $0<t_{i}^{*}<z$ and where the group optimum $t^{\circ}$ is such that $t^{\circ} \neq \sum_{i=N}^{N}, t_{i}^{*}$.

${ }^{129}$ For any utility/payoff functions the MPCR, for all players, will equal 1 at an interior Nash equilibrium.

${ }^{130}$ If there are asymmetries and either $x^{i} \neq x^{j}$ or $z^{i} \neq z^{j}$ then it is not clear what a group optimum is. Instead, there are many Pareto-optima. If the subjects are maximizing their total take then the best function to maximize is $\Sigma_{i} u^{i}$. But this may leave some subjects very badly off.

${ }^{131} \mathrm{As} N$ grows, $t$ goes to zero while $\hat{t}$ stays constant and the MPCR at $\hat{t}$ goes to 0 . To get some idea of the strength of the incentives consider $\alpha=\frac{2}{3}$ and $N=10$. Then, $\frac{t^{\circ}}{z} \cong 5 \%, \frac{\hat{i}}{z}=33 \%$, and $M P C R(\hat{t})=.10$. To make it possible to keep MPCR at $\hat{t}$ constant in $N$ one must use a $C E S$ utility function.
} 
of a corner non-cooperative equilibrium and not altruism. ${ }^{132}$

Another study which, serendipitously, was based on an environment with an interior non-cooperative equilibrium is that by Walker, Gardner, and Ostrom (1990). In their attempt to understand common property management problems, they created a public good world where $u^{i}=x^{i} y+p x^{i}, g\left(\Sigma x_{j}\right)=F\left(\Sigma x_{j}\right) /\left(\Sigma x_{j}\right)$, and imposed the constraint $0 \leq x^{i} \leq z$. The particular $F()$ they used was $23 x-.25 x^{2}$ with $p=5$. One can do the same analysis here as we did above to Andreoni's environment to find that $t^{*}$ is 8 and $\hat{t}$ is 4. One very interesting feature here is that $t^{*}$ and $\hat{t}$ are reversed so that $0<\hat{t}<t^{*}<z$. Ostrom, Walker, and Gardner found that contributions tended to be around $t^{*}$, the Nash equilibrium, providing more evidence against the simple altruism model of behavior.

Although no one has yet created an experimental study ${ }^{133}$ which would more closely compare the data from environments with interior non-cooperative equilibria to those without, the above experiments suggest that it would be worth the effort. If, as I suspect, the data in environments with interior Nash equilibria continues to be close to that predicted by non-cooperative behavior and if that is true for $\mathrm{N}=4,10,40,100$, then we would certainly need a close reexamination of the stylized fact that subjects contribute $40-60 \%$ of the optimal level because they are naturally group-regarding.

Let me conclude with some personal conjectures and beliefs arrived at while writing this survey. (1) Hard-nosed game theory cannot explain the data. Subjects contribute even though non-contribution is a dominant strategy. Even the most fervent economic experimentalist can not force rates of contribution much below $10 \%$ (see Isaac, McCue, and Plott (1985)). If these experiments are viewed solely as tests of game theory, that theory has failed. (2) Contributions are however certainly responsive to marginal selfish payoffs. (See Isaac, Walker, and Thomas (1984) and Palfrey and Prisbrey (1993).) Most of the $50 \%$ who are not Nash players seem to respond on average to selfish incentives. This is certainly consistent with the view that altruism, self-interest, decision costs, and fairness (among other possibilities) are all competing with each other in a subject's true preferences. A task facing experimentalists is to separate the effect of these forces from

\footnotetext{
${ }^{132} \mathrm{~A}$ methodological point to Andreoni's study must be noted with respect to the inducement of preferences, $u^{i}$. Rather than tell them the function - which they might not understand - he gave them a matrix; their $t^{i}$ as the column, the sum of others $t^{j}$ 's as the row and the entry's were $u^{i}=$ $\alpha \ln \left(z-t^{i}\right)+(1-\alpha) \ln t^{i}+\Sigma_{j \neq i} t^{j}$. As with Saijo and Yamaguchi this presentation of the data seems to provide subjects with computational help that leads them to choose more self-interestedly. The fact that the form of the payoff table affects behavior confirms the very delicate and sensitive nature of public good experiments and the need for better control if data are to be accepted.

An experimental design problem, as we move to more complicated environments, will be how to induce very complicated non-linear preferences with income effects and substitution among many (more than 2) dimensions. At some point experimentalists must let go of their simple world in which marginal willingness to pay schedules are the same as demand functions. Of course that is harder to control and will require new procedures.

${ }^{133}$ Isaac and Walker have responded to an early version of this paper by doing so but I have not yet seen the full set of data and analysis.
} 
each other. (3) Altruism or group-regarding preferences cannot explain the data. When the conflict between group interest and self-interest is removed, subjects still contribute in ways that are counter to both their self interest and their group interest. (See Saijo and Yamaguchi (1992).) Up to $50 \%$ of the subjects appear to be solely self-interested when they understand the experimental situation. ${ }^{134}$ (See Palfrey and Prisbrey (1993).) Further, experience, repetition, better detail in payoffs, and information about heterogeneity reduce the apparent altruistic instinct of $30-40 \%$ of other subjects. (4) It is possible to provide an environment in which at least $90 \%$ of subjects will become selfish Nash-players. Heterogeneous payoffs and resources, complete and detailed information particularly about the heterogeneity, anonymity from others and the experimenter, repetition and experience, and low marginal payoffs will all cause a reduction in rates of contribution especially with small numbers. Add unanimity to the mechanism and rates will go to zero. (See Banks, Plott and Porter (1988).) It is possible to extinguish any trace of "altruism" in the lab. (5) It is possible to provide an environment in which almost all of the subjects contribute towards the group interest. Homogeneous interest, little or rough information, face to face discussions in small groups, ${ }^{135}$ no experience, small numbers and high marginal payoffs from contributing will all cause an increase in contributions. Why and how often this all works remains a mystery. (6) There appear to be three types of players: dedicated Nash players who act pretty much as predicted by game theory with possibly a. small number of mistakes, a group of subjects who will respond to self-interest as will Nash players if the incentives are high enough but who also make mistakes and respond to decision costs, fairness, altruism, etc., and a group of subjects who behave in an inexplicable (irrational?) manner. Casual observation suggests the proportions are $50 \%, 40 \%, 10 \%$ in many subject pools. We, of course, need a lot more data before my outrageous conjectures can be tested.

Let me finish with one pessimistic and one optimistic observation from the point of view of the mechanism designer. My pessimistic remark is that although inexperienced subjects can be led to provide large contributions in one-time decisions with the use of relevant discussions, one cannot rely on these approaches as a permanent organizing feature without expecting an eventual decline to self-interested behavior. Thus, for example, techniques such as TQM (Total Quality Management), political orations, and half-time speeches can have at best a transitory effect in calling upon the altruistic impulses of some. Ultimately self-interest takes over. My optimistic remark is that since $90 \%$ of subjects seem to be responsive to private incentives, it will be possible to create new mechanisms which focus that self-interest towards the group interest. We need not rely on voluntary contributions approaches but can instead use new organizations such as those found in Smith (1979a), Groves and Ledyard (1977), or Ledyard and Palfrey (1992). Experiments will provide the basic empirical description of behavior which must

\footnotetext{
${ }^{134}$ Even Isaac, Walker, and Williams find $38 \%$ Nash-behavior in their large group - no money experiments by round 10 .

${ }^{135}$ One unanswered question is how or whether this works in large $(N \geq 40)$ groups.
} 
be understood by the mechanism designer and experiments will provide the test-bed in which the new organizations will be tested before implementation. But that is another paper. 


\section{References}

Abdalla, A., R. Cooper, D. V. DeJong, R. Forsythe, and T. W. Ross. 1989. Forward induction in coordination and battle of the sexes games: Some experimental results. Discussion paper, Dept. of Economics, Illinois State University, Normal, IL.

Admati, A. and M. Perry. 1991. Joint projects without commitment. Review of Economic Studies 58:259-276.

Alfano, G. and G. Marwell. 1980. Experiments on the provision of public goods by groups III: Nondivisibility and free riding in 'read' groups. Social Psychology Quarterly 43:300-309.

Andreoni, J. 1988a. Privately provided public goods in a large economy: The limits of altruism. Journal of Public Economics 35:57-73.

Andreoni, J. 1988b. Why free ride? Strategies and learning in public goods experiments. Journal of Public Economics 37:291-304.

Andreoni, J. 1989. Giving with impure altruism: applications to charity and Ricardian equivalence. Journal of Political Economy 97(6):1447-1458.

Andreoni, J. 1993a. Cooperation in public goods experiments: Kindness or confusion? Technical Report 9309, University of Wisconsin-Madison, Madison, WI.

Andreoni, J. 1993b. An experimental test of the public goods crowding-out hypothesis. American Economic Review 83:1317-1327.

Andreoni, J. 1993c. Warm-glow versus cold-prickly: The effects of positive and negative framing on cooperation. Technical report, University of Wisconsin-Madison, Madison, WI.

Andreoni, J. and J. Miller. 1993. Rational cooperation in the finitely repeated prisoner's dilemma: Experimental evidence. Economic Journal 103:570-585.

Andreoni, J. and H. Varian. 1992. Pre-play contracts in the prisoners' dilemma. Technical report, CREST Working Paper, University of Michigan.

Arrow, K. 1970. The organization of economic activity: Issues pertinent to the choice of market versus non-market allocation. In Haveman, R. and J. Margolis, eds., Public Expenditures and Policy Analysis, pages 59-73. Markham, Chicago.

Arrow, K. J. 1979. The property rights doctrine and demand revelation under incomplete information. In Economics and Human Welfare. Academic Press.

Austen-Smith, D. 1980. Individual contribution to public goods. Economic Letters $5: 359-361$. 
Bagnoli, M. and B. Lipman. 1989. Provision of public goods: Fully implementing the core through private contributions. Review of Economic Studies 56:583-601.

Bagnoli, M. and M. McKee. 1991. Voluntary contribution games: Efficient private provision of public goods. Economic Inquiry 29:351-366.

Banks, J. and R. Calvert. 1992. A battle-of-the-sexes game with incomplete information. Games and Economic Behavior 4(3):347-372.

Banks, J., J. Ledyard, and D. Porter. 1989. Allocating uncertain and unresponsive resources: An experimental approach. RAND Journal of Economics 20(1):1-25.

Banks, J., C. Plott, and D. Porter. 1988. An experimental analysis of unanimity in public goods provision mechanisms. Review of Economic Studies 55(182):301-322.

Banks, J. S. and R. L. Calvert. 1989. Communication and efficiency in coordination games. Working Paper 196, Dept. of Political Science, University of Rochester, Rochester, NY. Forthcoming in Games and Economic Behavior.

Bergstrom, T., L. Blume, and H. Varian. 1986. On the private provision of public poods. Journal of Public Economics 29:25-49.

Berman, S. and A. Schotter. 1982. When is the incentive problem real? Games, Economic Dynamics, and Time Series Analysis.

Bernheim, D. 1986. On the voluntary and involuntary provision of public goods. American Economic Review 76:789-793.

Bigman, D. 1992. Unanimity and exclusion as mechanisms to eliminate free riding in public goods. Journal of Economic Behavior and Organization 19:101-117.

Binger, B., E. Hoffman, and A. Williams. 1985. Implementing a Lindahl equilibrium with a modified tatonnement mechanism: Some preliminary experimental results. Discussion paper, Purdue University.

Bliss, C. and B. Nalebuff. 1984. Dragonslaying and ballroom dancing: The private supply of a public good. Discussion Paper 1038, Harvard University.

Bohm, P. 1972. Estimating demand for public goods: An experiment. European Economic Review 3:111-130.

Bohm, P. 1983. Revealing demand for an actual public good. Journal of Public Economics $24: 135-151$.

Bohm, P. 1987. Lindahl on public finance. In Eatwell, J., M. Millgate, and P. Newman, eds., The New Palgrave: A dictionary of economics. MacMillan Press Ltd., London. 
Bolle, F. and P. Ockenfels. 1990. Prisoners' dilemma as a game with incomplete information. Journal of Economic Psychology 11:69-84.

Bornstein, G. and A. Rapoport. 1988. Intergroup competition for the provision of steplevel public goods: Effects of preplay communication. European Journal of Social Psychology 18:125-142.

Bornstein, G., A. Rapoport, L. Kerpel, and T. Katz. 1989. Within- and between-group communication in intergroup competition for public goods. Journal of Experimental Social Psychology 25:422-436.

Boylan, R. T. 1990. Equilibria resistant to mutation. Social Science Working Paper 691, California Institute of Technology.

Boylan, R. T. and M. A. El-Gamal. 1990. Fictitious play: A statistical study of multiple economic experiments. Discussion paper, California Institute of Technology.

Brewer, M. 1985. Choice behavior in social dilemmas: Effects of social identity, group size, and decision framing. Discussion paper, University of California, Los Angeles.

Brookshire, D. and D. Coursey. 1987. Measuring the value of a public good: An empirical comparison of elicitation procedures. American Economic Review 77(4):554-566.

Brookshire, D., D. Coursey, M. Dickie, S. G. A. Fisher, and W. Schulze. 1985. Tests of parallelism between laboratory and the field. Discussion paper, University of Wyoming, Laramie.

Brookshire, D., D. Coursey, and H. Kunreuther. Forthcoming. Compensation schemes in the presence of negative externalities: A field experiment. In Smith (Forthcoming).

Brookshire, D., D. Coursey, and D. Redington. 1989a. Special interests and the voluntary provision of public goods. Discussion Paper, Washington University, St. Louis.

Brookshire, D., D. L. Coursey, and D. B. Redington. 1989b. Equity and the incentive compatible provision of public goods. Discussion paper, Dept. of Economics, University of Wyoming, Laramie, WY.

Brookshire, D. and W. Schulze. 1985. Experiments in the solicitation of private and public values: An overview. Discussion Paper, University of Wisconsin.

Brown, P. 1992. An experimental examination of voluntary compliance. Technical report, University of Massachusetts, Boston, MA.

Brown-Kruse, J. and D. Hummels. 1992. Gender effects in public goods contribution: Do individuals put their money where their mouth is? Technical report, University of Colorado, Boulder, CO. Forthcoming, Journal of Economic Behavior and Organization. 
Brubaker, E. and D. Gumucio. 1982. Sixty-eight percent free revelation and thirty-two percent free ride? demand disclosures under varying conditions on exclusion. In Smith, V., ed., Research in Experimental Economics, Volume 2, pages 151-166. JAI Press Inc.

Budescu, D., A. Rapoport, and R. Suleiman. 1990. Resource dilemmas with environmental uncertainty and asymmetric players. IPDM Report 83, Institute of Information Processing and Decision Making, University of Haifa.

Caldwell. 1976. Communication and sex differences in a five-person and prisoner's dilemma game. Journal of Personality and Social Psychology 33:283-280.

Calvert, R. and R. Wilson. 1984. Comment on van de Kragt, Orbell, and Dawes. The American Political Science Review 78:496-497.

Camerer, C. 1994. Individual decisionmaking. In Kagel, J. and A. Roth, eds., The Handbook of Experimental Economics. Princeton University Press.

Carter, J., B. Drainville, and R. Poulin. 1992. A test for rational altruism in a publicgoods experiment. Technical report, College of the Holy Cross, Worcester, MA.

Carter, J. R. and M. D. Irons. 1991. Are economists different, and if so, why? Journal of Economic Perspectives 5:171-177.

Castore, C. and J. Murnighan. 1978. Determinants of support for group decisions. Organizational Behavior and Human Performance 22:75-92.

Chamberlin, J. 1974. Provision of collective goods as a function of group size. The American Political Science Review 68:707-716.

Chamberlin, J. 1978. The logic of collective action: some experimental results. Behavioral Science 23:441-445.

Champsaur, P., D. J. Roberts, and R. W. Rosenthal. 1975. On cores in economies with public goods. International Economic Review.

Chan, K., S. Mestelman, R. Moir, and R. Muller. 1993. The voluntary provision of public goods under varying endowment distributions. Technical Report Working Paper No. 93-02, McMaster University, Hamilton, Ontario, Canada.

Chander, P. 1988. Incentives and a process converging to the core of a public goods economy. Social Science Working Paper 677, California Institute of Technology, Pasadena, CA.

Chari, V. V. and L. E. Jones. 1988. A reconsideration of the problem of social cost: free riders and monopolists. Working Paper 324, Federal Reserve Bank of Minneapolis, Research Department, Minneapolis, MN. 
Chen, K.-Y. 1993. Subrational equilibria in voluntary contribution games. Technical report, California Institute of Technology.

Clarke, E. H. 1971. Multipart pricing of public goods. Public Choice 8:19-33.

Cohen, S. and M. Loeb. 1984. Theory and experiments in decentralized organization. Paper presented at TIMS XXVI, Copenhagen.

Cooper, R., D. V. DeJong, R. Forsythe, and T. Ross. 1987. Selection criteria in -coordination games: Some experimental results. Department of Economics Working Paper 87-20, University of Iowa, Iowa City.

Cooper, R., D. V. DeJong, R. Forsythe, and T. Ross. 1989. Communication in coordination games. Department of Economics Working Paper 89-16, University of Iowa, Iowa City.

Cooper, R., D. V. DeJong, R. Forsythe, and T. W. Ross. 1990. Cooperation without reputation. Discussion paper, College of Business Administration, University of Iowa, Iowa City, IA.

Cornes, R. and T. Sandler. 1985. The simple analytics of pure public good provision. Economica 52:103-116.

Cornes, R. and T. Sandler. 1986. The theory of externalities, public goods, and club goods. Cambridge, England: Cambridge University Press.

Coursey, D. and W. Schulze. 1986. The application of laboratory experimental economics to the contingent valuation of public goods. Public Choice 49:47-68.

Coursey, D. and V. L. Smith. 1984. Experimental tests of an allocation mechanism for private, public or externality goods. Scandinavian Journal of Economics 86(4):468484.

Cowen, T., ed. 1988. The theory of market failure, a critical examination. Fairfax VA: George Mason University Press.

Cox, J., B. Roberson, and V. L. Smith. 1982. Theory and behavior in single object auctions. In Smith (1982c).

Crawford, V.'P. 1990. Thomas Schelling and the analysis of strategic behavior. Discussion Paper 90-11, Dept. of Economics, University of California at San Diego.

Crawford, V. P. and H. Haller. 1990. Learning how to cooperate: Optimal play in repeated coordination games. Econometrica 58(3):571-575.

Cremer, J. and M. Riordan. 1982. A Stackelberg solution to the public goods problem. CARESS working paper, University of Pennsylvania. 
Cremer, J. and M. Riordan. 1985. A sequential solution to the public goods problem. Econometrica 53:77-84.

Danzinger, L. and A. Schnytzer. 1991. Implementing the Lindahl voluntary-exchange mechanism. European Journal of Political Economy 7:55-64.

Darley, J. and B. Latane. 1968. Bystander intervention in emergencies: diffusion of responsibility. Journal of Personality and Social Psychology 8:377-383.

d'Aspremont, C. and L. A. Gerard-Varet. 1979. On Bayesian incentive compatible mechanisms. In Laffont (1979), pages 269-288.

Daughety, A. F. and R. Forsythe. 1987. Complete information outcomes without common knowledge. Working Paper Series 87-24, Dept. of Economics and Management Sciences, College of Business Administration, The University of Iowa, Iowa City, IA.

Dawes, R. 1975. Formal models of dilemmas in social decision-making. In Kaplan, M. and S. Schwartz, eds., Human Judgement and Decision Processes, pages 87-107. Academic Press, New York.

Dawes, R. 1980. Social dilemmas. Annual Review of Psychology 31:169-193.

Dawes, R., J. McTavish, and H. Shaklee. 1977. Behavior, communication, and assumptions about other people's behavior in a commons dilemma situation. Journal of Personality and Social Psychology 35(1):1-11.

Dawes, R. and J. Orbell. 1982. Cooperation in social dilemma situations: Thinking about it doesn't help. In Smith (1982c), pages 167-173.

Dawes, R., J. Orbell, R. Simmons, and A. van de Kragt. 1986. Organizing groups for collective action. American Political Science Review 8:1171-1185.

Dawes, R., J. Orbell, and A. van de Kragt. 1985. A 'great society' or a 'small society'?: The threshold-of-the-room effect in social dilemmas. Prepared for the Public Choice Society Meetings, New Orleans, February 1985.

Dawes, R. and R. Thaler. 1988. Cooperation. Journal of Economic Perspectives 2(3):187197.

Dawes, R., A. van de Kragt, and J. Orbell. 1987. Not me or thee but we: The importance of group identity in eliciting cooperation in dilemma situations: Experimental manipulations. Carnegie Mellon University; Presented at the Public Choice Meeting, Tucson, AZ, March 28, 1987 and the Midwestern Psychological Association Meeting (invited address), Chicago, IL, May 8, 1987.

Dorsey, R. 1992. The voluntary contributions mechanism with real time revisions. Public Choice 73:261-282. 
Downs, A. 1957. An economic theory of democracy. New York: Harper and Row.

Dreze, J. and D. de la Vallee-Poussin. 1971. A tatonnenment process for public goods. Review of Economic Studies 38:133-150.

Dutta, P. K. and R. K. Sundaram. 1989. The tragedy of the commons? A complete characterization of stationary equilibria in dynamic resource games. Discussion paper, Department of Economics, Columbia University, New York.

Easley, D. and J. Ledyard. 1992. Theories of price formation and exchange in double oral auctions. In Friedman, D., J. Geanakoplos, D. Lane, and J. Rust, eds., The Double Auction Market, volume XV. Addison-Wesley. Santa Fe Institute Studies in the Sciences of Complexity, Proceedings.

Edney, J. and C. Harper. 1978. Profile: The commons dilemma. Environmental Management 2(6):491-507.

Edwards, J. H. Y. 1990. Indivisibility and private preference for collective provision. Discussion paper, Department of Economics, Tulane University, New Orleans, LA.

El-Gamal, M. A., R. D. McKelvey, and T. R. Palfrey. 1991. A Bayesian sequential experimental study of myopia and strategic learning in the centipede game. Social science working paper, California Institute of Technology.

Erev, I. and A. Rapoport. 1990. Provision of step-level public goods, the sequential contribution mechanism. Journal of Conflict Resolution 34(3):401-425.

Evans, R. and F. Harris. 1982. A Bayesian analysis of free rider metagames. Southern Economic Journal 49(1):137-149.

Ferejohn, J., R. Forsythe, and R. Noll. 1979. Practical aspects of the construction of decentralized decisionmalking systems for public goods. In Collective Decision Making: Applications from Public Choice Theory. Johns Hopkins University Press, Baltimore, MD.

Ferejohn, J., R. Forsythe, R. Noll, and T. Palfrey. 1982. An experimental examination of auction mechanisms for discrete public goods. In Smith (1982c).

Ferejohn, J. and R. Noll. 1976. An experimental market for public goods: The PBS station program cooperative. American Economic Review 66:267-273.

Fernandez-Arias, E. and A. Kofman. 1989. Equilibrium characterization in finite-horizon games of reputation. Discussion paper, Dept. of Economics, University of California at Berkeley.

Fiorina, M. P. and C. R. Plott. 1978. Committee decisions under majority rule: An experimental study. The American Political Science Review 72:575-598. 
Fisher, J., R. Isaac, J. Schatzberg, and J. Walker. 1988. Heterogeneous demand for public goods: Effects on the voluntary contributions mechanism.

Foley, D. 1967. Resource allocation and the public sector. Yale Economic Essays 7.

Fouraker, L. and S. Siegel. 1963. Bargaining behavior. New York: McGraw-Hill.

Franciosi, R., R. Isaac, D. Pingry, and S. Reynolds. 1991. An experimental investigation of the Hahn-Noll revenue neutral auction for emission licenses. University of Arizona.

Frank, R. 1985. If homo economicus could choose his own utility function, would he want one with a conscience? Liberty Fund Symposium.

Frank, R., T. Gilovich, and D. Regan. 1993. Does studying economics inhibit cooperation? Journal of Economic Perspectives 7(2):159-171.

Frohlich, N., T. Hunt, J. Oppenheimer, and R. H. Wagner. 1975. Individual contributions for collective goods. The Journal of Conflict Resolution 19(2):310-329.

Fudenberg, D. and E. Maskin. 1990. Evolution and cooperation in noisy repeated games. American Economic Review pages 274-279.

Gardner, R. and E. Ostrom. 1989. Rules and games. Public Choice 70:121-149.

Gradstein, M. 1991. Time dynamics and incomplete information in the private provision of public goods. Technical report, Ben-Gurion University, Beer Sheva, Israel.

Gradstein, M. and S. Nitzan. 1990. Binary participation and incremental provision of public goods. Social Choice and Welfare 7:171-192.

Gradstein, M., S. Nitzan, and S. Slutsky. 1991a. Neutrality and the private provision of public goods with incomplete information.

Gradstein, M., S. Nitzan, and S. Slutsky. 1991b. Private provision of public goods under price uncertainty.

Green, J. and J. J. Laffont. 1977. Characterization of satisfactory mechanisms for the revelation of preferences for public goods. Econometrica 45:427-438.

Green, J. and J. J. Laffont. 1978. Incentives in public decision making. Amsterdam: North Holland.

Grether, D., M. Isaac, and C. Plott. 1989. The allocation of scarce resources: Experimental economics and the problem of allocating airport slots. Boulder, CO: Westview Press.

Groves, T. 1970. The allocation of resources under uncertainty. PhD thesis, University of California, Berkeley. 
Groves, T. 1973. Incentives in teams. Econometrica 41:617-663.

Groves, T. 1976. Information, incentives, and the internalization of production externalities. In Lin, S., ed., Theory and Measurement of Economic Externalities. Academic Press, New York.

Groves, T. 1979a. Efficient collective choice when compensation is possible. Review of Economic Studies 46:227-241.

Groves, T. 1979b. Efficient collective choice with compensation. In Laffont (1979), pages $37-59$.

Groves, T. and J. Ledyard. 1977. Optimal allocation of public goods: A solution to the 'free rider' problem. Econometrica 45:783-809.

Groves, T. and J. Ledyard. 1987. Incentive compatibility since 1972. In Groves, T., R. Radner, and S. Reiter, eds., Information, Incentives, \& Economic Mechanisms. Essays in Honor of Leonid Hurwicz, pages 48-111. University of Minnesota Press, Minneapolis.

Guler, K., C. Plott, and Q. Vuong. 1987. A study of zero-out auctions: Experimental analysis of a process of allocating private rights to the use of public property. Social Science Working Paper 650, California Institute of Technology.

Guttman, J. 1978. Understanding collective action: Matching behavior. American Economic Review 68:251-255.

Guttman, J. 1987. A non-Cournot model of voluntary collective action. Economica. $54: 1-19$.

Hardin, R. 1968. The tragedy of the commons. Science 162:1243-1248.

Hardin, R. 1976. Group provision of step goods. Behavioral Science 21:101-106.

Harris, R. J. 1988. The altruism modification model (AMM). Presented at a colloquium at UGA on October 7, 1988; also, informal paper at Univ. of Wisconsin (SESP).

Harrison, G. and J. Hirshleifer. 1987. Experiments testing weakest-link/best-shot models for provision of public goods. Journal of Political Economy 95.

Harrison, G. and J. Hirshleifer. 1989. An experimental evaluation of weakest link/best shot models of public goods. Journal of Political Economy 97(1):201-225.

Harstad, R. and M. Marrese. 1978. Experimentation on the effects of decision processes on public good allocations. Discussion Paper 78-50, University of British Columbia. 
Harstad, R. and M. Marrese. 1981. Implementation of mechanisms by processes: Public good allocation experiments. Journal of Economic Behavior and Organization 2:129151.

Harstad, R. and M. Marrese. 1982. Behavioral explanations of efficient public good allocations. Journal of Public Economics 19:367-383.

Hirshleifer, D. and E. Rasmusen. 1989. Cooperation in a repeated prisoners' dilemma with ostracism. Journal of Economic Behavior and Organization 12:87-106.

Hirshleifer, J. 1983. From weakest-link to best-shot: The voluntary provision of public goods. Public Choice 41:371-386.

Hoffman, E., K. McCabe, K. Shachat, and V. Smith. 1992. Preferences, property rights and anonimity in bargaining games.

Hoffman, E. and M. Spitzer. 1985. Entitlements, rights and fairness: An experimental examination of subjects concepts of distributive justice. Journal of Legal Studies 15:254-297.

Holmstrom, B. 1979. Groves schemes on restricted domains. Econometrica 47:1137-1144.

Holt, C. 1994. Industrial organization: A survey of laboratory research. In Kagel, J. and A. Roth, eds., The Handbook of Experimental Economics. Princeton University Press.

Huberman, B. and N. Glance. 1992. Diversity and collective action. Technical report, Dynamics of Computation Group, Xerox Palo Alto Research Center.

Hurwicz, L. 1972. On informationally decentralized systems. In Radner, R. and C. B. McGuire, eds., Decision and Organization: A Volume in Honor of Jacob Marschak, pages 297-336. North-Holland, Amsterdam.

Hurwicz, L. 1973. The design of mechanisms for resource allocation. American Economic Review 63:1-30.

Hurwicz, L. 1979a. On allocations attainable through Nash-equilibria. In Laffont (1979), pages $397-419$.

Hurwicz, L. 1979b. Outcome functions yielding Walrasian and Lindahl allocations at Nash equilibrium points. Review of Economic Studies 46:217-225.

Hurwicz, L. and M. Walker. 1990. On the generic nonoptimality of dominant-strategy allocation mechanism: A general theorem that includes pure exchange economies. Econometrica 58(3):683-704. 
Hylland, A. and R. Zeckhauser. 1979. A mechanism for selecting public goods when preferences must be elicited. Discussion Paper 70D, Harvard University.

Isaac, R., D. Schmidtz, and J. Walker. 1988. The assurance problem in a laboratory market. Public Choice 62(3):217-236.

Isaac, R. M., K. McCue, and C. Plott. 1985. Public goods provision in an experimental environment. Journal of Public Economics 26:51-74.

Isaac, R. M. and J. Walker. 1983. Marginal private returns and public goods provision.

Isaac, R. M. and J. Walker. 1984. The effects of communication on free riding behavior. Discussion paper, University of Arizona, Tucson.

Isaac, R. M. and J. Walker. 1987. Success and failure of the voluntary contributions process: some evidence from experimental economics. Discussion Paper 87-1, University of Arizona, Tucson, AZ.

Isaac, R. M. and J. Walker. 1988a. Communication and free riding behavior: The voluntary contribution mechanism. Economic Inquiry 26(2):585-608.

Isaac, R. M. and J. Walker. 1988b. Group size effects in public goods provision: The voluntary contributions mechanism. The Quarterly Journal of Economics pages 179-199.

Isaac, R. M. and J. Walker. 1989. Complete information and the provision of public goods. Discussion paper 89-18, University of Arizona, Tucson, AZ.

Isaac, R. M. and J. Walker. 1991. Costly communication: An experiment in a nested public goods problem. In Palfrey, T., ed., Laboratory Research in Political Economy, pages 269-286. University of Michigan Press, Ann Arbor, MI.

Isaac, R. M., J. Walker, and S. Thomas. 1984. Divergent evidence on free riding: An experimental examination of possible explanations. Public Choice 43(1):113-149.

Isaac, R. M., J. Walker, and A. Williams. 1990. Group size and the voluntary provision of public goods: Experimental evidence utilizing very large groups. Working papers in economics, Indiana University.

Jackson, M. and H. Moulin. 1992. Implementing a public project and distributing its cost. Journal of Economic Theory 57(1):125-140.

Johansen, L. 1977. The theory of public goods: misplaced emphasis? Journal of Public Economics pages 147-52.

Johansen, L. 1982. On the status of the Nash type of non-cooperative equilibrium in economic theory. Scandinavian Journal of Economics 84(3):421-441. 
Kagel, J., C. Kim, and D. Moser. 1992. "Fairness" in ultimatum games with asymmetric information and asymmetric payoffs. Technical report, Univ. of Pittsburgh.

Kalai, E. and E. Lehrer. 1990. Rational learning leads to Nash equilibrium. Discussion Paper 895, Center for Mathematical Studies in Economics and Management Science, Northwestern University, Evanston, IL.

Kim, O. and M. Walker. 1984. The free rider problem: Experimental evidence. Public Choice 43:3-24.

Kiser, L. and E. Ostrom. 1982. The three worlds of action: A metatheoretical synthesis of institutional approaches. In Ostrom, E., ed., Strategies of Political Inquiry. Sage Publications, Beverly Hills, CA.

Kolm, S.-C. 1989. Cooperative-game properties of international coordination. Technical report, Paris.

Kreps, D., P. Milgrom, J. Roberts, and R. Wilson. 1982. Rational cooperation in the finitely repeated prisoners' dilemma. Journal of Economic Theory 27:245-252.

Kunreuther, H., P. Kleindorfer, P. Knez, and R. Yaksick. 1986. A compensation mechanism for siting noxious facilities: Theory and experimental design.

Laffont, J., ed. 1979. Aggregation and revelation of preferences. Amsterdam: NorthHolland.

Laffont, J. and E. Maskin. 1982. The theory of incentives: An overview. In Hildebrand, W., ed., Advances in Economic Theory: Invited Papers for the Fourth World Congress of the Econometric Society 1980, Aix-en-Provence, pages 31-94. Cambridge University Press, Cambridge.

Laffont, J. J. and E. Maskin. 1983. A characterization of strongly locally incentive compatible planning procedures with public goods. Review of Economic Studies pages $171-186$.

Ledyard, J. and T. Palfrey. 1992. Voting and lottery drafts as efficient public goods mechanisms. Social Science Working Paper 717, California Institute of Technology.

Ledyard, J. and J. Roberts. 1974. On the incentive problem with public goods. Discussion Paper 116, Center for Mathematical Studies in Economics and Management Science, Northwestern University.

Ledyard, J. and K. Szakaly. 1992. Designing organizations for trading in permit rights. mimeo, H\&SS, California Institute of Technology. 
Li, Q., S. Nakamura, and G. Tian. 1989. Nash-implementation of the Lindahl correspondence with decreasing returns to scale technology. Discussion paper, Dept. of Economics, Texas A\&M University, College Station, TX.

Lindahl, E. 1958 (1919). Die gerichtigkeit der besteuerung. In Musgrave, R. and A. Peacock, eds., Classics in the Theory of Public Finance. London: Macmillan. Lund: Greerup. Part I, ch. 4, 'Positive Lösung', trans. by E. Henderson and reprinted as 'Just taxation - a positive solution'.

Lipnowski, I. and S. Maital. 1983. Voluntary provision of a pure public good as the game of chicken. Journal of Public Economics 20:381-386.

MacCrimmon, K. and D. Messick. 1976. A framework for social motives. Behavioral Science 21:86-100.

Mailath, G. and A. Postlewaite. 1990. Asymmetric information bargaining problems with many agents. The Review of Economic Studies 57 (3)(191):351-367.

Makowski, L. and J. Ostroy. 1984. Vickrey-Clarke-Groves mechanisms and perfect competition.

Malinvaud, E. 1967. Decentralized procedures for planning. In Malinvaud, E. and M. O. L. Bacharach, eds., Activity Analysis in the Theory of Growth and Planning, pages 170-208. Macmillan, London.

Malinvaud, E. 1971. A planning approach to the public goods problem. Swedish Journal of Economics 1:96-111.

Mansbridge, J. J. 1990. Beyond self-interest. Chicago, IL: The University of Chicago Press.

Martin, F. 1989. Common pool resources and collective action: a bibliography. Discussion paper, Indiana University, Bloomington, IN. Workshop in Political Theory and Policy Analysis.

Marwell, G. 1982. Altruism and the problem of collective action. In Derlega, V. and J. Grzelak, eds., Cooperation and Helping Behavior: Theories and Research. Academic Press, New York.

Marwell, G. and R. Ames. 1979. Experiments on the provision of public goods I: Resources, interest, group size, and the free-rider problem. American Journal of Sociology 84(6):1335-1360.

Marwell, G. and R. Ames. 1980. Experiments on the provision of public goods II: Provision points, stakes, experience, and the free-rider problem. American Journal of Sociology 85(4):926-937. 
Marwell, G. and R. Ames. 1981. Economists free ride, does anyone else? Experiments on the provision of public goods, IV. Journal of Public Economics 15:295-310.

Mason, C. F., O. R. Phillips, and D. B. Redington. 1991. The role of gender in a noncooperative game. Journal of Economic Benavior and Organization 15:215-235.

McGuire. 1974. Group homogeneity and aggregate provision of a pure public good under Cournot behavior. Public Choice 18:107-126.

McKelvey, R. and T. Palfrey. 1992. An experimental study of the centipede game. Econometrica 60(4):803-836.

McKelvey, R. D. and P. C. Ordeshook. 1990. A decade of experimental research on spatial models of elections and committees. In Hinich, M. and J. Enelow, eds., Advances in Spatial Theory of Voting. Cambridge University Press, Cambridge.

McLean, I., J. Orbell, and R. Dawes. 1991. What should rational cognitive misers do? American Political Science Review 85(4):1417-1426.

McMillan, J. 1978. The efficient supply of public inputs. Research Report 7805, Dept. of Economics, The University of Western Ontario.

Merlo, A. and A. Schotter. 1990. Experimentation and learning in laboratory experiments: Harrison's criticism revisited. Discussion Paper 90-23, Department of Economics, New York University, New York.

Messick, D. and M. Brewer. 1983. Solving social dilemmas, a review. In Wheeler, L. and P. Shaver, eds., Review of Personality and Sociall Psychology, volume 4, pages 11-44. Sage, Beverly Hills.

Meyer, R. and C. Plott. 1975. The technology of public goods, externalities and the exclusion principle. In Mills, E., ed., Economics Analysis of Environmental Problems, pages 65-94. Columbia University Press, New York.

Miller, J. and J. Andreoni. 1991. Can evolutionary dynamics explain free riding in experiments? Economics Letters 36:9-15.

Monderer, D. and D. Samet. 1989. Approximating common knowledge with common beliefs. Technical Report 545, Institute for Mathematical Studies in the Social Sciences, Stanford University, Stanford, CA.

Morrison, C. C. and H. Kamarei. 1990. Some experimental testing of the Cournot-Nash hypothesis in small group rivalry situations. Journal of Economic Behavior and Organization 13:213-231.

Mount, K. and S. Reiter. 1974. The informational size of message spaces. Journal of Economics Theory 8:161-191. 
Muench, T. and M. Walker. 1979. Identifying the free rider problem. In Laffont (1979), pages $61-90$.

Muench, T. and M. Walker. 1983. Are Groves-Ledyard equilibria attainable? Review of Economic Studies 50:393-396.

Murnighan, J., T. King, and F. Schoumaker. 1987. The dynamics of cooperation in asymmetric dilemmas. Discussion paper, University of Illinois.

Myerson, R. 1991. Game theory analysis of conflict. Cambridge, MA: Harvard University Press.

Nitzan, S. and E. Ostrom. 1990. The nature and severity of collective action problemsthe voluntary provision of mixed public goods approach. Discussion paper, Workshop in Political Theory and Policy Analysis, Indiana University, Bloomington, IN.

Nitzan, S. and S. Slutsky. More on free riding and uncertainty. Discussion paper, Department of Economics, University of Florida, Gainesville, FL.

Olson, M. 1971. The logic of collective action, volume CXXIV. Harvard University Press.

Olson, M. and D. Porter. 1994. An experimental examination into the design of decentralized methods to solve the assignment problem with and without money. Economic Theory 4:11-40.

Orbell, J. and R. Dawes. 1981. Social dilemmas. In Stephenson, J. and J. Davis, eds., Progress in Applied Social Psychology, volume 1, pages 117-133. New York: Wiley.

Orbell, J. and R. Dawes. 1993. Social welfare, cooperators' advantage, and the option of not playing the game. American Sociological Review 58:787-800.

Orbell, J., R. Dawes, and P. Schwartz-Shea. 1993. Trust, social categories, and individuals: The case of gender. Technical report, University of Oregon, Eugene, OR. Submitted to Ethics.

Orbell, J., R. Dawes, and A. van de Kragt. 1990. The limits of multilateral promising. Ethics 100:616-627.

Orbell, J. and R. M. Dawes. 1991. A 'cognitive miser' theory of cooperators' advantage. American Political Science Review 85:515-528.

Orbell, J., P. Schwartz-Shea, R. Dawes, and D. Elvin. 1992. Gender as a basis for choosing partners in prisoner's dilemma games. Technical report, University of Oregon. presented at the American Political Science Association Annual Meeting in Chicago, 1992. 
Orbell, J., P. Schwartz-Shea, and R. Simmons. 1984. Do cooperators exit more readily than defectors. APSR 78(1):147-162.

Orbell, J., A. van de Kragt, and R. Dawes. 1988. Explaining discussion-induced cooperation. Journal of Personality and Social Psychology 54(5):811-819.

Orbell, J. and L. Wilson. 1976. Institutional solutions to the N-Prisoners' Dilemma. Working Paper 3, Institute for Social Science Research.

Ostrom, E. 1992. Governing the commons. The evolution of institutions for collective action. Cambridge University Press.

Ostrom, E., J. Walker, and R. Gardner. 1990. Sanctioning by participants in collective action problems. Discussion paper, Workshop in Political Theory and Policy Analysis, Indiana University, Bloomington, IN. Presented at the Conference on Experimental Research on the Provision of Public Goods and Common-Pool Resources, Indiana University.

Ostrom, E., J. Walker, and R. Gardner. 1992. Covenants with and without a sword: Self-governance is possible. American Political Science Review 86(2):404-417.

Ostrom, E. and J. M. Walker. 1991. Communication in a commons: Cooperation without external enforcement. In Palfrey, T., ed., Laboratory Research in Political Economy, pages 287-322. University of Michigan Press, Ann Arbor, MI.

Palfrey, T. and J. Prisbrey. 1993. Anomalous behavior in linear public goods experiments: How much and why? Working Paper 833, California Institute of Technology, Pasadena, CA.

Palfrey, T. and H. Rosenthal. 1984. Participation and the provision of discrete public goods: A strategic analysis. Journal of Public Economics 24:171-193.

Palfrey, T. and H. Rosenthal. 1988. Private incentives in social dilemmas: The effects of incomplete information and altruism. Journal of Public Economics 28:309-332.

Palfrey, T. and H. Rosenthal. 1991a. Testing game-theoretic models of free riding: New evidence on probability bias and learning. In Palfrey, T., ed., Laboratory Research in Political Economy, pages 239-268. University of Michigan Press, Ann Arbor, MI.

Palfrey, T. and H. Rosenthal. 1992. Repeated play, cooperation and coordination: An experimental study. Social science working paper 785, H\&SS, California Institute of Technology.

Palfrey, T. R. and H. Rosenthal. 1991b. Testing for effects of cheap talk in a public goods game with private information. Games and Economic Behavior 3:183-220. 
Plott, C. 1979. The application of laboratory experimental methods to public choice. In Russell, C., ed., Collective Decision Making: Applications from Public Choice Theory. Resources for the Future, Washington DC.

Plott, C. 1983. Externalities and corrective policies in experimental markets. The Economic Journal 93:106-127.

Plott, C. R. 1990. Will economics become an experimental science? Social science working paper 758, H\&SS, California Institute of Technology.

Poppe, M. and L. Utens. 1986. Effects of greed and fear of being gypped in a social dilemma situation with changing pool size. Journal of Economic Psychology 7:6173.

Pratt, J. W. and R. Zeckhauser. 1980. Incentive-based decentralization: Expected externality payments induce efficient behavior in groups. Discussion Paper Series 83 D, John Fitzgerald Kennedy School of Government, Harvard University, Cambridge, MA.

Prisbrey, J. 1990. An experimental study of equilibrium selection in a public goods setting. Social Science Working Paper, California Institute of Technology, Pasadena, CA.

Radner, R. 1987. Decentralization and incentives. In Groves, T., R. Radner, and S. Reiter, eds., Information, Incentives, \& Economic Mechanisms. Essays in Honor of Leonid Hurwicz, pages 48-111. University of Minnesota Press, Minneapolis.

Rapoport, A. 1985. Public goods and the MCS experimental paradigm. American Political Science Review 79:148-155.

Rapoport, A. 1987. Research paradigms and expected utility models for the provision of step-level public goods. Psychological Review 94(1):74-83.

Rapoport, A. 1988. Provision of step-level public goods: Effects of inequality in resources. Journal of Personality and Social Psychology 54(3):432-440.

Rapoport, A. and G. Bornstein. 1987. Intergroup competition for the provision of binary public goods. Psychological Review 94(3):291-299.

Rapoport, A., G. Bornstein, and I. Erev. 1989. Intergroup competition for public goods: Effects of unequal resources and relative group size. Journal of Personality and Social Psychology 56(5):748-756.

Rapoport, A., D. Budescu, and R. Suleiman. 1991. Sequential requests from randomly distributed shared resources. Technical report, University of Arizona, Tucson, AZ. in press, Journal of Mathematical Psychology. 
Rapoport, A., D. Budescu, R. Suleiman, and E. Weg. 1993. Social dilemmas with uniformly distributed resources. In Liebrand, W., D. Messick, and H. Wilke, eds., A Social Psychological Approach to Social Dilemmas. Pergamon Press, New York. in press.

Rapoport, A. and A. M. Chammah. 1965. Sex differences in factors contributing to the level of cooperation in a prisoner's dilemma game. Journal of Personality and Social Psychology 2:831-838.

Rapoport, A. and D. Eshed-Levy. 1989. Provision of step-level public goods: Effects of greed and fear of being gypped. Organizational Behavior and Human Decision Processes 44:325-344.

Rapoport, A. and R. Suleiman. 1992. Equilibrium solutions for resource dilemmas. Technical report, University of Arizona, Tucson, AZ. in press, Group Decision and Negotiation.

Rapoport, A. and R. Suleiman. 1993. Incremental contribution in step-level public goods games with asymmetric players. Organizational Behavior and Human Decision Processes. in press.

Rassenti, S., V. L. Smith, and R. Bulfin. 1982. A combinatorial auction mechanism for airport time slot allocation. Bell Journal of Economics 13:402-417.

Reiter, S., ed. 1986. Studies in mathematical economics, volume 25. The Mathematical Association of America.

Rob, R. 1989. Pollution claim settlements under private information. Journal of Economic Theory 47:307-333.

Roberts, D. J. 1972. Notes on the existence of Lindahl equilibrium with a measure space of consumers. Working paper, Northwestern University, Graduate School of Management.

Roberts, J. 1976. The incentives for the correct revelation of preferences and the number of consumers. Journal of Public Economics 6:359-374.

Roberts, J. 1979. Strategic behavior in the MDP planning procedure. In Laffont (1979), pages $353-362$.

Roberts, J. 1987a. Lindahl equilibrium. In Eatwell, J., M. Millgate, and P. Newman, eds., The New Palgrave: A dictionary of economics. MacMillan Press Ltd., London.

Roberts, J. and A. Postlewaite. 1976. The incentives for price-taking behavior in large economies. Econometrica 44:115-128. 
Roberts, R. 1984. A positive model of private charity and public transfers. Journal of Political Economy 92(1):136-148.

Roberts, R. 1985. A taxonomy of public provision. Public Choice 47:267-303.

Roberts, R. 1987b. Financing public goods. Journal of Political Economy 95:420-437.

Roberts, R. D. 1990. The tragicomedy of the commons: Why communities rationally choose 'inefficient' allocations of shared resources. Political Economy Working Paper 140, School of Business and Center in Political Economy, Washington University, St. Louis, MO.

Romer, T. and H. Rosenthal. 1980. A constitution for solving the asymmetric n-prisoners' dilemma.

Roth, A. 1988. Laboratory experimentation in economics: A methodological overview. The Economic Journal 98:974-1031.

Roth, A. 1994. Bargaining experiments. In Kagel, J. and A. Roth, eds., The Handbook of Experimental Economics. Princeton University Press.

Saijo, T. and Y. Tatamitani. 1991. Characterizing neutrality in the voluntary contribution mechanism. Working Paper, Institute of Socio-Economic Planning, University of Tsukuba, Tsukuba, Japan.

Saijo, T. and H. Yamaguchi. 1992. The "spite" dilemma in voluntary contribution mechanism experiments.

Sally, D. 1992. Conversation and cooperation in social dilemmas: Experimental evidence from 1958 to 1992.

Samuelson, C. D. and S. T. Allison. 1990. Social decision heuristics, role schemas, and the consumption of shared resources. Discussion paper, Workshop in Political Theory and Policy Analysis, Indiana University, Bloomington, IN. Conference on Experimental Research on the Provision of Public Goods and Common-Pool Resources, Indiana University.

Samuelson, P. A. 1954. The pure theory of public expenditure. The Review of Economics and Sta.tistics pages $387-389$.

Samuelson, P. A. 1975. Diagrammatic exposition of a, theory of public expenditures. Review of Economic Theory 10:187-217.

Sandler, T., F. P. Sterbenz, and J. Posnett. 1987. Free riding and uncertainty. European Economic Review 31:1605-1617. 
Sarkar, A. 1990. Joint provision of public goods with incomplete information about costs. BEBR Faculty Working Paper 90-1657, University of Illinois at Urbana-Champaign.

Satterthwaite, M. 1975. Strategy-proofness and arrow's conditions: Extence and correspondence theorems for voting procedures and social welfare functions. Journal of Economic Theory 10:187-217.

Scherr, B. and E. Babb. 1975. Pricing public goods: An experiment with two proposed pricing systems. Public Choice pages $35-48$.

Schmidtz, D. 1991. The limits of government, an essay on the public goods argument. Boulder, CO: Westview Press.

Schneider, F. and W. Pommerehne. 1981a. On the rationality of free riding: An experiment. Quarterly Journal of Economics 96:689-704.

Schneider, F. and W. W. Pommerehne. 1981b. Free riding and collective action: An experiment in public microeconomics. The Quarterly Journal of Economics pages $689-704$.

Schram, A. and J. Sonnemans. 1992. Voter turnout and the role of groups: Participation game experiments. Technical report, University of Amsterdam, Amsterdam, The Netherlands.

Schwartz-Shea, P. and R. Simmons. 1987. Social dilemmas and perceptions: Experiments on framing and inconsequentiality. Forthcoming in Social Dilemmas, D. Schroeder (ed.), Praeger Press.

Sell, J. and R. K. Wilson. 1990. The effects of signalling on the provisioning of public goods. Discussion paper, Workshop in Political Theory and Policy Analysis, Indiana University.

Selten, R. and R. Stoecker. 1986. End behavior in sequences of finite prisoner's dilemma supergames. Journal of Economic Behavior and Organization 7:47-70.

Shenker, S. 1990a. A brief overview of congestion control in computer networks from a mechanism design viewpoint. Technical report, Xerox Palo Alto Research Center, Palo Alto, CA.

Shenker, S. 1990b. Efficient network allocations with selfish users. Technical report, Xerox Palo Alto Research Center, Palo Alto, CA.

Shenker, S. 1990c. Making greed work in networks: A game-theoretic analysis of gateway service disciplines. Technical report, Xerox Palo Alto Research Center. Preliminary Draft. 
Shepperd, J. 1993. Productivity loss in performance groups: A motivation analysis. Psychological Bulletin 113(1):67-81.

Shotter, A., K. Weigelt, and C. Wilson. 1990. A laboratory investigation of multi-person rationality and presentation effects. Economic research report 90-24, Department of Economics, New York University, New York.

Smith, V., A. Williams, W. Bratton, and M. Vannoni. 1982. Competitive market institutions: Double auctions vs. sealed bid-offer auctions. The American Economic Review 72(1):58-77.

Smith, V. L. 1976. Mechanisms for the optimal provision of public goods. pages 19-21, Tucson, AZ. Conference on American Re-evolution.

Smith, V. L. 1977. The principle of unanimity and voluntary consent in social choice. Journal of Political Economy 85(6):1125-1139.

Smith, V. L. 1978. Experimental mechanisms for public choice. In Ordeshook, P., ed., Game Theory and Political Science, pages 323-355. New York University Press, New York.

Smith, V. L. 1979a. An experimental comparison of three public good decision mechanisms. Scandinavian Journal of Economics 81:198-215.

Smith, V. L. 1979b. Incentive compatible experimental processes for the provision of public goods. In Smith (1979c), pages 59-168.

Smith, V. L., ed. 1979c. Research in experimental economics, volume 1. Greenwich, CT: JAI Press.

Smith, V. L. 1980. Experiments with a decentralized mechanism for public good decision. American Economic Review pages 584-589.

Smith, V. L. 1982a. Microeconomic systems as an experimental science. American Economic Review 72(5):923-955.

Smith, V. L. 1982b. Reflections on some experimental mechanisms for classical environments. In McAlister, L., ed., Research in Marketing, Supplement 1: Choice Models for Buyer Behavior. JAI Press, Greenwich, CT.

Smith, V. L., ed. 1982c. Research in experimental economics, a research annual, volume 2. Greenwich, CT: JAI Press.

Smith, V. L. 1990. Experimental economics: Behavioral lesson for microeconomic theory and policy. Discussion Paper 90-14, Dept. of Economics, University of Arizona, Tucson, AZ. Nancy L. Schwartz Memorial Lecture, Northwestern University. 
Smith, V. L., ed. Forthcoming. Research in experimental economics, volume 4. Greenwich, CT: JAI Press.

Smith, V. L. and J. M. Walker. 1992. Monetary rewards and decision cost in experimental economics. Forthcoming, Economic Inquiry.

Smith, V. L. and A. W. Williams. 1990. Experimental market economics. Discussion Paper 90-7, Department of Economics, University of Arizona, Tucson, AZ.

Stark, O. 1985. On private charity and altruism. Public Choice 46:325-332. Liberty Fund Symposium.

Sugden, R. 1985. Consistent conjectures and voluntary contributions to public goods: Why the conventional theory does not work. Journal of Public Economics 27:117124.

Suleiman, R. and A. Rapoport. 1988. Environmental and social uncertainty in single-trial resource dilemmas. Acta Psychologica 68:99-112.

Suleiman, R. and A. Rapoport. 1992. Provision of step-level public goods with continuous contribution. Journal of Behavioral Decision Making 5:133-153.

Sunder, S. 1987. Structure of organizations for production of public and private goods. mimeo, Carnegie-Mellon University.

Sunder, S. 1994. Experimental asset markets: A survey. In Kagel, J. and A. Roth, eds., The Handbook of Experimental Economics. Princeton University Press.

Taylor, M. and H. Ward. 1982. Chickens, whales, and lumpy goods: Alternative models of public-goods provision. Political Studies 30(3):350-370.

Thomson, W. 1987. Monotonic allocation mechanisms in economies with public goods. Working Paper 117, University of Rochester, Rochester, NY.

Tian, G. 1989. Implementation of the Lindahl correspondence by a single-valued, feasible and continuous mechanism. Review of Economic Studies 56:613-621.

Tian, G. and Q. Li. 1990. Implementation of the ratio-balanced cost share correspondence viewed as a state-ownership system with the general variable returns in production. Discussion paper, Department of Economics, Texas A\&M University, College Station, TX.

Tian, G., Q. Li, and S. Nakamura. 1990. Nash-implementation of the Lindahl correspondence with decreasing returns to scale technology. Working Paper 90-17, Dept. of Economics, Texas A\&M University, College Station, TX. 
Truchon, M. 1984. Non-myopic strategic behavior in the MDP planning procedure. Econometrica 52:1179-1190.

van de Kragt, A. 1984. Experimental N-person dilemmas and group size an elaboration. Also presented at the Meetings of the Public Choice Society, March 1984, Phoenix, AZ.

van de Kragt, A., J. Orbell, and R. Dawes. 1983. The minimal contributing set as a solution to public goods problems. American-Political Science Review 77:112-122.

Varian, H. R. 1990a. Sequential provision of public goods. Discussion paper, University of Michigan.

Varian, H. R. 1990b. A solution to the problem of externalities and public goods when agents are well-informed. Discussion paper, Dept. of Economics, University of Michigan.

Vega-Redondo, F. 1989. Public projects and private contributions. Discussion paper, CSIC, Universitat Autonoma de Barcelona.

Vickrey, W. 1961. Counterspeculation, auctions, and competitive sealed tenders. Journal of Finance 16:8-37.

Walker, J. M., R. Gardner, and E. Ostrom. 1990. Rent dissipation in limited access common-pool resource environments: Experimental evidence. Journal of Environmental Economics and Management 19:203-211.

Walker, M. 1978. A note on the characterization of mechanisms for the revelation of preferences. Econometrica 46:147-152.

Walker, M. 1980. A simple incentive compatible scheme for attaining Lindahl allocations. Econometrica. 48:1521-1540.

Warr, P. 1982. Pareto optimal redistribution and private charity. Journal of Public Economics 19:131-138.

Warr, P. 1983. The private provision of a public good in independent of the distribution of income. Economics Letters 13:207-211.

Wicksell, K. 1958. A new principle of just taxation. In Musgrave, R. and A. Peacock, eds., Classics in the Theory of Public Finance. Macmillan, London.

Young, D. J. 1989. A 'fair share' model of public good provision. Journal of Economic Behavior and Organization 11:137-147. 


\section{Appendix}

Examples of Public Good Environments

Utility, $U^{i} \quad$ Endowment Production, $G\left(t_{s}\right)$ Feasible, $t^{i}$

Sample Reference

$+p x^{i}$

$+p x^{i}$

$+v_{i} x^{i}$

$+p x^{i}$

$z$

$\left\|y-\mu_{i}\right\|$

$(y)+x^{i}$

$+p x^{i}$

$-c^{i}\left(x^{i}\right)$

$\left.x^{i}\right)-W^{i}-E(y)$

$-c^{j}\left(x^{j}\right)-E(y)$
$\frac{a}{N} t_{s}$

$\frac{a}{N} t_{s}$

1 if $t_{s} \geq \frac{K}{N}$

0 else

$y /$ if $a_{1}<t_{s} \leq a_{2} \quad a \leq t^{i} \leq z \quad$ Marwell and Ames (1979)

$y / l$ if $a_{2}<t_{s} \leq a_{3}$

$\vdots$

$y \epsilon Y$

$\frac{1}{C} t_{s}$

$\frac{1}{C} t_{s}$

$F\left(t_{s}\right) / t_{s}$

$D^{-1}\left(x_{s}\right)$

$y=x_{s}$

$\Sigma_{j}-\omega^{j}=\Sigma_{i} \omega^{i}$
$0 \leq t^{i} \leq z \quad$ Isaac, Walker, and Thomas (1984)

$t^{i} \in\{0,1\} \quad$ Dawes, McTavish, and Shaklee (1977)

$t^{i} \epsilon\{0,1\} \quad$ Palfrey and Rosenthal (1984)

$t^{i}=0 \quad$ Fiorina and Plott (1978)

$0 \leq t^{i} \leq z \quad$ Isaac, McCue, and Plott (1985)

$0 \leq t^{i} \leq z \quad$ Shenker (1990c)

$0 \leq t^{i} \leq z \quad$ Walker, Gardner, and Ostrom (1990)

$0 \leq x^{i} \quad$ Chapter (Holt)

$x^{i} \epsilon\{0,1\} \quad$ Plott (1983) 